University of Tennessee Health Science Center

UTHSC Digital Commons

\title{
Design, Synthesis, and Evaluation of Novel Positron Emission Tomography Radiotracers
}

Christopher Philip Surdock

University of Tennessee Health Science Center

Follow this and additional works at: https://dc.uthsc.edu/dissertations

Part of the Medicinal and Pharmaceutical Chemistry Commons

\section{Recommended Citation}

Surdock, Christopher Philip (http://orcid.org/0000-0001-5439-5851), "Design, Synthesis, and Evaluation of Novel Positron Emission Tomography Radiotracers" (2017). Theses and Dissertations (ETD). Paper 424. http://dx.doi.org/10.21007/etd.cghs.2017.0427. 


\title{
Design, Synthesis, and Evaluation of Novel Positron Emission Tomography Radiotracers
}

\begin{abstract}
Neuroblastoma (NB) is the most common extracranial tumor in patients under 1 year of age and it constitutes about $8-10 \%$ of all childhood cancer. It originates from neural crest cells that normally differentiate to form the sympathetic ganglia, adrenal medulla and other paraspinal sites where sympathetic nervous system tissue is present. Even with an extensive treatment regimen that typically includes surgery, chemotherapy, total body irradiation and autologous stem cell transplantation, the 5-year event-free survival is $<50 \%$ for high risk patients, and there are numerous long-term side effects associated with treatment. This body of work investigated two projects for improving patient outcomes through the development of positron emission tomography (PET) radiotracers that could be used for therapy planning. The goal of the first project was to design, synthesize, and evaluate PET radiotracers that could measure the enzymatic activation of Irinotecan (CPT-11), a potent chemotherapeutic used in the treatment of colon cancer and several pediatric solid tumors. CPT-11 itself is a prodrug which is converted in vivo to SN-38, via metabolism by carboxylesterase (CE) enzymes. St. Jude Children's Research Hospital researchers have designed a two-pronged protocol of tumor-targeted CPT-11 chemotherapy combining the complementary approaches of a) specific modulation of human CE in normal tissues to improve drug delivery, and $b$ ) tumor-targeted activation of prodrug using neural progenitor cells (NPC) transfected with a mutant human CE CDNA. The tumor-selective trafficking of NPC allows over-expression of CE within the tumor. This prodrug/activating enzyme therapeutic approach has shown extremely encouraging preclinical results in the treatment of NB (90\% 1-year survival in mice). However, successful translation of this novel therapeutic approach into general clinical practice requires a better understanding of progenitor cell trafficking, duration and intensity of enzymatic activity and the ultimate biological fate of the therapeutic construct. Toward this end, PET radiotracers were developed based on extensive structure-activity relationship (SAR) studies of CE binding. The goal of the second project was to design, synthesize, and evaluate PET radiotracers that could identify the presence of the tropomyosin receptor kinase $B(T r k B)$. TrkB is not normally found in sympathetic nervous tissue, which is the tissue NB develops from, and thus is a potential target for imaging and therapy. The presence of TrkB and its neurotrophin, brain derived neurotrophic factor (BDNF), have been reported to protect neuroblastoma tumor cells from chemotherapy-induced apoptosis via a phosphatidylinositol 3'-kinase pathway. Radiotracers were synthesized and evaluated for their ability to identify TrkB both in vitro and in vivo. PET radiosynthetic procedures were optimized to synthesize novel radiotracers for imaging targets that could help clinicians monitor therapy or identify markers that would aid in therapy planning for NB patients. The method development could be applied to future compounds that show improved chemical characteristics for synthesis and selectivity.
\end{abstract}

\section{Document Type}

Dissertation

\section{Degree Name}

Doctor of Philosophy (PhD)

\section{Program}

Pharmaceutical Sciences

\section{Research Advisor}

Vivian S. Loveless, PharmD 


\section{Keywords}

Carboxylesterase, Neuroblastoma, PET, TrkB

\section{Subject Categories}

Medicinal and Pharmaceutical Chemistry | Medicine and Health Sciences | Pharmacy and Pharmaceutical Sciences 


\title{
Design, Synthesis, and Evaluation of Novel Positron Emission Tomography
} Radiotracers

\author{
A Dissertation \\ Presented for \\ The Graduate Studies Council \\ The University of Tennessee \\ Health Science Center
}

\begin{abstract}
In Partial Fulfillment
Of the Requirements for the Degree

Doctor of Philosophy

From The University of Tennessee
\end{abstract}

By

Christopher Philip Surdock

May 2017 
Copyright (C) 2017 by Christopher Philip Surdock. All rights reserved. 


\section{DEDICATION}

This dissertation is dedicated

to my wife Amanda who has

stood by my side from day one. 


\section{ACKNOWLEDGEMENTS}

I would like to thank Dr. Scott Snyder for his mentorship, guidance, and the opportunity to pursue my dissertation work in his lab. I appreciate the time, effort, and patience he invested in me and am grateful for his support.

I would like to thank Dr. Vivian Loveless for her unending support and words of encouragement throughout the long road leading to this dissertation work. I am thankful for her insight and her determination.

I would like to thank all my committee members, Drs. Richard Lee, Isaac Donkor, and Duane Miller for their advice, criticism, and understanding. I appreciate the lessons of educational politics that were invaluable for navigating the process of obtaining my degree.

I would like to thank the many colleagues, lab members, and co-workers that I have worked with during this journey. There are too many to name but I want each to know that I appreciate every minute of time each expended on me helping me achieve this goal. Each has provided enlightening discussions, supportive critiques, and comic relief that made this an experience to remember for a lifetime.

I could not have done any of this without the support from St. Jude Children's Research Hospital and the University of Tennessee Health Science Center in the form of providing me a place to obtain my training and education. I am thankful that these institutions are investing in research and the academic pursuits of those who wish to learn.

Next, there are my friends and family that deserve my gratitude. So many have encouraged me when I was down and laughed with me during times of joy. Brenda, thank you for listening to my stories and offering sage council in times of stress. Mom, thank you for lighting that fire of determination in me that led me down this path.

Finally, to my wife, Amanda. I have loved you since the day we met, and your love has carried me through many challenges in this world. Without you, I could not have made it this far and I cannot wait for our next adventure to begin. 


\begin{abstract}
Neuroblastoma (NB) is the most common extracranial tumor in patients under 1 year of age and it constitutes about $8-10 \%$ of all childhood cancer. It originates from neural crest cells that normally differentiate to form the sympathetic ganglia, adrenal medulla and other paraspinal sites where sympathetic nervous system tissue is present. Even with an extensive treatment regimen that typically includes surgery, chemotherapy, total body irradiation and autologous stem cell transplantation, the 5-year event-free survival is $<50 \%$ for high risk patients, and there are numerous long-term side effects associated with treatment. This body of work investigated two projects for improving patient outcomes through the development of positron emission tomography (PET) radiotracers that could be used for therapy planning.
\end{abstract}

The goal of the first project was to design, synthesize, and evaluate PET radiotracers that could measure the enzymatic activation of Irinotecan (CPT-11), a potent chemotherapeutic used in the treatment of colon cancer and several pediatric solid tumors. CPT-11 itself is a prodrug which is converted in vivo to SN-38, via metabolism by carboxylesterase (CE) enzymes. St. Jude Children's Research Hospital researchers have designed a two-pronged protocol of tumor-targeted CPT-11 chemotherapy combining the complementary approaches of a) specific modulation of human CE in normal tissues to improve drug delivery, and b) tumor-targeted activation of prodrug using neural progenitor cells (NPC) transfected with a mutant human CE cDNA. The tumor-selective trafficking of NPC allows over-expression of CE within the tumor. This prodrug/activating enzyme therapeutic approach has shown extremely encouraging preclinical results in the treatment of NB (90\% 1-year survival in mice). However, successful translation of this novel therapeutic approach into general clinical practice requires a better understanding of progenitor cell trafficking, duration and intensity of enzymatic activity and the ultimate biological fate of the therapeutic construct. Toward this end, PET radiotracers were developed based on extensive structure-activity relationship (SAR) studies of CE binding.

The goal of the second project was to design, synthesize, and evaluate PET radiotracers that could identify the presence of the tropomyosin receptor kinase $\mathrm{B}$ (TrkB). TrkB is not normally found in sympathetic nervous tissue, which is the tissue NB develops from, and thus is a potential target for imaging and therapy. The presence of TrkB and its neurotrophin, brain derived neurotrophic factor (BDNF), have been reported to protect neuroblastoma tumor cells from chemotherapy-induced apoptosis via a phosphatidylinositol 3'-kinase pathway. Radiotracers were synthesized and evaluated for their ability to identify TrkB both in vitro and in vivo.

PET radiosynthetic procedures were optimized to synthesize novel radiotracers for imaging targets that could help clinicians monitor therapy or identify markers that would aid in therapy planning for NB patients. The method development could be applied to future compounds that show improved chemical characteristics for synthesis and selectivity. 


\section{TABLE OF CONTENTS}

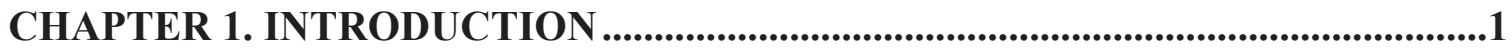

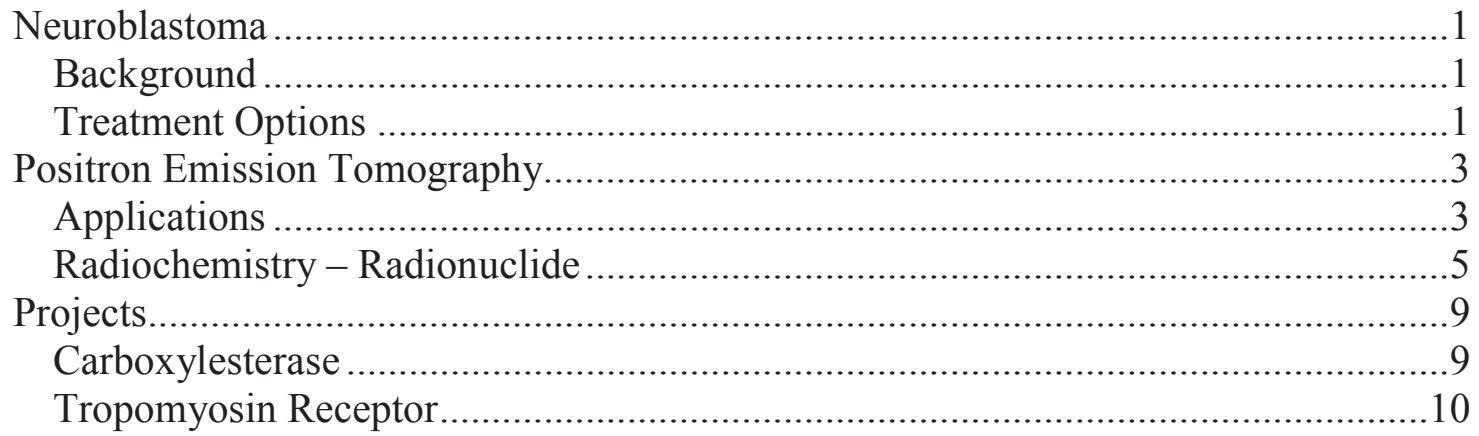

\section{CHAPTER 2. FLUORINE-18 LABELING OF BENZILS AND SUBSTITUTED} BENZIL DERIVATIVES FOR IMAGING CARBOXYLESTERASE ......................15

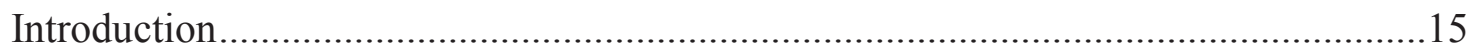

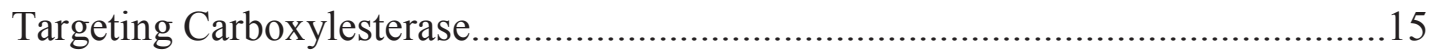

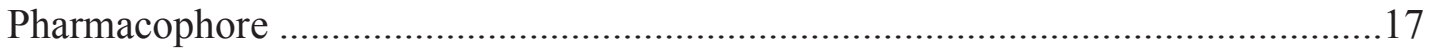

Synthesis of Radiosynthetic Standards and Precursors …….......................................17

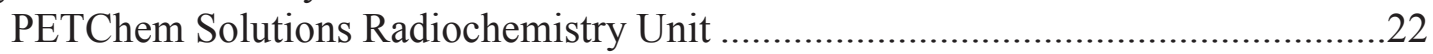

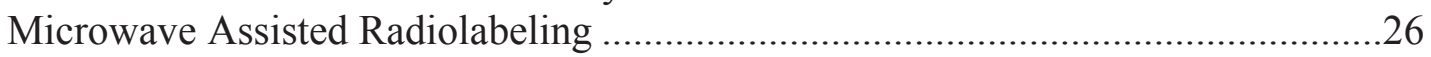

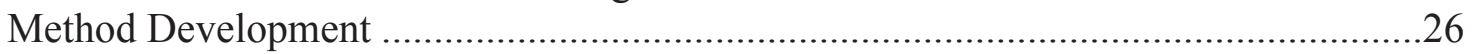

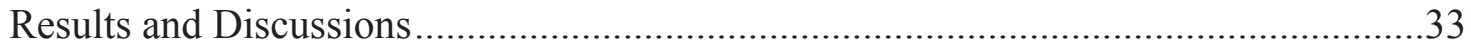

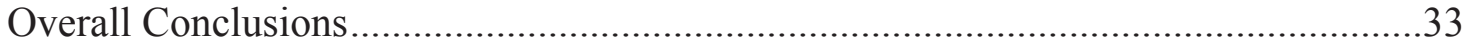

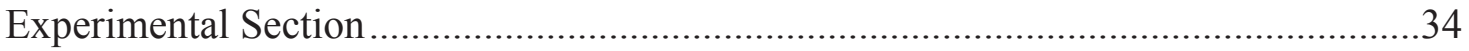

Full Synthesis of Radiosynthetic Standards and Precursors .........................................34

General procedure for the synthesis of the $N$-substituted

3-((5-nitropyridin-2-yl)ethynyl)aniline (2b-i) ..................................................... 34

General procedure for the synthesis of the $N$-substituted

3-((5-fluoropyridin-2-yl)ethynyl)aniline (2k-n) ................................................ 36

General procedure for the synthesis of the $N$-substituted (4-(2-(5-nitropyridin-2-

yl)-2-oxoacetyl)phenyl)amide or (4-(2-(5-fluoropyridin-2-yl)-2oxoacetyl)phenyl)amide (2o-2z)....................................................................... 37

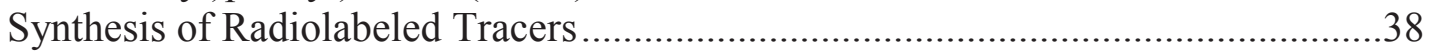

\section{CHAPTER 3. DESIGN OF A TRKB SELECTIVE IMAGING AGENT FOR NEUROBLASTOMA AND ITS POTENTIAL USE IN DIRECTING THERAPY..41}

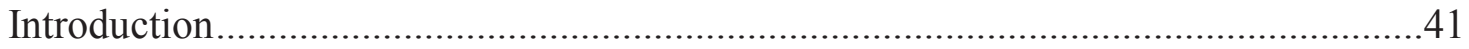

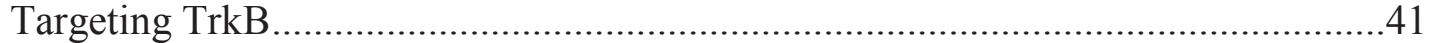

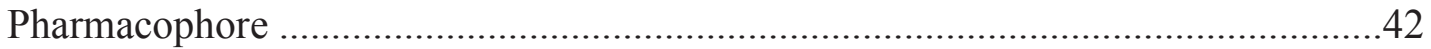

Synthesis of Radiosynthetic Standards and Precursors ..............................................46

Microwave Assisted Organic Synthesis................................................................54

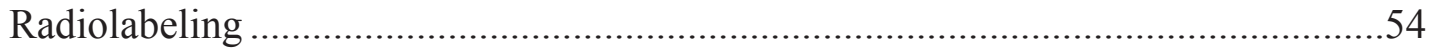

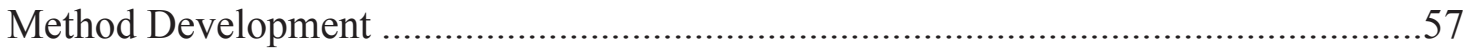

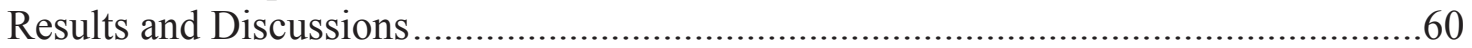




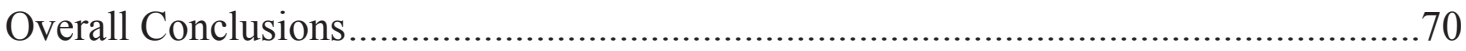

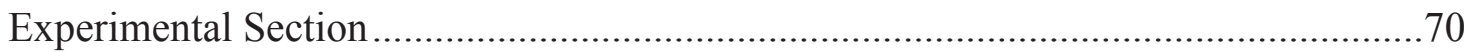

Synthesis of Radiosynthetic Standards and Precursors ............................................70

General procedure for the synthesis of $N$-(4-isopropylphenyl)-2-(pyrrolidin-3-

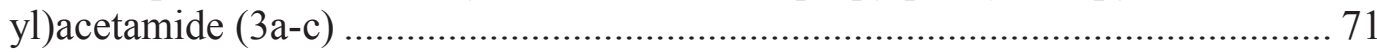

General procedure for the coupling of the quinazoline and pyrrolidine (3d-o).... 72

General procedure for the coupling of the quinazoline and pyrrolidine using

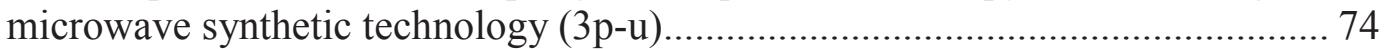

Synthetic options for demethylation of the 6 or 7 position of the aminoquina-

zoline......

General procedure for the synthesis of the benzyl protected 6 or 7 position aminoquinazoline (3z-am)

Synthetic options for debenzylation of the 6 or 7 position of the 4-substituted

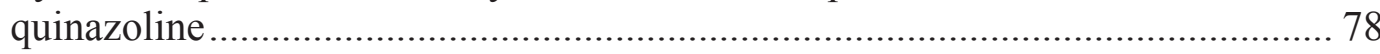

Synthesis of Radiolabeled Tracers.......................................................................

CHAPTER 4. OVERALL DISCUSSION OF RESEARCH PROJECTS ....................80

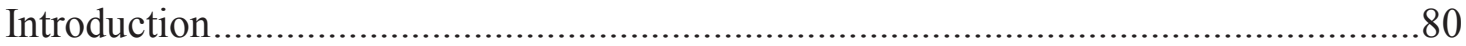

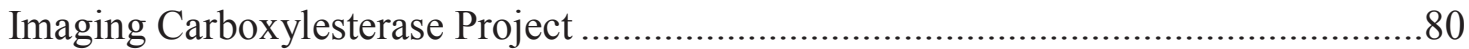

Imaging Tropomyosin Receptor Kinase B Project ......................................................81

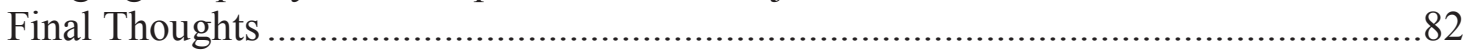

LIST OF REFERENCES ...................................................................................................84

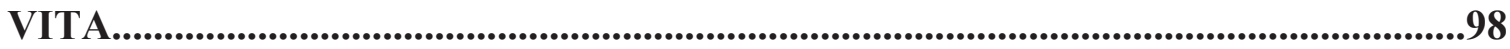




\section{LIST OF TABLES}

Table 1-1. 5-year event-free survival statistics for NB patients based on category........2

Table 1-2. Treatment course options based on NB patient risk group..........................4

Table 1-3. Common PET radionuclides used in radiochemistry...............................8

Table 2-1. Substituted benzil CE activity against various CE isoforms. .....................19

Table 2-2. Radiolabeling reaction condition optimization for 1-(4- $\left[{ }^{18} \mathrm{~F}\right]$ fluorophenyl)-2-phenylethane-1,2-dione (2aa)........................29

Table 2-3. Radiochemical yield for $N$-(3-(2-(5-[ $\left.{ }^{18} \mathrm{~F}\right]$ fluoropyridin-2-yl)-2-oxoacetyl)phenyl)acetamide (2ab) using precursor $N$-(3-(2-(5-nitropyridin-2-yl)-2oxoacetyl)phenyl)propionamide (2q)

Table 3-1. Radiolabeling reaction condition optimizations for 2-(1-(6-methoxy-7-[ $\left[{ }^{11} \mathrm{C}\right]-$ methoxyquinazolin-4-yl)pyrrolidin-3-yl)- $N$ (4-isopropylphenyl)acetamide (3as).

Table 3-2. Results of optimized conditions for 2-(1-(6-methoxy-7-[ $\left.{ }^{11} \mathrm{C}\right]-$ methoxyquinazolin-4-yl)pyrrolidin-3-yl)- $N$ (4-isopropylphenyl)acetamide (3as).

Table 3-3. ADME testing for radiosynthetic standard 2-(1-(6,7-dimethoxyquinazolin-4-yl)pyrrolidin-3-yl)- $N-(4-$ isopropylphenyl)acetamide $(3 \mathrm{~d})$.

Table 3-4. $\mathrm{IC}_{50}$ against Trks for radiosynthetic standard 2-(1-(6,7-dimethoxyquinazolin-4-yl)pyrrolidin-3-yl)- $N$-(4isopropylphenyl)acetamide (3d).

Table 3-5. Abbreviated kinase profiling report for radiosynthetic standard 2-(1-(6,7-dimethoxyquinazolin-4-yl)pyrrolidin-3-yl)- $N-(4-$ isopropylphenyl)acetamide (3d). 


\section{LIST OF FIGURES}

Figure 1-1. Annihilation Photon.........................................................................

Figure 1-2. Schematic representation of typical PET technology..................................

Figure 1-3. Proposed TrkB receptor pathway activation..........................................12

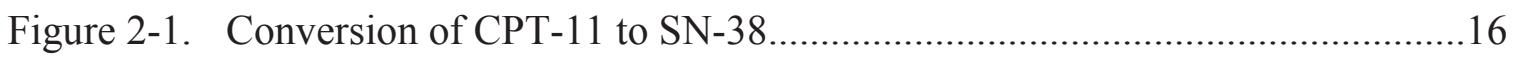

Figure 2-2. Carboxylesterase Catalytic Triad.........................................................18

Figure 2-3. Generic structure of substituted benzil. ....................................................19

Figure 2-4. Phenyl Pyridinyl 1,2-dione derivatives.................................................20

Figure 2-5. PETChem automated radiosynthesis technology...................................23

Figure 2-6. Lead-shielded radiosynthesis fume hood............................................24

Figure 2-7. Microwave technology for use in radiolabeling. ...................................27

Figure 2-8. HPLC chromatogram of radiolabeling 4-nitrobenzil using ${ }^{18} \mathrm{~F}$..................30

Figure $3-1 . \quad$ Current compounds targeting Trk.....................................................43

Figure 3-2. HPLC chromatogram of radiotracer 3 ar using $\left[{ }^{11} \mathrm{C}\right]$ methyl iodide. .............51

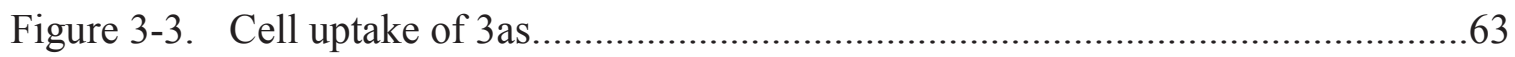

Figure 3-4. TrkB protein as detected by Western blot analysis of tumor and cell

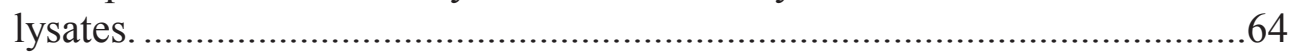

Figure 3-5. Small animal PET/CT image of the biodistribution of 3as.......................66

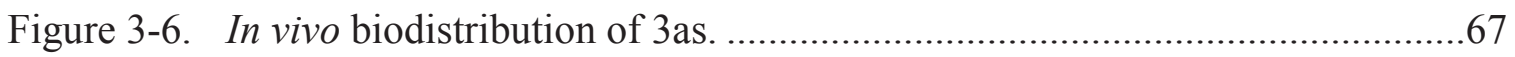

Figure 4-1. New Trk inhibitors under investigation that have radiotracer potential. ......83 


\section{LIST OF SCHEMES}

Scheme 2-1. Generic synthesis of disubstituted benzil derivatives. ............................21

Scheme 2-2. Fluorine-18 production and solubilization for organic synthesis. ............25

Scheme 2-3. Radiolabeling of benzil compounds using fluorine-18 …......................25

Scheme 2-4. Generic synthesis of phenyl pyridinyl radiosynthetic precursors..............31

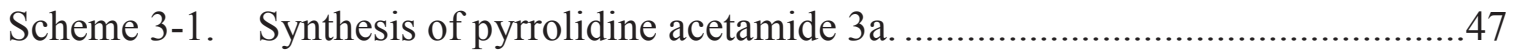

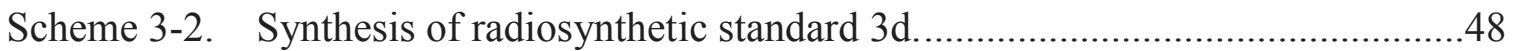

Scheme 3-3. Methods investigated for the demethylation of the radiosynthetic

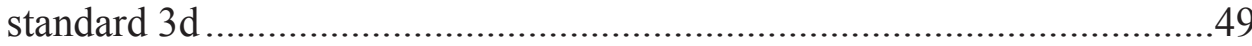

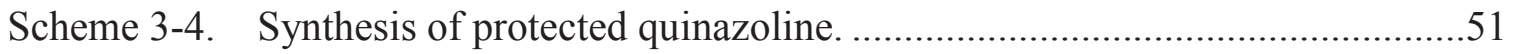

Scheme 3-5. Reduction of 3ad with iron(II) acetate ...............................................52

Scheme 3-6. Attempted coupling of the tosyl protected quinazolinone with pyrrolidine.

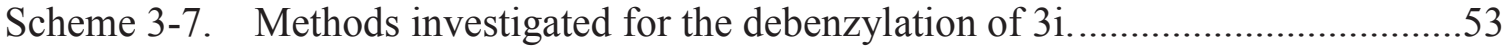

Scheme 3-8. Optimized synthesis conditions for the radiosynthetic precursor.............55

Scheme 3-9. Radiosynthesis of 3aq using $\left[{ }^{11} \mathrm{C}\right]$ methyl iodide ..................................56

Scheme 3-10. Radiosynthesis of 3aq using $\left[{ }^{11} \mathrm{C}\right]$ methyl triflate ...................................58 


\section{LIST OF ABBREVIATIONS}

$\mathrm{ACN}$

ADME

BDNF

CBT

CE

CHOP

$\mathrm{Ci}$

COG

CPT-11

CT

DBSTP

DCM

DIEA

DMF

DMSO

EFS

EtOAc

hCE1

hCE1mut6

hiCE

HPLC

$\mathrm{IC}_{50}$
Acetonitrile

Adsorption, distribution, metabolism, and excretion

Brain-derived-neurotrophic factor

Chemical Biology and Therapeutics

Carboxylesterase

Children's Hospital of Philadelphia

Curie

Children's Oncology Group

Irinotecan

X-ray computed tomography

Developmental Biology of Solid Tumors Program

Dichloromethane

$N,-N$-diisopropylethylamine

Dimethylformamide

Dimethyl sulfoxide

Event-free survival

Ethyl acetate

Human liver CE

Mutant human liver CE

Human intestinal CE

High performance liquid chromatography

Half maximal inhibitory concentration 


\begin{tabular}{|c|c|}
\hline Kryptofix ${ }^{\circledR} 2.2 .2$ & $4,7,13,16,21,24$-hexaoxa-1,10-diazabicyclo[8.8.8]hexacosane \\
\hline LAH & Lithium aluminum hydride \\
\hline $\mathrm{MeV}$ & Mega electronvolt \\
\hline mIBG & Metaiodobenzylguanidine \\
\hline MRI & Magnetic resonance imaging \\
\hline NB & Neuroblastoma \\
\hline $\mathrm{NCI}$ & National Cancer Institute \\
\hline NDEPT & Neural stem/progenitor cell-directed enzyme prodrug therapy \\
\hline NGF & Nerve growth factor \\
\hline NIH & National Institutes of Health \\
\hline NMP & $N$-methyl-2-pyrrolidone \\
\hline NT & Neurotrophin \\
\hline NT-3 & Neurotrophin-3 \\
\hline $\mathrm{PdBr}_{2}$ & Palladium(II) bromide \\
\hline PET & Positron emission tomography \\
\hline PK & Pharmacokinetic \\
\hline PLC & Programmable logic controller \\
\hline PMT & Photo multiplier tube \\
\hline PS & Polystyrene \\
\hline SAR & Structure activity relationship \\
\hline SJCRH & St. Jude Children's Research Hospital \\
\hline$t_{1} / 2$ & Half-life \\
\hline
\end{tabular}


TARGET

TBAOH

TFA

THF

TLC

TrkB

Trks

USP

${ }^{11} \mathrm{C}$

${ }^{18} \mathrm{~F}$
Therapeutically Applicable Research to Generate Effective Treatments

Tetrabutylammonium hydroxide

Trifluoroacetic acid

Tetrahydrofuran

Thin layer chromatography

Tropomyosin receptor kinase $b$

Tropomyosin receptor kinases

United States Pharmacopeia

Carbon-11

Fluorine-18 


\title{
CHAPTER 1. INTRODUCTION
}

\author{
Neuroblastoma
}

\section{Background}

Neuroblastoma (NB) is the second most common solid tumor in childhood and the most common extracranial solid tumor in children with 650-700 new cases diagnosed each year in the US. ${ }^{1-2}$ This accounts for $8-10 \%$ of all childhood cancers and $15 \%$ of all childhood cancer related deaths. ${ }^{2}$ NB is a perplexing disease that can have a prognosis that spans from spontaneous cure to death and has been one of the most challenging diseases to treat. This disease is one that targets the young with the average age of diagnosis is 22 months and more than $95 \%$ of NB cases diagnosed by age $10 .^{2}$

NB is an embryonal tumor that originates from the neural crest cells that normally differentiate to form the sympathetic ganglia, adrenal medulla and other paraspinal sites where sympathetic nervous system tissue is present such as the neck, chest, abdomen, or pelvis. ${ }^{3}$ The reason for the development of NB could be linked to the failure of normal neuroblasts to convert into the expected nerve cells. Common metastatic sites include the lymph nodes, bone marrow or bones. The common presenting symptoms of NB are abdominal swelling, bowel and urinary complications, and pain, but could range from a mass on the neck to fatigue, fever, and difficulty breathing based on the location of the tumor.

Patients with NB are categorized into four groups based on age, and three groups based on several risk factors, each group with a different 5-year event-free survival (EFS) rate with high risk being $<50 \% \mathrm{EFS},{ }^{3-4}$ Table $1-1$. The high-risk group describes those patients that are older than 18 months of age at diagnosis, have an adrenal primary tumor with or without lymph node involvement on the opposite side of the tumor, undifferentiated tumor, decreased reduction of NB cells in bone marrow after treatment, and segmented chromosome abnormalities. ${ }^{4}$ There are more groups and staging based on these criteria and they each have varying EFS statistics, for further discussion on these categories please see the NCI PDQ cancer information summary. ${ }^{4}$

\section{Treatment Options}

Cancer is defined by Merriam-Webster as "a malignant tumor of potentially unlimited growth that expands locally by invasion and systematically by metastasis." In other words, it is a disease of rapidly dividing cells that is outside the normal biological functions, and most chemotherapy agents target these cells. However, no treatment is free of adverse effects and the treatment regimen for NB is no exception. There is a litany of general and drug specific side effects associated with the approved drugs used to treat NB patients. Chemotherapy drugs do not always differentiate cancer from healthy 
Table 1-1. 5-year event-free survival statistics for NB patients based on category.

\begin{tabular}{lc}
\hline Category & 5-year EFS \\
\hline Risk Group & \\
Low & $>95 \%$ \\
Intermediate & $90-95 \%$ \\
High & $40-50 \%$ \\
& \\
Age at Diagnosis & \\
$<1$ year & $90 \%$ \\
1-4 years & $68 \%$ \\
5-9 years & $52 \%$ \\
10-14 years & $66 \%$ \\
\hline
\end{tabular}

Sources: Maris, J. M., Recent advances in neuroblastoma. N Engl J Med 2010, 362 (23), 2202-11, and PDQ ${ }^{\circledR}$ Pediatric Treatment Editorial Board. PDQ Neuroblastoma Treatment. Bethesda, MD: National Cancer Institute. Updated $<08 / 25 / 2016>$. Available at: http://www.cancer.gov/types/neuroblastoma/hp/neuroblastoma-treatment-pdq. Accessed <11/06/2016>. [PMID: 26389190]. 
cells like hair, bone marrow, and intestine which can lead to a host of side effects like hair loss, fatigue, infections, bruising/bleeding, and mouth sores as well as decreased appetite, nausea, and diarrhea or constipation. These may seem tolerable and expected for most therapy but there are greater side effects that are specific to each of the commonly used drugs.

Currently there is a large variation in the treatment of NB based on the patients' risk group, which can be as simple as observation to a full barrage of therapies including chemotherapy, radiation therapy, antibody therapy, and stem cell transplantation. This variation is easily seen in Table 1-2. Patients are categorized as "high-risk" based on age at diagnosis, disseminated disease, and histological and genetic factors which represent $45 \%$ of all NB cases. ${ }^{2}$ Even with an aggressive combination of chemotherapy that could include parts of the Memorial Sloan-Kettering Cancer Center regimen of cisplatin, etoposide, vincristine, doxorubicin, and cyclophosphamide as well as the Children's Oncology Group (COG) recommendation to add topotecan, ${ }^{3}$ surgery, stem cell transplantation, and radiation, survival for these patients is only $<50 \%$. $^{2-3}$ There is opportunity for improvement in the treatment of NB patients and several new therapeutic approaches are currently in development ${ }^{3,5-7}$ or are undergoing clinical trials that can be found on clinicaltrials.gov (NCT02048488, NCT02097810, NCT02637687). Since July 2011, the COG has included the use of anti-GD2 monoclonal antibodies, ${ }^{8}$ anti-angiogenic agents, and topoisomerase I inhibitors in combination with traditional alkylating agents, platinum compounds, topoisomerase II inhibitors, and vincristine. ${ }^{1,3,9}$

The St. Jude Children's Research Hospital (SJCRH) Comprehensive Cancer Center has designated NB for special emphasis as part of an expansion of the Developmental Biology of Solid Tumors Program (DBSTP). SJCRH currently has three active clinical protocols for NB, a Phase I immunotherapy trial, and two NB tumor biology studies which are enrolling an average of 20 new patients per year. Patients are also eligible for seven Phase I and II studies of recurrent/progressive solid tumors that include NB as a study group. In addition, there are numerous ongoing preclinical NB research studies working toward improved therapeutic methods for this devastating disease. These include development of transgenic mouse models of spontaneously arising NB that recapitulate the human disease genetics. ${ }^{10}$ DBSTP researchers also have access to numerous well-characterized, subcutaneous, and orthotopic NB xenograft models through the Cancer Center's Xenograft Core $^{11}$ and through individual investigators.

\section{Positron Emission Tomography}

\section{Applications}

Positron Emission Tomography (PET) is a non-invasive diagnostic imaging technology, like magnetic resonance imaging (MRI) or x-ray computed tomography $(\mathrm{CT})$ scans. But in PET, as low as picomolar ${ }^{12-13}$ concentrations of a chemical that has been 
Table 1-2. Treatment course options based on NB patient risk group.

\begin{tabular}{|c|c|c|c|c|c|c|c|c|}
\hline Risk Group & Observation & Surgery & Chemotherapy & $\begin{array}{l}\text { Radiation } \\
\text { Therapy }\end{array}$ & $\begin{array}{l}\text { Myeloablative } \\
\text { Therapy }\end{array}$ & $\begin{array}{l}\text { Stem Cell } \\
\text { Transplant }\end{array}$ & $\begin{array}{l}\text { Antibody } \\
\text { Therapy }\end{array}$ & Isotretinoin \\
\hline Low &,+- &,$+(*)$ & $*$ & $\mathrm{n} / \mathrm{a}$ & $\mathrm{n} / \mathrm{a}$ & $\mathrm{n} / \mathrm{a}$ & $\mathrm{n} / \mathrm{a}$ & $\mathrm{n} / \mathrm{a}$ \\
\hline Intermediate & $*$ & $(+), *$ & + & - & $\mathrm{n} / \mathrm{a}$ & $\mathrm{n} / \mathrm{a}$ & $\mathrm{n} / \mathrm{a}$ & $\mathrm{n} / \mathrm{a}$ \\
\hline High & $\mathrm{n} / \mathrm{a}$ & + & + & + & + & + & + & + \\
\hline
\end{tabular}

Notes: +: primary option, *: secondary option, -: tertiary option, (): with or without, n/a: not applicable.

Source: PDQ ${ }^{\circledR}$ Pediatric Treatment Editorial Board. PDQ Neuroblastoma Treatment. Bethesda, MD: National Cancer Institute. Updated $<08 / 25 / 2016>$. Available at: http://www.cancer.gov/types/neuroblastoma/hp/neuroblastoma-treatment-pdq. Accessed

$<11 / 06 / 2016>$. [PMID: 26389190]. 
tagged with a positron-emitting radionuclide is injected into the patient. The radioactive chemical can be any biologically active compound, like a drug or a vitamin or water. This sub-pharmacological dose can be imaged in real time as it travels through the patient's body, determining the sites of accumulation, and could measure the biological process using a scanner designed to detect the energy of PET radionuclides.

\section{Radiochemistry - Radionuclide}

In PET, the radionuclide emits a positron from the unstable nucleus. The positron undergoes annihilation with an electron from a neighboring atom, ${ }^{14-15}$ converting both particles to two annihilation photons of equal energy $(511 \mathrm{keV})$ and traveling at approximately $180^{\circ}$ of each other, Figure 1-1. The annihilation photons are detected almost simultaneously by the PET scanner. The PET scanner consists of multiple rings of scintillator crystals, arranged in a circle around the target that the photon interacts with ultimately giving off light that is detected by a photo multiplier tube (PMT). The PMT converts the light to an electrical signal and, using annihilation coincidence detection, can localize the origin of two photons that were detected in a straight line, ${ }^{14}$ Figure 1-2. The recorded events undergo processing to produce an image. The images have an out-offocus appearance to them that can be partially attributed to the energies of the positron from each nuclide. The higher the positron energy the greater the distance traveled before it annihilates with an electron. The lower the energy, the sharper the image. ${ }^{14}$

Common radionuclides used in research are tritium, $\mathrm{t}_{1 / 2}=12.32$ years, or phosphorus-32, $\mathrm{t}_{1} / 2=14.29$ days, but PET radionuclides tend to have much shorter halflives, usually on the order of hours to minutes, for example carbon-11 $\left({ }^{11} \mathrm{C}\right), \mathrm{t}_{1} / 2=20.4$ minutes and fluorine-18 $\left({ }^{18} \mathrm{~F}\right), \mathrm{t}_{1} / 2=109.8$ minutes. The short radioactive half-life of these compounds is a double-edged sword. The drug can be administered, imaged, and eliminated from the body in a short period providing informative images with minimal risk to the patient. The rapid decay of the starting radionuclide is a key element that is considered when developing the synthesis for radiotracers.

There are several cyclotron-produced radionuclides. The SJCRH cyclotron accelerates protons to $18 \mathrm{MeV}$, or about 200 thousand miles per hour using an oscillating radio frequency. The magnets in the cyclotron steer the protons in a circular path to the target material. The target material is bombarded by protons $(\mathrm{p})$ and causes the release of a neutron $(\mathrm{n})$, or alpha particle $(\alpha)$, yielding the radionuclide, ${ }^{15-17}$ Table $1-3 .{ }^{11} \mathrm{C}$ and ${ }^{18} \mathrm{~F}$ labeled radiotracers are commonly employed in PET research due to their flexibility. Any molecule that has a carbon atom, could potentially be labeled with ${ }^{11} \mathrm{C}$ and ${ }^{18} \mathrm{~F}$ is often used as a bioisostere of hydrogen and is regularly used in pharmaceutical development. ${ }^{15}$

Radiochemistry using PET radionuclides allows development of radiotracers that are radioactive versions of compounds that have a physiologic response, but are given in such a low quantity that the blood accumulation is below the therapeutic window. This is achieved through the specific activity of the radiotracer. The starting mass of the 


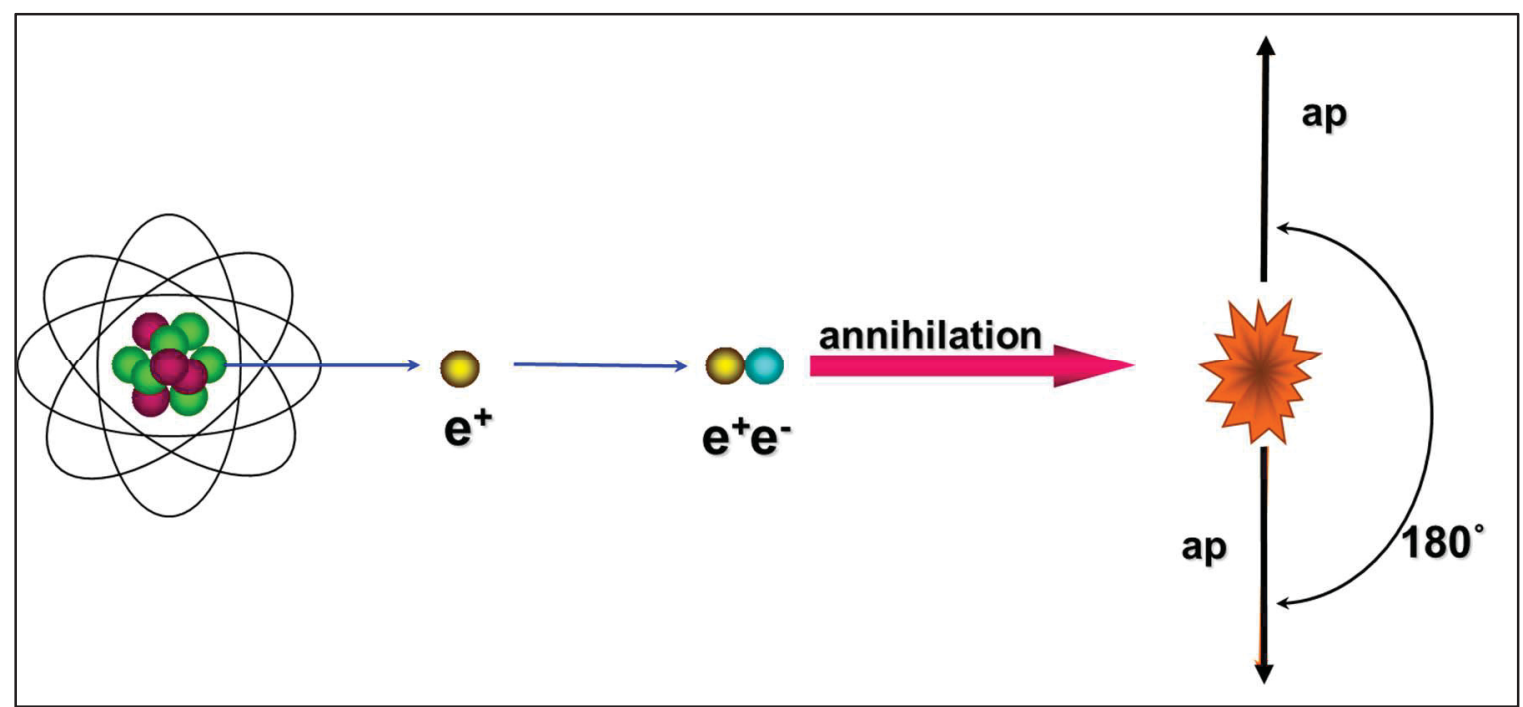

Figure 1-1. Annihilation Photon.

A radionuclide emits a positron $\left(\mathrm{e}^{+}\right)$from the unstable nucleus in a tortuous path and undergoes annihilation with an electron ( $\left.\mathrm{e}^{-}\right)$from a neighboring atom. This converts both particles to two annihilation photons (ap) of equal energy $(511 \mathrm{keV})$ and travelling in opposite directions. 


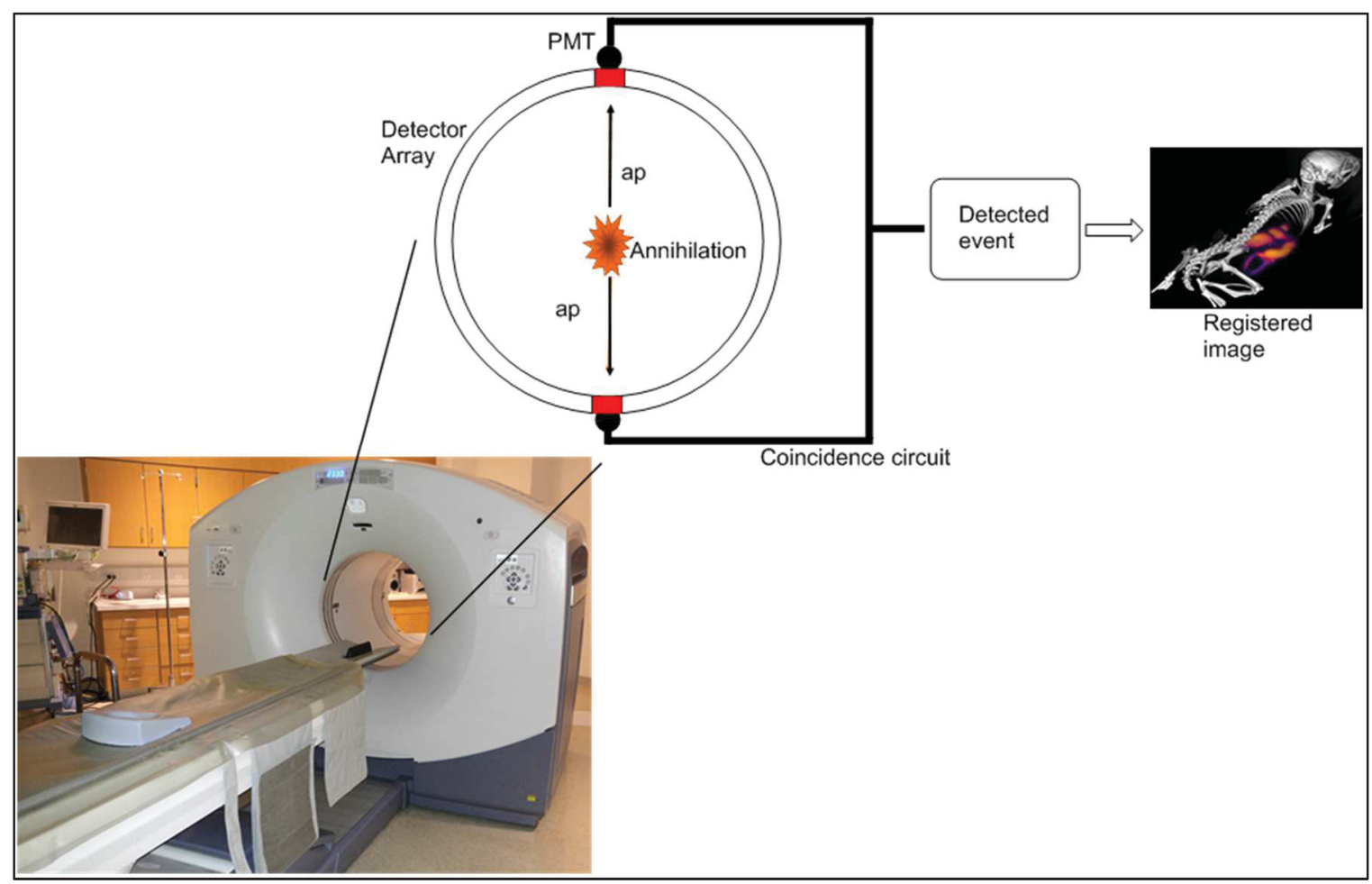

Figure 1-2. Schematic representation of typical PET technology. The annihilation event occurs from a source that is moved to the center of the ring of detectors of the PET scanner. The annihilation photons (ap) are detected almost simultaneously at the detector. The interaction of the photon with the detector gives off light that is amplified in the photo multiplier tube (PMT), and the coincidence circuit sends the signal to the processor. The processor localizes the origin of two photons that were detected in a straight line and provides an image. 
Table 1-3. Common PET radionuclides used in radiochemistry.

\begin{tabular}{lcl}
\hline \multicolumn{1}{c}{ Radioisotope } & $\mathbf{t}_{\mathbf{1} / 2}(\mathbf{m i n})$ & \multicolumn{1}{c}{ Production } \\
\hline Oxygen-15 $\left[{ }^{15} \mathrm{O}\right]$ & 2 & $\left.{ }^{16} \mathrm{O}(\mathrm{p}, \mathrm{pn})\right)^{15} \mathrm{O}$ \\
Nitrogen-13 $\left[{ }^{13} \mathrm{~N}\right]$ & 10 & ${ }^{16} \mathrm{O}(\mathrm{p}, \alpha){ }^{13} \mathrm{~N}$ \\
Carbon-11 $\left[{ }^{11} \mathrm{C}\right]$ & 20 & ${ }^{14} \mathrm{~N}(\mathrm{p}, \alpha){ }^{11} \mathrm{C}$ \\
Fluorine-18 $\left[{ }^{18} \mathrm{~F}\right]$ & 110 & ${ }^{18} \mathrm{O}(\mathrm{p}, \mathrm{n}){ }^{18} \mathrm{~F}$ \\
Galium-68 $\left[{ }^{68} \mathrm{Ga}\right]$ & 68 & ${ }^{68} \mathrm{Zn}(\mathrm{p}, \mathrm{n}){ }^{68} \mathrm{Ga}$ \\
Copper-64 $\left[{ }^{64} \mathrm{Cu}\right]$ & 762 & ${ }^{64} \mathrm{Ni}(\mathrm{p}, \mathrm{n}){ }^{64} \mathrm{Cu}$ \\
\hline
\end{tabular}

Source: Cherry, S. R.; Sorenson, J. A.; Phelps, M. E., Physics in Nuclear Medicine. Third ed.; The Curtis Center: Philadelphia, Pennsylvania, 2003; p 523. 
radiosynthetic precursor is generally less than $1 \mathrm{mg}$ but is on the order of 1700 equivalents of the radionuclide. ${ }^{18}$ The radiosynthetic precursor is purified from the radiotracer and the specific activity is on the order of $\mathrm{Ci} / \mu$ mol. This allows flexibility in the radiotracers for imaging, as even toxic molecules could be approved for use in humans at specific activities of $>2 \mathrm{Ci} / \mu \mathrm{mol}$.

The mission of SJCRH is to advance cures, and means of prevention, for pediatric catastrophic diseases through research and treatment. SJCRH has a fully operational suite of laboratories that are focused on the production and development of PET radiotracers designed to carry out that mission. The studies described here focus on designing PET radiotracers to facilitate NB therapeutic development. Specifically, ${ }^{11} \mathrm{C}$ and ${ }^{18} \mathrm{~F}$-labeled radiotracers, for in vivo measurement of a) carboxylesterase (CE) or b) tropomyosin receptor kinase $\mathrm{b}(\operatorname{TrkB})$ will be developed.

\section{Projects}

\section{Carboxylesterase}

Carboxylesterase (CE) is a ubiquitous family of enzymes found throughout mammalian tissues that hydrolyze numerous ester-containing xenobiotics from their carboxylic acid esters to the corresponding acid and alcohol. ${ }^{19}$ The CEs under investigation by Dr. Potter are the human intestinal CE (hiCE), the human liver CE (hCE1), and a mutant human liver CE (hCE1mut6) with modified substrate selectivity. ${ }^{20-21}$ Irinotecan (CPT-11) is a potent chemotherapeutic used in the treatment of several cancers, including NB. Irinotecan itself is a 1000 times less potent prodrug ${ }^{22}$ which is converted in vivo to the active metabolite SN-38 via metabolism by CE enzymes. $^{23}$ The major side effect of CPT-11 is intractable diarrhea due to the high levels of SN-38 created in the bowels by the hiCE isoform. When the hiCE is blocked, there is decreased activation of CPT-11 to SN-38. This minimizes the amount of active drug that has the capability to affect the intestinal tract leading to the diarrhea side effect.

Researchers at SJCRH are taking advantage of CE isoform diversity to design a two-pronged protocol of tumor specific chemotherapy. These complementary approaches combine specific inhibition of human CE activity in normal tissues ${ }^{24}$ to increase drug delivery to the tumor, and tumor-specific activation of prodrugs using neural progenitor cells transfected with a CE cDNA. ${ }^{19,25}$ The inherent tumor-selective trafficking of neural progenitor cells allows over-expression of CE within the tumor. ${ }^{25}$ For further explanation of the neural stem/progenitor cell-directed enzyme prodrug therapy (NDEPT), please review Dr. Danks' and Dr. Potter's research. ${ }^{19,23,25-26}$ This opens a door to pretreat with a CE inhibitor selective to the isoform in the intestine, preventing the side effect and allowing a prodrug to be activated at the site of up regulation of the transgenic $\mathrm{CE}$ at the tumor. 
Whether researchers inhibit the peripheral CE isoform or increase the CE isoform at the tumor, therapeutic development would be facilitated by non-invasive measurement of the actual enzyme concentration change due to therapy and monitoring of this change over time. This project proposes to design PET radiotracers that could show the localization of the neural progenitor cells by targeting the CE isoform of interest and then measure the change in concentration of that $\mathrm{CE}$ in the living subject. This could allow monitoring of how much $\mathrm{CE}$ the neural progenitor cells are producing at the tumor and for how long, or the extent of inhibition of the peripheral CE isoforms. Optimal dose and frequency for treatment with the neural progenitor cells could then be identified and nontarget sites where there is $\mathrm{CE}$ activity that may be of concern could be visualized. Thus both lines of investigation would benefit from in vivo quantification of $\mathrm{CE}$ activity in tumors and normal tissues, allowing titration of drug dosing for $\mathrm{CE}$ inhibitors and measurement of CE increases selectively at tumor foci in progenitor cell studies.

One aspect of this research project was to design PET radiotracers based on CE inhibitors developed at SJCRH, many of which contain a benzil (diphenylethane-1,2-dione) core structure. ${ }^{26}$ To determine whether the benzil structure was sufficiently activated for direct labeling with ${ }^{18} \mathrm{~F}$, the conversion of the commercially available, mono-substituted 4-nitro to 4-fluorobenzil was performed as proof of concept for radiolabeling.

The nitrobenzil compounds are good precursors for fluorination reactions. New radiolabeled compounds were synthesized based on the structure activity relationship scaffold of the benzil compounds, to design a radiotracer with a low nanomolar affinity for the CE. The initial results of the synthesis of the $4-\left[{ }^{18} \mathrm{~F}\right]$ fluorobenzil has opened the door for the Molecular Imaging Research laboratory to create more selective compounds with improved solubility and pharmacokinetics.

\section{Tropomyosin Receptor}

There are many prognostic factors that are looked at for NB patients. These include age, tumor histology, DNA ploidy, MYCN gene amplification, chromosome changes, neurotrophin (NT) receptors, and serum markers. Researchers have tried to target some of these prognostic factors for therapy or early diagnosis and one of note is the presence or absence of TrkB.

The tropomyosin receptor kinases (Trks) belong to the group of receptor tyrosine kinases in the protein kinase family. ${ }^{27}$ These Trks (TrkA, TrkB, and TrkC) show structural similarity with approximately $50 \%$ peptide sequence identity ${ }^{28}$ but are activated by selective NTs known as nerve growth factor (NGF), brain-derived-neurotrophic factor (BDNF), and neurotrophin-3 (NT-3), respectively. ${ }^{27-28}$ The NT NGF was discovered over 50 years ago, ${ }^{29}$ and the oncogene OncD (aka Trk) was discovered over 32 years ago, ${ }^{30}$ which ultimately led to the identification of Trks in 19 different tumor types, ${ }^{30}$ including NB. 
From 2002-2008, numerous Pharma companies have reported either through journals or patent applications the development of targeted Trk inhibitors. ${ }^{27}$ This supports the suggestion that the Trks are potential targets of interest in the pharmaceutical development industry. There are currently several non-selective receptor kinase inhibitors on the US market ${ }^{7}$ used to target various receptor kinases including EGF, ${ }^{31-35}$ $\mathrm{PI} 3 \mathrm{~K},{ }^{36}$ and $\mathrm{Akt}^{37-38}$ Some of these have been approved for use in various cancers ${ }^{34}$ and as they are non-selective can be assumed to have activity against the Trks as well. ${ }^{39-41}$ This non-targeted approach has proven to be worth investigating in other receptor tyrosine kinases and there has been some investigation in relation to Trks. ${ }^{42}$ It is conceivable that some portion of the benefits of these non-selective kinase inhibitors is related to anti-Trk activity. ${ }^{43-53}$ However, some assessment of Trk inhibition by these various non-selective agents would be required to validate this assumption. There have been several pan-Trk inhibitors identified ${ }^{33}$ that may be of clinical significance ${ }^{54}$ that have been studied in Phase 1 clinical trials. ${ }^{55}$

The Trks control the surplus of neurons initially produced in vertebrate nervous systems, by inducing apoptosis or differentiation through primarily TrkA and partially through TrkC, or inducing cell survival through TrkB. ${ }^{42,56}$ The peripheral nervous system, under normal development, requires Trk expression and any lack thereof yields both central and peripheral nervous system anomalies. ${ }^{27-28,42,56}$ According to Brodeur and colleagues, TrkB is rarely, if ever seen in sympathetic neurons but it is required in early stages of development of sensory neurons. ${ }^{28}$ Trks can be highly expressed in cells of neural origin and TrkB specifically is found at the pre- and post-synaptic membranes at times of sensory neurogenesis. ${ }^{42,56}$ The activation of Trks during neuronal development facilitates their survival and differentiation whereas in the adult, activation is required for maintenance of growth and function of neuronal synapses. The Trk-NT signaling dynamic offers protection to neurons after biochemical insults, transient ischemia, or physical injury has occurred. ${ }^{42}$ Several investigators propose that the upregulation of TrkB is caused by the release of intracellular BDNF in an autocrine signaling pathway. ${ }^{57-70}$

The membrane bound TrkB specifically activates signaling pathways involved in growth factor regulation. ${ }^{1,42}$ Figure 1-3 shows that the receptor has an extracellular domain, a transmembrane region and an intracellular region. The extracellular region is cysteine rich and contains fibronectin type III repeats. The actual extracellular site of NT ligand binding is an Ig-like domain forming a dimer of the receptor that activates the intracellular tyrosine kinase domain. Activation leads to phosphorylation of multiple tyrosines in the domain that ultimately serve as docking sites for the cytoplasmic proteins. Once the cytoplasmic proteins are engaged, activation of downstream mediators of kinase pathways, such as the Ras/MAPK pathway and the PI3Kinase/3-phosphoinositide-dependent protein kinase-1/Akt pathway occurs. This cascade of events ultimately leads to the regulation of cellular functions, namely growth, survival and differentiation., 42 Activation of the PI3K pathway is reported to be responsible for the chemo-resistant nature of tumors of high-risk patients. ${ }^{71}$ 


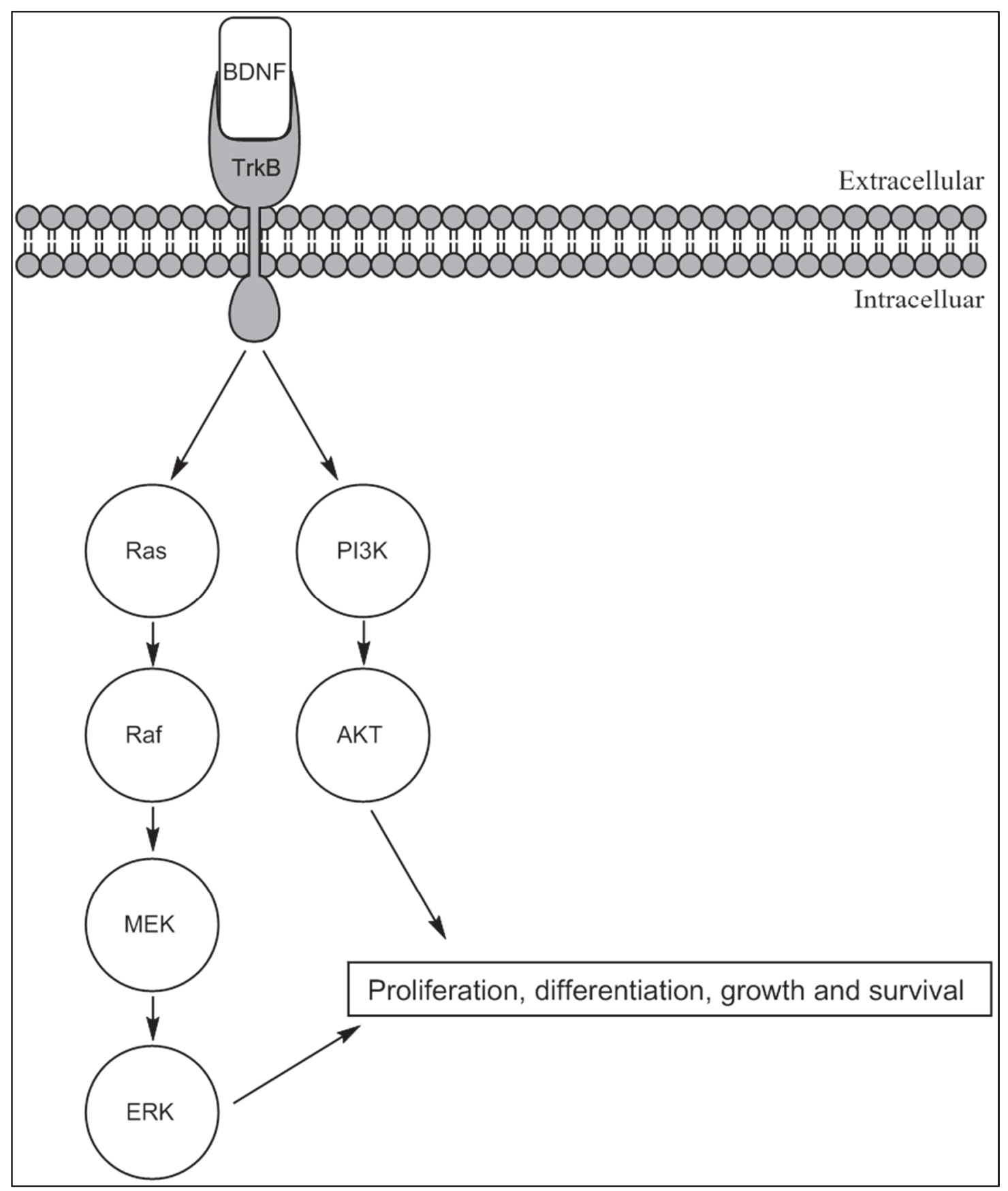

Figure 1-3. Proposed TrkB receptor pathway activation.

The extracellular neurotrophin ligand binding site is shown. Once activated, the intracellular region of tyrosine phosphorylation allows docking of cytoplasmic proteins and thus the activation of downstream mediators of kinase pathways leading to cell proliferation, differentiation, growth and survival. Data Source: Thiele CJ, Li Z, McKee AE. On Trk--the TrkB signal transduction pathway is an increasingly important target in cancer biology. Clin Cancer Res. Oct 1 2009,15(19):5962-5967. 
There have been numerous retrospective studies that have shown the presence of Trks can classify the prognosis of NB patients. The presence of TrkA is generally considered a favorable indicator and the presence of TrkB is an unfavorable indicator. Aoyama reported that $80 \%$ of NB patients with unfavorable prognosis had TrkB present in the primary tumors. ${ }^{72}$ Fung reported that from the KK Women's and Children's hospital in Singapore $52.6 \%$ of the NB patients' primary tumors expressed TrkB. ${ }^{73}$ Nakagawara reported that $36 \%$ of primary NB cases examined expressed TrkB. ${ }^{67}$ Weinreb reported that in metastatic olfactory NB cases, $85 \%$ tested positive for TrkB. ${ }^{74}$ These data imply that the presence of TrkB is associated with high-risk NB patients that have a 5-year EFS of $<50 \%,{ }^{41,75-80}$ possibly due to the induction of chemoresistance ${ }^{71-72,}$ 81-82 and others have studied the significance of TrkB in the survival of NB tumors. ${ }^{74,83-85}$ The reason for the negative outcome seen in these patients is not completely understood, but there are multiple hypotheses in the literature.

Researchers also indicated that TrkB is strongly correlated with MYCN amplification. ${ }^{67}$ The amplification of $\mathrm{MYCN}$, an oncogene, has been used as an indicator of poor prognosis in cancer patients ${ }^{1}$ including $31 \%$ of advanced stage NB patients. ${ }^{1}$ Others have investigated pathways that are tyrosine kinase mediated including the MAPK/Ras-ERK, PI3K-AKT, and the PLCg1-PKC pathways. ${ }^{29}$ These pathways regulate cell survival and differentiation and are believed to be initiated by the binding of BDNF to TrkB. ${ }^{30}$ The presence of Galectin- 1 and its upregulation has been reported ${ }^{76,86}$ as a mode of tumor-immune escape through the forced apoptosis of activated T-cells. ${ }^{87}$ Galectin-1 is a protein that serves several functions such as regulation of inflammation and T-cell homeostatis ${ }^{88}$ No matter if only one of these processes, or all of them, are the reason for high risk NB patients having such poor prognosis, the underlying commonality of these hypotheses is the presence of TrkB. Investigating TrkB may give researchers additional insight regarding this disease.

The TrkB imaging project involved the development of radiotracers for the in vivo measurement of TrkB as a prognostic identifier that could enable quicker initiation and personally tailored therapeutic regimen for NB patients. The project entailed developing new PET radiotracers based on the Trk inhibitor QSAR studies ${ }^{27,89}$ that will provide in vivo data on the concentration and location of TrkB. There are selective TrkB inhibitors with nanomolar activity into which a positron emitting radionuclide could be integrated and further developed to synthesize novel ligands of TrkB.

The production of these radiotracers could provide valuable prognostic data regarding the gene expression of the NB tumors identified in the preliminary diagnosis screening. It is well documented that TrkB-positive, NB tissues are chemo-resistant and have a high incidence of refractory disease. Since a TrkB scan will provide data regarding the presence of TrkB associated with NB tissues, this scan could make available the option to change clinical therapy due to the presence of TrkB. The early initiation of alternate therapy for a NB patient that is chemo-resistant to the first line therapy based on the presence of TrkB is invaluable and could minimize the exposure to the chemotherapy that is not effective and any side effects that are associated with it. ${ }^{90}$ The current drug therapy for NB consists of varying regimens of select chemotherapy 
agents that may not be effective against tumors expressing TrkB such as cisplatin, doxorubicin, etoposide, vinblastine or topotecan. ${ }^{91-94}$ Therefore, the regimen could be altered to utilize secondary agents that have been reported to be successful, such as retinoids, ${ }^{90}$ nitrogen mustards, ${ }^{33}$ other alkylating agents, ${ }^{33}$ or PI3K or Akt inhibitors ${ }^{37-38}$ that are currently in clinical trials like Idelalisib. ${ }^{36}$

Another option would be to initiate a Trk selective inhibitor that would block the functions of TrkB and its ligand, or add an available tyrosine kinase inhibitor that nonselectively targets the TrkB like Lestaurtinib. ${ }^{33,90,95}$ Early diagnosis and treatment are important for any cancer therapy, and these TrkB radiolabeled inhibitors would present the opportunity to alter therapy early and improve survival based on the earlier initiation of effective treatment. TrkB has been studied in several other cancers, such as papillary thyroid carcinomas, secretory breast cancers, pediatric sarcomas and leukemia, ${ }^{28}$ with similar effects, extending the benefits of this work to multiple patient populations. The value of TrkB in NB may be of greater importance if the Therapeutically Applicable Research to Generate Effective Treatments (TARGET) program that is being conducted with the Cancer Genome Atlas project uncovers critical data that supports TrkB as a reliable prognostic marker. 


\section{CHAPTER 2. FLUORINE-18 LABELING OF BENZILS AND SUBSTITUTED BENZIL DERIVATIVES FOR IMAGING CARBOXYLESTERASE}

\section{Introduction}

As described in Chapter 1, there is a need to find new therapy options for highrisk NB patients that will increase the 5 -year survival above $50 \%$. The extensive therapy regimen is typically separated into three stages: induction, consolidation and maintenance. During induction, the goal is to move the cancer into remission while removing or destroying as much of the cancer as possible prior to surgery. Once adequate progress has been made either through induction and/or surgery, the patient will move to consolidation where the regimen is the most intense with the goal of removing any remaining cancer cells, especially micro-metastasis. Once the patient has had a full response based on the individual protocol they are moved to the maintenance stage where the intent is to lower the chance of recurrence.

Traditional chemotherapeutic agents include carboplatin or cisplatin, cyclophosphamide or ifosfamide, vincristine, doxorubicin, etoposide, topotecan, and busuflan and melphalan ${ }^{96}$ have had varying levels of success in the treatment of NB. Not every NB patient is the same and the therapy for one risk group is not as effective for another risk group. The chemotherapeutic drugs mentioned previously include the platinum-containing alkylating agents, nitrogen mustards, vinca alkaloids, anthracycline antibiotics, topoisomerase inhibitors, and alkyl sulfonates. These drugs are all plagued by a variety of serious side effects and most have a black box warning in the respective drug package inserts ${ }^{9,97-98}$ including myelosuppression, organ toxicity, tissue necrosis if extravasation occurs, or being leukemogenic. Regardless of the therapy used, clinicians must keep in mind all possible side effects associated with the chosen treatment plan. Ideally, clinicians want to minimize the severity of treatment and make every effort to reduce side effects.

\section{Targeting Carboxylesterase}

There is a fine line to balance on where chemotherapeutic agents are cytotoxic to the unwanted cancer cell but ignore or have minimal interaction with normal healthy cells. What if there was a way to have the chemotherapeutic agent of choice only activate at the site of the cancer cells? Several chemotherapeutic agents, like 5-fluorocytosine, banoxantrone dihydrochloride, and CB-1954, ${ }^{99}$ used in NB are prodrugs $^{100}$ that are activated by some biologic action. CPT-11 is a potent chemotherapeutic used in the treatment of several cancers, including recurrent or refractory $\mathrm{NB}^{4}$ in pediatric populations. CPT-11 is a prodrug which is converted in vivo to the cytotoxic form, SN-38, via metabolism by CE enzymes, Figure 2-1, at the carbamate bond between the camptothecin moiety and the dipiperidino side chain. CEs exist as differing isoforms in various mammalian tissues. ${ }^{24,26}$ They express a conserved 


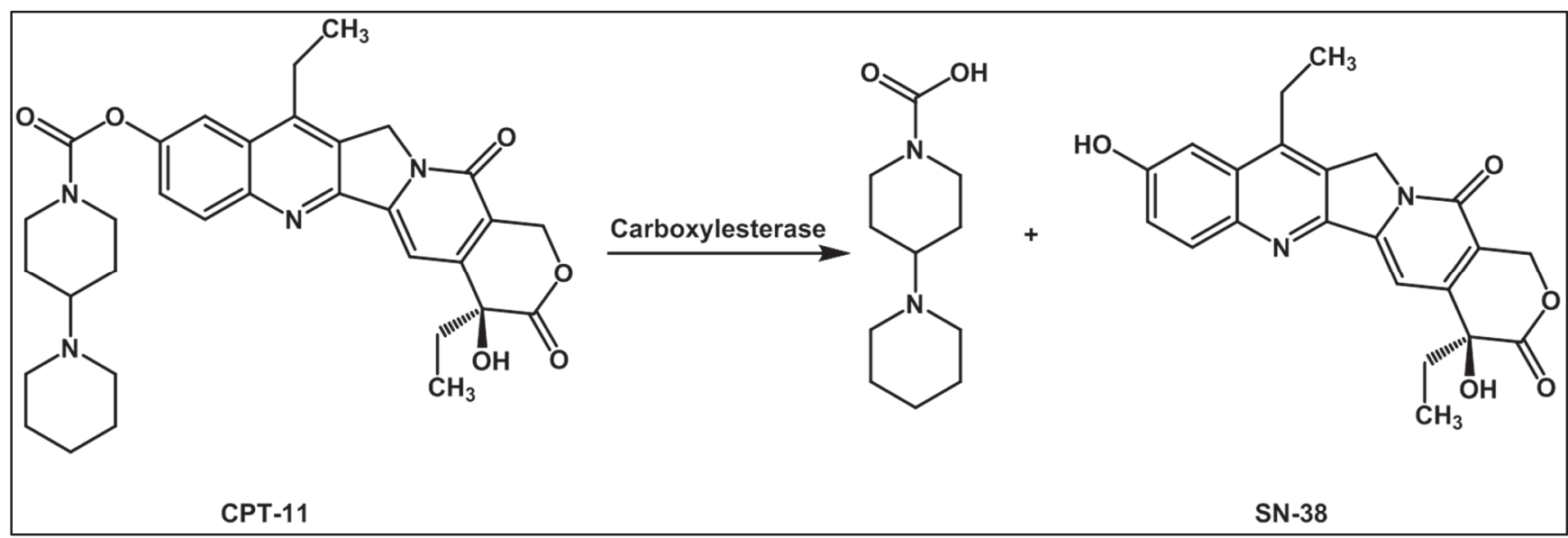

Figure 2-1. Conversion of CPT-11 to SN-38. 
catalytic triad of amino acids required for activity, but access to the active site is restricted and varies among CE isoforms, ${ }^{23,101-102}$ Figure 2-2.

Whether the path of investigation is to inhibit peripheral CEs or using NDEPT to increase the expression of $\mathrm{CE}$ within the tumor, either would benefit from an in vivo method for quantification of $\mathrm{CE}$ activity in tumors and normal tissues, allowing titration of drug dosing for $\mathrm{CE}$ inhibitors and measurement of increases in $\mathrm{CE}$ concentration at tumor foci in progenitor cell studies. This project focused on developing radiotracers for PET based on CE inhibitors developed at SJCRH. Such radiotracers could provide in vivo quantification of $\mathrm{CE}$ in tissues, aiding preclinical therapy development.

\section{Pharmacophore}

The initial medicinal chemistry work performed in the Potter lab led to a library of substituted benzil derivatives, Figure 2-3. Benzil is a compound that shows activity as a generic, nonselective inhibitor of CEs, ${ }^{24}$ Table 2-1. The adjacent ketones of benzil are required for $\mathrm{CE}$ inhibition. This is because the oxygen atom from the catalytic serine of the $\mathrm{CE}$ attacks one of the carbonyl groups and the resulting tetrahedral intermediate is relatively stable and is not cleaved like the $\mathrm{C}-\mathrm{O}$ bond present in esters. This interaction inhibits the enzyme.

The aromatic rings are necessary for activity in the micro- to nanomolar range, while the substituents on the aromatic rings dictate the compound's activity and CE isoform selectivity. It is known that if the substituents are too big and bulky, inhibitor potency is decreased due to reduced access to the $\mathrm{CE}$ active site containing the catalytic triad. ${ }^{23-24,26,101}$

The compound library discovery identified that substituted benzil compounds can selectively inhibit $\mathrm{CE}$ isoforms and that the di-substituted analogues were most active. However, for simplicity in method development, synthesis of the mono-substituted analogue was used for proof of concept in the radiolabeling of this project.

The benzil core was the starting point, but investigators in the Webb lab found that a phenyl pyridinyl-1,2-dione compound had better activity against the CE of interest, ${ }^{103}$ Figure 2-4, while maintaining the aromatic diketone core and improving the water solubility. Therefore, once initial radiolabeling conditions were identified using the benzyl derivatives, this project's focus was shifted to these compounds as the next in the series for radiolabeling. The original library did not have any substituents on the pyridine ring, but incorporation of an ${ }^{18} \mathrm{~F}$ nuclide at this site is possible.

\section{Synthesis of Radiosynthetic Standards and Precursors}

The precursor, 4-nitrobenzil, was generously provided by Dr. Potter's lab for initial studies. The synthesis is shown in Scheme 2-1. This provides the benzil core, and 


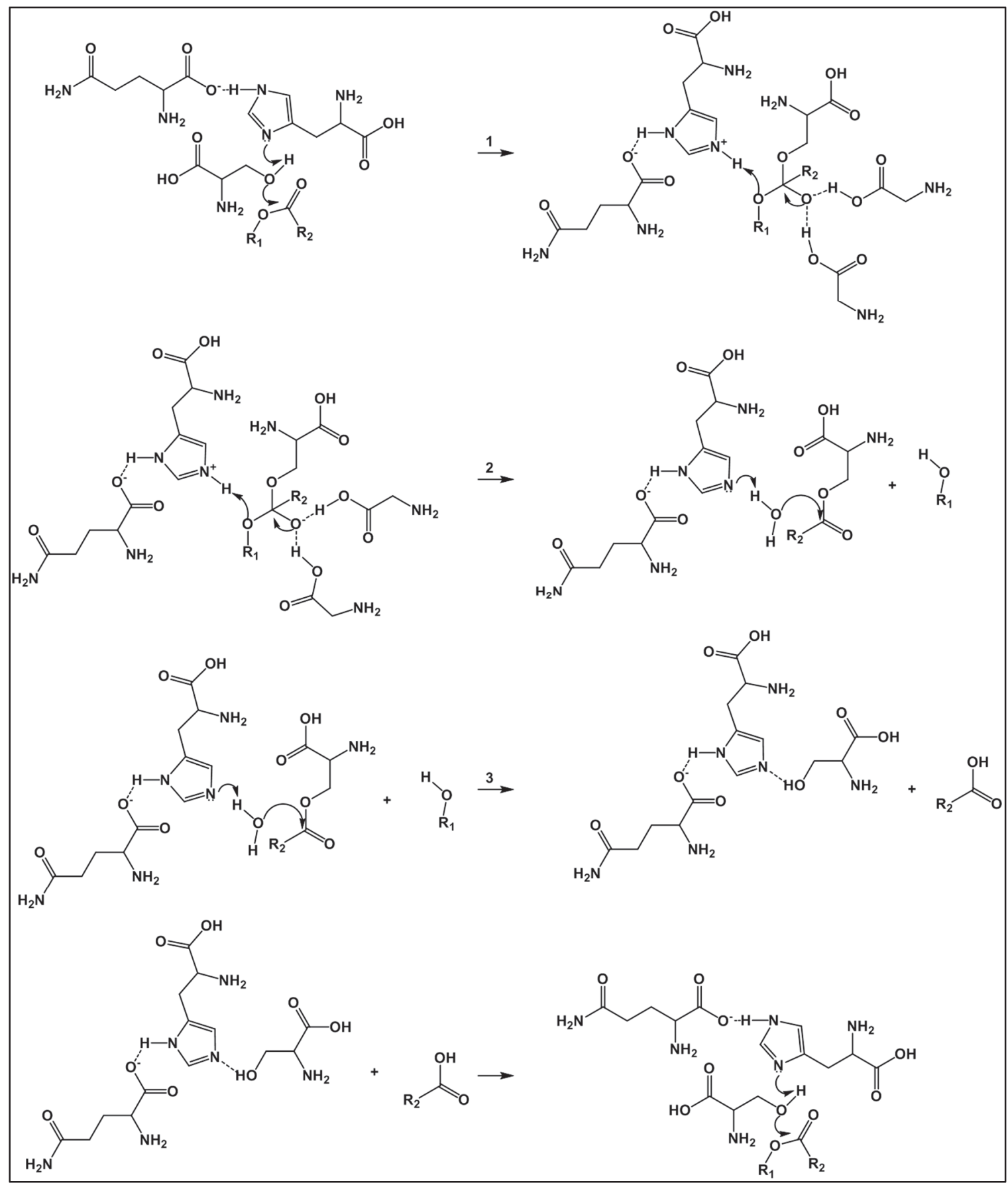

\section{Figure 2-2. Carboxylesterase Catalytic Triad.}

Proposed mechanism of carboxylesterase. The catalytic triad of serine, histidine, and glutamic acid, facilitate nucleophilic attack on a carbonyl carbon (1), production of an intermediate with serine (2), degradation of the intermediate (3), and resetting the enzyme. Data Source: Ross, M. K.; Borazjani, A., Enzymatic activity of human carboxylesterases. Curr Protoc Toxicol 2007, Chapter 4, Unit 424. 


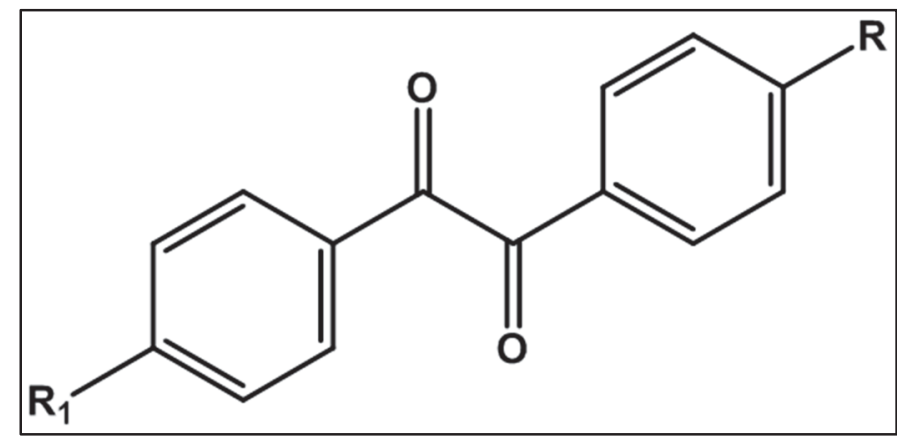

Figure 2-3. Generic structure of substituted benzil.

Table 2-1. Substituted benzil CE activity against various $\mathrm{CE}$ isoforms.<smiles>[R]c1ccc(C(=O)C(=O)c2ccc([R])cc2)cc1</smiles>

\begin{tabular}{llccc}
\hline R & R1 & hiCE $\mathbf{K} \boldsymbol{i}(\mathbf{n M})$ & hCE1 Ki $(\mathbf{n M})$ & hCE1 mut6 Ki $(\mathbf{n M})$ \\
\hline $\mathrm{H}$ & $\mathrm{H}$ & $15.1 \pm 1.9$ & $45.1 \pm 3.4$ & $5.1 \pm 0.28$ \\
$\mathrm{H}$ & $\mathrm{F}$ & $76.1 \pm 2.6$ & $171 \pm 10$ & $15.75 \pm 0.75$ \\
$\mathrm{~F}$ & $\mathrm{~F}$ & $170 \pm 12$ & $230 \pm 11.8$ & $33.4 \pm 3.2$ \\
\hline
\end{tabular}

Data Source: Hicks, L. D.; Hyatt, J. L.; Moak, T.; Edwards, C. C.; Tsurkan, L.; Wierdl, M.; Ferreira, A. M.; Wadkins, R. M.; Potter, P. M., Analysis of the inhibition of mammalian carboxylesterases by novel fluorobenzoins and fluorobenzils. Bioorg Med Chem 2007, 15 (11), 3801-17, and personal communication from Phil Potter 3 Mar 2009. 


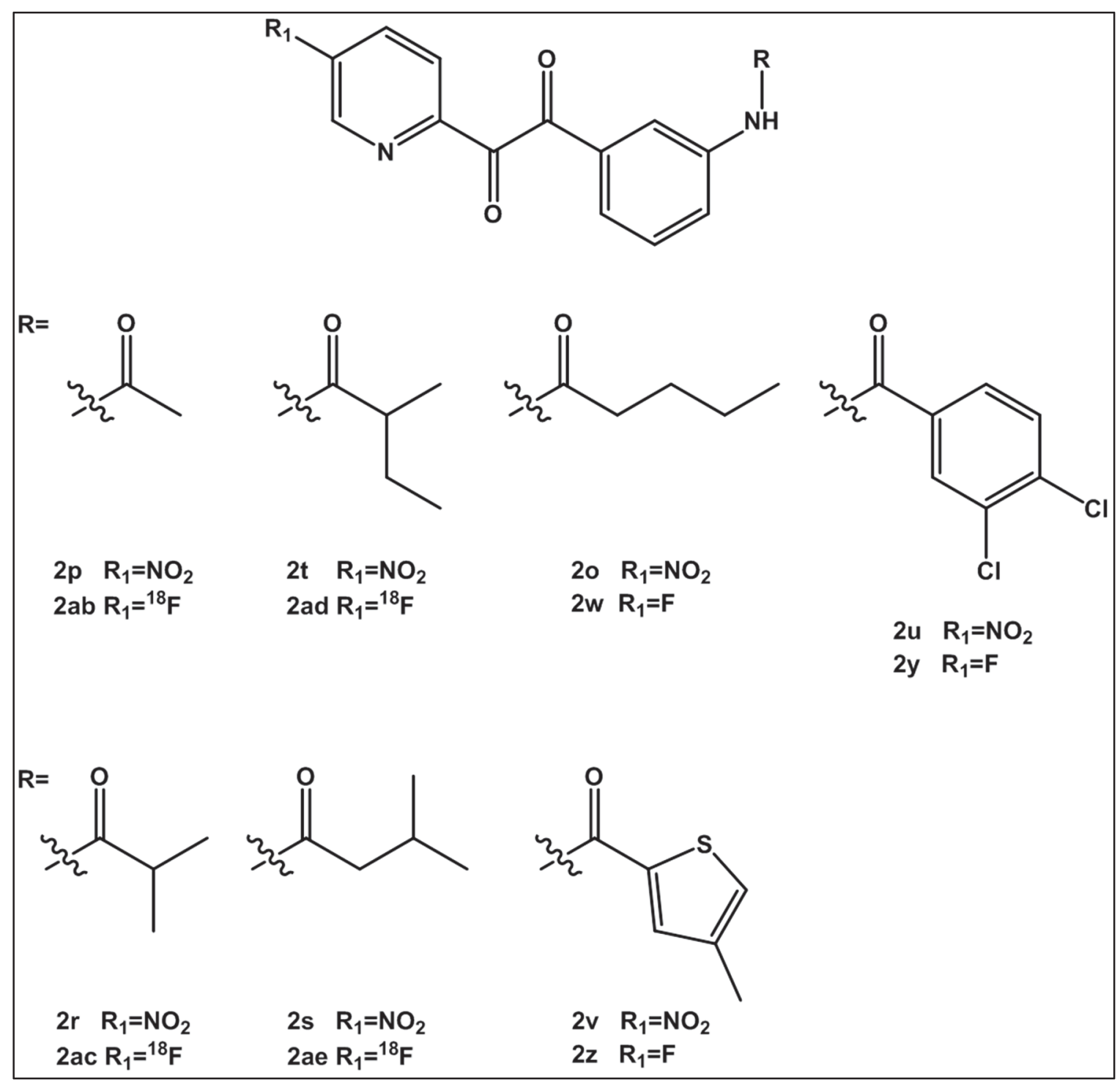

Figure 2-4. Phenyl Pyridinyl 1,2-dione derivatives.

Synthesized radiosynthetic precursor library used for radiotracer development. Data Source: Young, B. M.; Hyatt, J. L.; Bouck, D. C.; Chen, T.; Hanumesh, P.; Price, J.; Boyd, V. A.; Potter, P. M.; Webb, T. R., Structure-activity relationships of substituted 1-pyridyl-2-phenyl-1,2-ethanediones: potent, selective carboxylesterase inhibitors. $J$ Med Chem 2010, 53 (24), 8709-15 


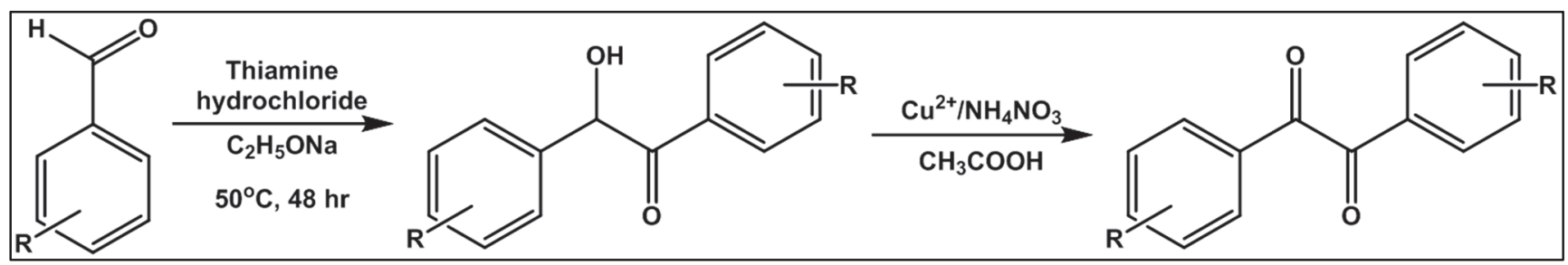

Scheme 2-1. Generic synthesis of disubstituted benzil derivatives.

Commercially available substituted benzaldehydes are condensed using thiamine hydrochloride and sodium ethoxide to give the benzoin. Then oxidation was performed using copper(II) acetate and ammonium nitrate in acetic acid. 
substituents could be introduced into the ortho, meta, or para positions based on the desired starting material.

\section{PETChem Solutions Radiochemistry Unit}

Keeping radioactivity exposure as low as reasonably achievable is important when working with radioactive compounds. One way to do this is to utilize automated synthesis technology to perform the manual steps of non-radioactive organic chemistry generally carried out on the bench top or in the hood. The PETChem Solutions automated synthesis instrument is a versatile, flexible device, Figure 2-5A, set up inside a fume hood that is surrounded by $75 \mathrm{~mm}$ of lead, known as a hot cell, Figure 2-6. The hot cell has an access port that is sealed using a plexiglass panel and a rubber gasket inflated to be airtight. This plexiglass panel is then enclosed by a lead door. The PETChem Solutions radiochemistry unit is controlled remotely by a laptop through a Programmable Logic Controller (PLC) and the commercially available Lookout Direct software interface, Figure 2-5B. This system controls every aspect of the automated synthesis technology. Every valve, temperature block, and gas flow is adjustable and managed through this interface. Once the synthesis is optimized, a PLC control script is written into the software to proceed automatically improving reproducibility.

${ }^{18} \mathrm{~F}$ is produced by proton irradiation of ${ }^{18} \mathrm{O}$-water in a $(\mathrm{p}, \mathrm{n})$ nuclear reaction, Scheme 2-2. Aqueous fluoride was captured using a QMA anion exchange resin to remove as much of the ${ }^{18} \mathrm{O}$-water as possible, which could be recycled for future use. Elution of the fluoride ion from the QMA resin is accomplished with a mixture of 4,7,13,16,21,24-Hexaoxa-1,10-diazabicyclo[8.8.8] hexacosane (Kryptofix ${ }^{\circledR}$ 2.2.2) and $\mathrm{K}_{2} \mathrm{CO}_{3}$ in $(2: 1)$ acetonitrile and water. Kryptofix ${ }^{\circledR}$ 2.2.2 is a three-dimensional analogue of a crown ether that chelates $\mathrm{K}^{+}$ions and removes the fluoride from the QMA cartridge as KF. Taking advantage of the resulting acetonitrile/water azeotrope, the water was evaporated at $85^{\circ} \mathrm{C}$. The mixture could be washed with an additional volume of acetonitrile and evaporated again as needed, yielding the anhydrous $\mathrm{K}^{18} \mathrm{~F}$-Kryptofix ${ }^{\circledR}$ 2.2.2 complex.

The 4-nitrobenzil precursor was dissolved in anhydrous dimethyl sulfoxide (DMSO), Scheme 2-3, and added to the reaction vial containing the $\mathrm{K}^{18} \mathrm{~F}-\mathrm{Kryptofix}^{\circledR}$ 2.2.2 complex. The resulting mixture was sealed and heated at $130{ }^{\circ} \mathrm{C}$ for 45 minutes yielding a 20-25\% labeled compound 2aa. Optimization of the synthetic process was performed through modification of multiple variables including the solvent system, amount of 4-nitrobenzil precursor, reaction temperature, and reaction time.

These experiments were conducted using ${ }^{18} \mathrm{~F}$, which has a 110 -minute half-life, as the initial radionuclide for labeling. This allows some flexibility with the timing of the synthesis, but the synthetic scheme could benefit from a decrease in the overall reaction time for this and future radiotracers. Microwave assisted organic synthesis provided a viable option to obtain this goal. 


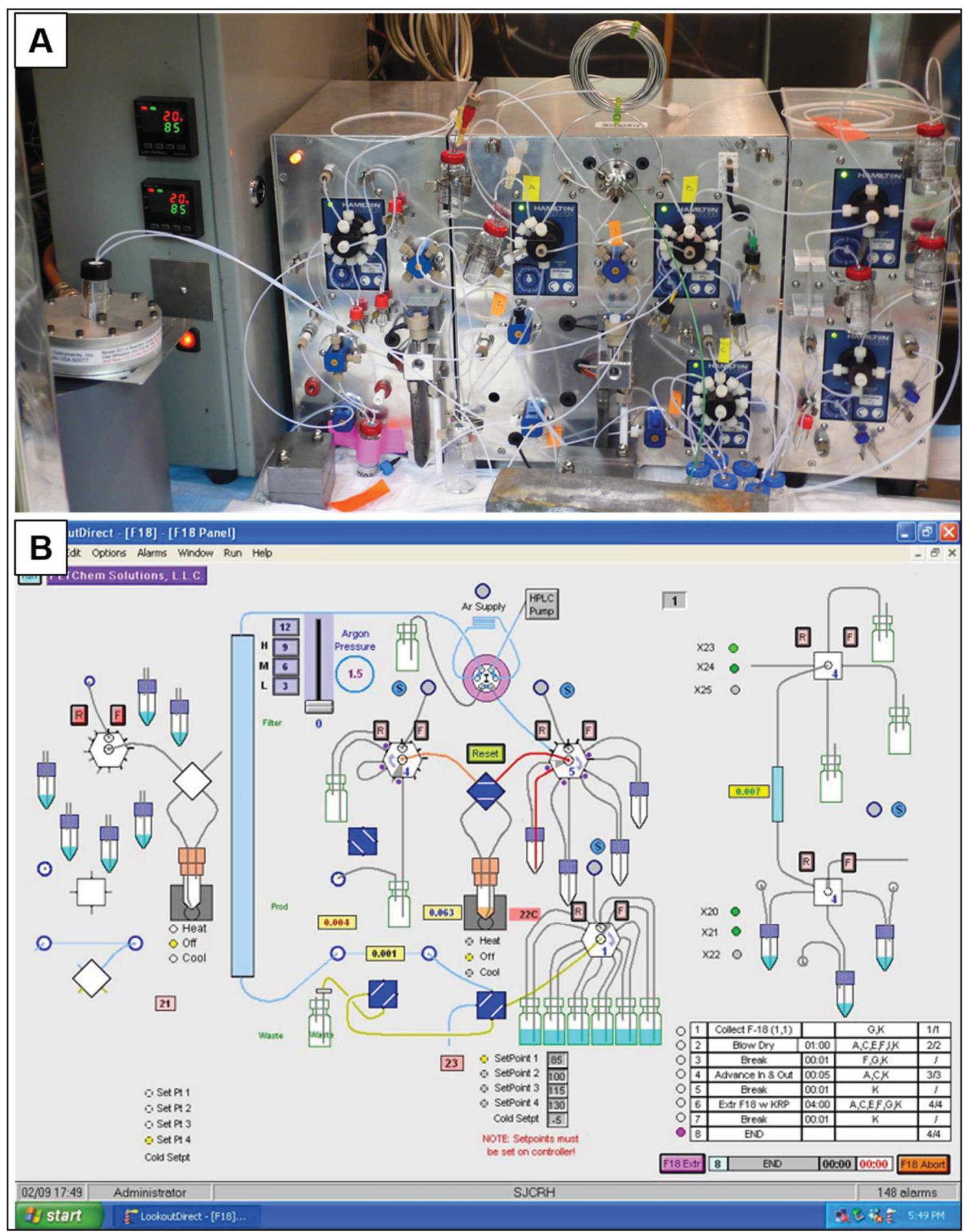

Figure 2-5. PETChem automated radiosynthesis technology.

A: PETChem hardware. B: Lookout Direct software screen. 


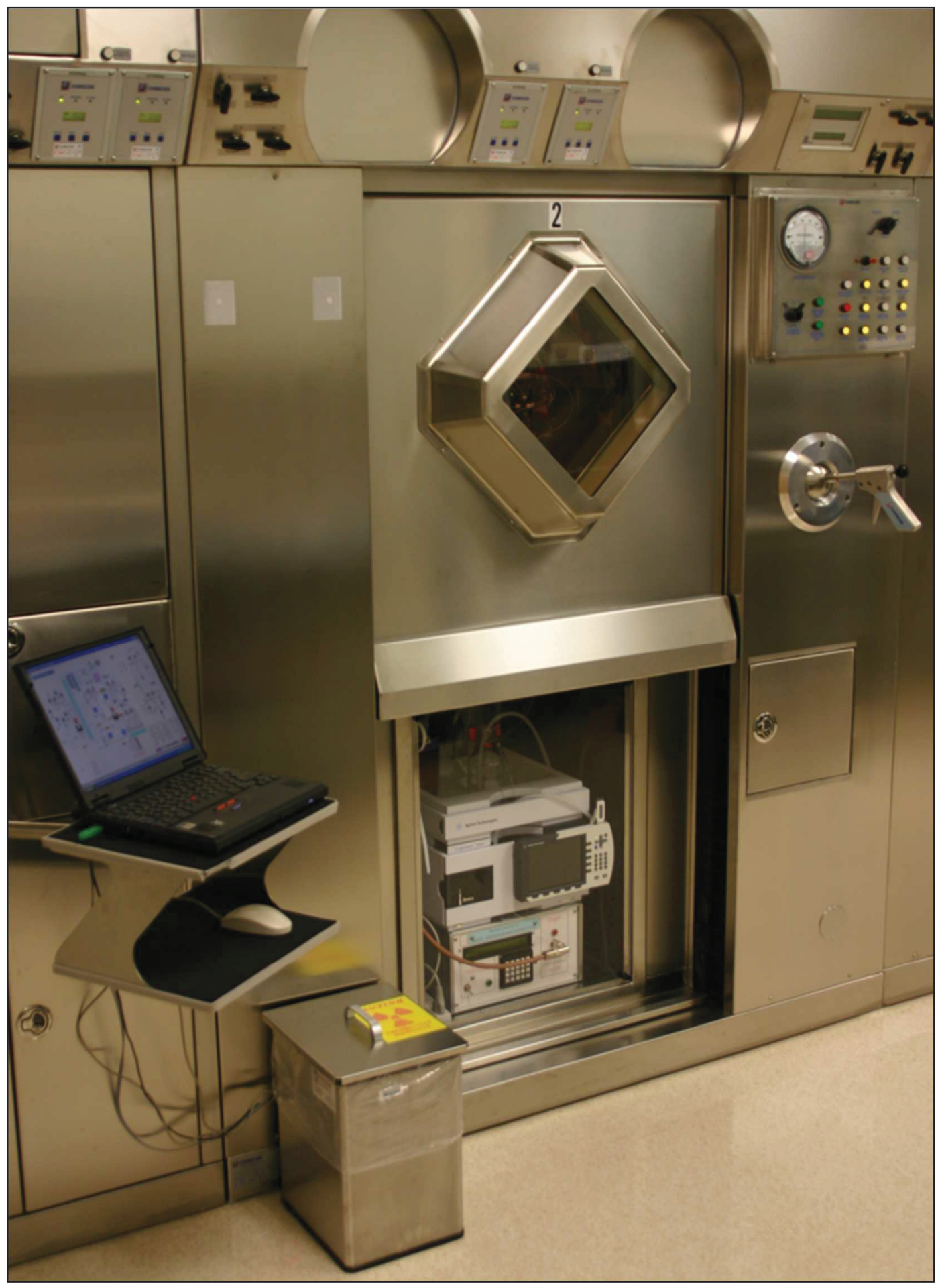

Figure 2-6. Lead-shielded radiosynthesis fume hood.

The laptop is visible on the left side of the image and the HPLC control unit and the microwave control unit are visible below the leaded access door. 


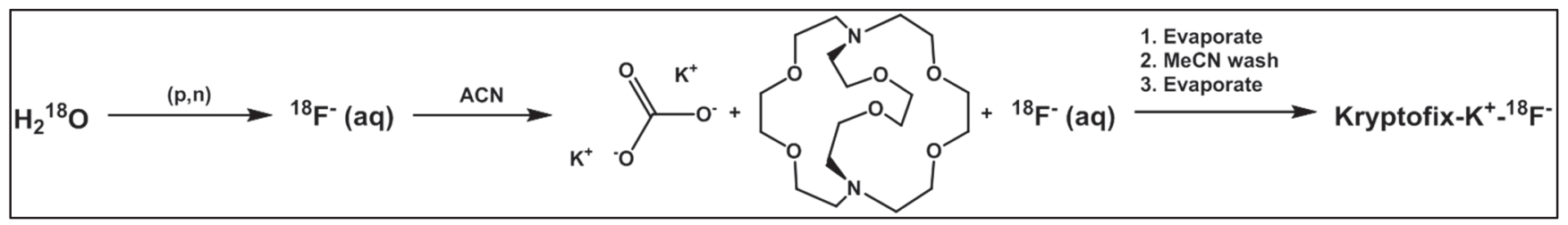

Scheme 2-2 Fluorine-18 production and solubilization for organic synthesis.

${ }^{18} \mathrm{~F}$ was produced by proton irradiation of ${ }^{18} \mathrm{O}$-water in a $(\mathrm{p}, \mathrm{n})$ nuclear reaction. Aqueous

fluoride was captured using a QMA anion exchange resin. Elution of the fluoride ion with a mixture of 4,7,13,16,21,24-Hexaoxa-1,10-diazabicyclo[8.8.8]hexacosane (Kryptofix ${ }^{\circledR}$ 2.2.2) and $\mathrm{K}_{2} \mathrm{CO}_{3}$ in $(2: 1)$ acetonitrile and water. The water was evaporated at $85{ }^{\circ} \mathrm{C}$ yielding the anhydrous $\mathrm{K}^{18} \mathrm{~F}-\mathrm{Kryptofix}^{\circledR}$ 2.2.2 complex.

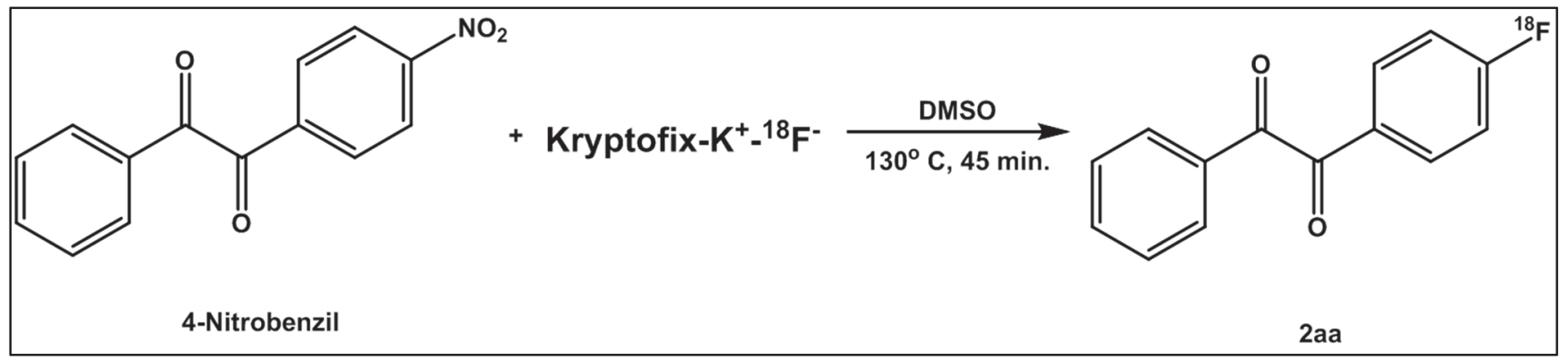

\section{Scheme 2-3. Radiolabeling of benzil compounds using fluorine-18.}

The 4-nitrobenzil precursor was dissolved in anhydrous dimethyl sulfoxide (DMSO), and added to the reaction vial containing the $\mathrm{K}^{18} \mathrm{~F}$-Kryptofix ${ }^{\circledR} 2.2 .2$ complex. The resulting mixture was sealed and heated at $130{ }^{\circ} \mathrm{C}$ for 45 minutes yielding a $20-25 \%$ labeled compound 2aa. 


\section{Microwave Assisted Radiolabeling}

Microwave assisted organic synthesis methods have been utilized since the mid1980s. ${ }^{104}$ A major benefit of microwaves is that they provide very rapid heating of the entire reaction sample almost immediately compared to traditional heating which applies the heat to the surface of the vessel which then diffuses to the center until perceived uniform heating is achieved. ${ }^{105}$ Superheating is also possible utilizing this method. Other benefits reported with microwave heating are that the reactions may be cleaner, require decreased reaction times, and potentially exhibit greater reproducibility. ${ }^{104-106}$

The radiosynthesis was performed using a Resonance Instruments Inc. (Skokie, IL), model 521 microwave instrument for accelerated microwave chemistry, Figure 2-7. The microwave instrument provides a continuous source of power that can be programmed and the temperature output can be varied depending on the conditions of the reaction. To maintain a desired temperature, it monitors the temperature at the surface of the reactor vessel and adjusts as necessary. A $10-\mathrm{mL}$ glass V-vial was used with a modified septum-sealed cap that allowed automation of the process and that could be sealed to permit reactions to occur under increased pressure. The septum was fitted with peek tubing running from the PETChem Solutions radiochemistry unit to allow transfer of the reaction mixture using Argon gas. After heating for various time points, an aliquot of the crude reaction mixture was analyzed by thin layer chromatography (TLC) with radioactivity detection. This allowed the reaction time to be reduced from 45 minutes to 7 minutes at a power of 100 watts and a temperature setting at $130{ }^{\circ} \mathrm{C}$. The final heating time was applied for 2 minutes and 5 minutes with a 30 second rest in-between. This heating time was used to prevent over pressurization of the V-vial. Once optimized, the crude reaction mixture was then loaded in a $5 \mathrm{~mL}$ high performance liquid chromatography (HPLC) sample loop for injection onto the ZORBAX Eclipse XDB-C18 semi-preparative column, 9.4 x $250 \mathrm{~mm}, 5 \mu \mathrm{m}$ particle size (Agilent, Santa Clara, CA). As the mobile phase exits the column, it passes a radiation detector and fractions are collected in $10 \mathrm{~mL}$ vials (Hollister Stier, Spokane, WA). The vial of interest can be removed from the hot cell using the manipulator and passed through a door in the side of the hot cell. The final product can then be analyzed for conformity to the quality control tests, yielding the radiochemical purity.

The HPLC pump and solvents are located under the hot cell that feed into the module through a septum. The microwave controller is also located here and is easily accessible during the synthesis or can be controlled remotely as well.

\section{Method Development}

The organic synthesis of the radiosynthetic standards was previously optimized ${ }^{103}$ in the SJCRH Chemical Biology and Therapeutics (CBT) department and the procedure was used in this project without modification to synthesize the precursors and standards. The variations to the side chain of the amide of the phenyl pyridinyl-1,2-dione was intended to provide a library of potential precursors. The radiochemistry development 


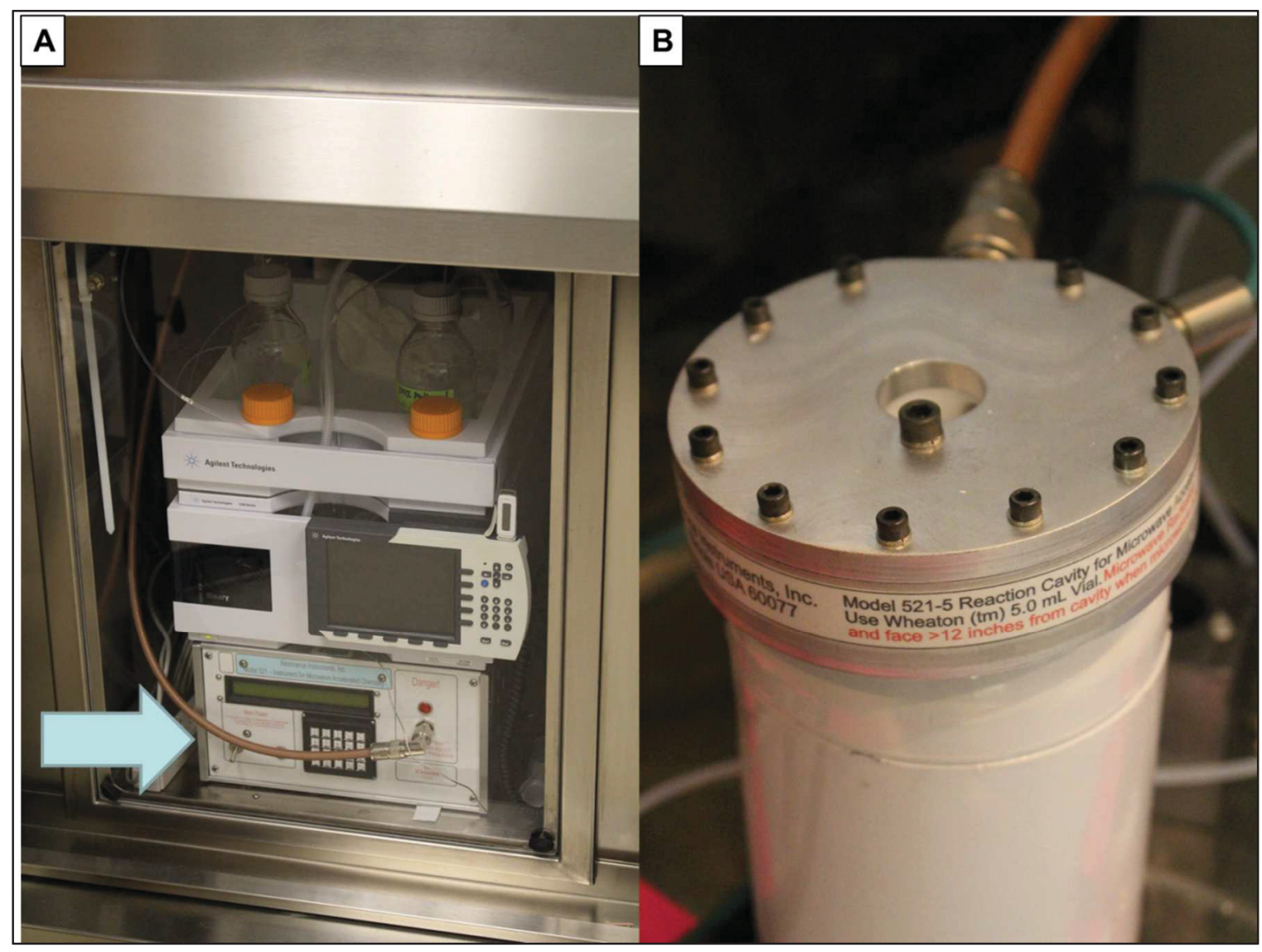

Figure 2-7. Microwave technology for use in radiolabeling.

A: Programmable logic controller for the microwave reactor (arrow). B: The microwave reaction cavity. 
was the sole focus of this project. The ${ }^{18} \mathrm{~F}$ production is a well-developed and documented synthesis; therefore, no alterations were pursued. The radiolabeling was optimized by first investigating DMSO, dimethylformamide (DMF), and acetonitrile (ACN) as reaction solvents. Next, the optimal temperature was determined through testing temperatures in $20^{\circ} \mathrm{C}$ increments starting at $100{ }^{\circ} \mathrm{C}$ and ending at $180{ }^{\circ} \mathrm{C}$. Finally, reaction times of 30,45 , and 60 minutes were compared to the microwave assisted heating times of 2, 5, 7 and 15 minutes for the 4-fluorobenzil compound, Table 2-2. The reaction was monitored by TLC and visualized using a Bioscan AR2000 TLC scanner. Each step of the optimization requires a complete separate cleaning, set-up, and reaction sequence on the PETChem Solutions radiochemistry unit. There is also a necessary amount of time required for the radioactivity to decay to a safe level to allow access to the inside of the hot cell before beginning the reset, thus limiting the number of reactions to 2-3 tests per day.

Conditions for purification and analysis by HPLC were determined for the 4- $\left[{ }^{18} \mathrm{~F}\right]$ fluorobenzil (2aa) and the nitro and fluoro radiosynthetic precursor and standard. Adequate separation was achieved on the ZORBAX Eclipse DBX-C18 analytical column, 4.6 × $250 \mathrm{~mm}, 5 \mu \mathrm{m}$ particle size (Agilent, Santa Clara, CA) eluted with $90 \%$ acetonitrile and $10 \%$ water with a flow rate of $1 \mathrm{~mL} / \mathrm{min}$ and the temperature of the column maintained at $25^{\circ} \mathrm{C}$. Under these conditions, injection of $10 \mu \mathrm{L}$ of unlabeled 4nitrobenzil and 4-fluorobenzil with a concentration of less than $20 \mu \mathrm{g} / \mathrm{mL}$ provided retention times of 3.2 and 3.4 minutes respectively. Analysis of the crude product showed a radiation peak corresponding to the unlabeled 4-fluorobenzil compound and a residual 4-nitrobenzil precursor on the UV chromatogram, Figure 2-8.

To synthesize the precursor and the radiosynthetic standards of the phenyl pyridinyl-1,2-dione compounds, Scheme 2-4, start with a Sonogashira coupling of the ethynyl-aniline with the 2-bromo-5-nitropyridine. This yields the diarylalkyne. The amide formation happens in basic conditions with the chosen acid chloride or acid anhydride in tetrahydrofuran (THF), treated with triethylamine, at room temperature and allowed to react overnight. The alkyne can then be oxidized using palladium bromide in DMSO in the microwave at $200{ }^{\circ} \mathrm{C}$ for 3 minutes.

The optimized conditions for the benzil compounds were utilized with the phenyl pyridinyl-1,2-dione compounds with equal success. These conditions were retested using the method development program of an Advion NanoTek ${ }^{\circledR}$ (Ithaca, NY) instrument, a microfluidic continuous flow radiochemistry platform. The technology allows the control of reaction conditions of temperature, flow, and precursor/radionuclide ratio. The temperature was varied by $20^{\circ} \mathrm{C}$ increments starting at $140{ }^{\circ} \mathrm{C}$ and ending at $220^{\circ} \mathrm{C}$ and the flow rate for the reaction was tested at 5, 10, 20, and $30 \mu \mathrm{L} / \mathrm{min}$. The maximum radiochemical conversion as reported by TLC was $17 \%$ with conditions of $210{ }^{\circ} \mathrm{C}$ at 10 $\mu \mathrm{L} / \mathrm{min}$ in a 1:1 ratio, Table $\mathbf{2 - 3}$. 
Table 2-2. Radiolabeling reaction condition optimization for 1-(4- $\left[{ }^{18} \mathrm{~F}\right]$ fluorophenyl)2-phenylethane-1,2-dione (2aa).

\begin{tabular}{crrr}
\hline \multirow{2}{*}{$\begin{array}{c}\text { Condition } \\
(\mathbf{n}=\mathbf{1})\end{array}$} & \multicolumn{3}{c}{ Radiochemical Yield (\%) } \\
\cline { 2 - 4 } & DMSO & DMF & ACN \\
\hline Temperature $\left({ }^{\circ} \mathrm{C}\right)$ & & & \\
100 & 9.60 & 12.01 & 0 \\
120 & 26.95 & 8.09 & 0 \\
140 & 68.64 & 11.12 & 0 \\
160 & 37.11 & 20.8 & 0 \\
180 & 54.71 & 15.79 & 0 \\
& & & \\
Time (minutes) & & & \\
30 & 17.52 & 0 & 1.35 \\
45 & 68.64 & 0 & 9.05 \\
60 & 19.07 & 2.09 & 1.71 \\
& & & \\
Microwave Time & & & \\
100W, 130 ${ }^{\circ} \mathrm{C}$, & & & \\
(minutes) & & & \\
2 & 5.35 & 5.58 & 3.88 \\
5 & 34.46 & 5.12 & 4.46 \\
7 & 60.53 & 7.77 & 5.68 \\
15 & 31.22 & 8.25 & nd \\
\hline
\end{tabular}

Note: nd: not determined. 


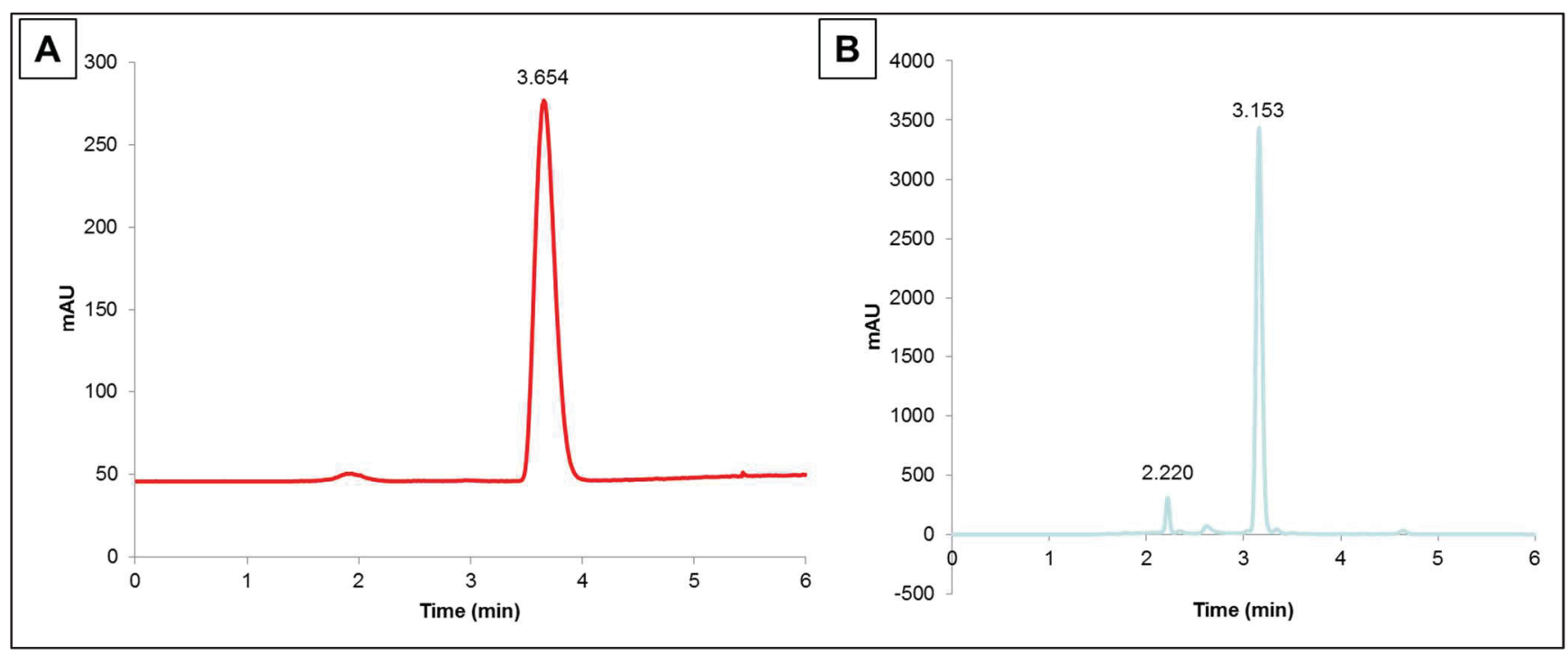

Figure 2-8. HPLC chromatogram of radiolabeling 4-nitrobenzil using ${ }^{18} \mathbf{F}$. A: Radioactivity signal of $\left[{ }^{18} \mathrm{~F}\right]$-4-fluorobenzil (2aa) $\left(\mathrm{t}_{\mathrm{R}}=3.654\right)$. B: UV signal $(254 \mathrm{~nm})$ of non-radioactive 4-fluorobenzil ( $t_{R}=3.153 \mathrm{~min}$.). Conditions: radiolabeled using Kryptofix ${ }^{\circledR} 2.2 .2-{ }^{18} \mathrm{~F}-\mathrm{K}$ complex, DMSO, heated to $130{ }^{\circ} \mathrm{C}$ for 7 minutes at $100 \mathrm{~W}$. HPLC: mobile phase of $90 \%$ acetonitrile and $10 \%$ water with a flow rate of $1 \mathrm{~mL} / \mathrm{min}$ on an Agilent ZORBAX Eclipse XDB-C18 analytical column, 4.6 x $250 \mathrm{~mm}, 5 \mu \mathrm{m}$ particle size. 


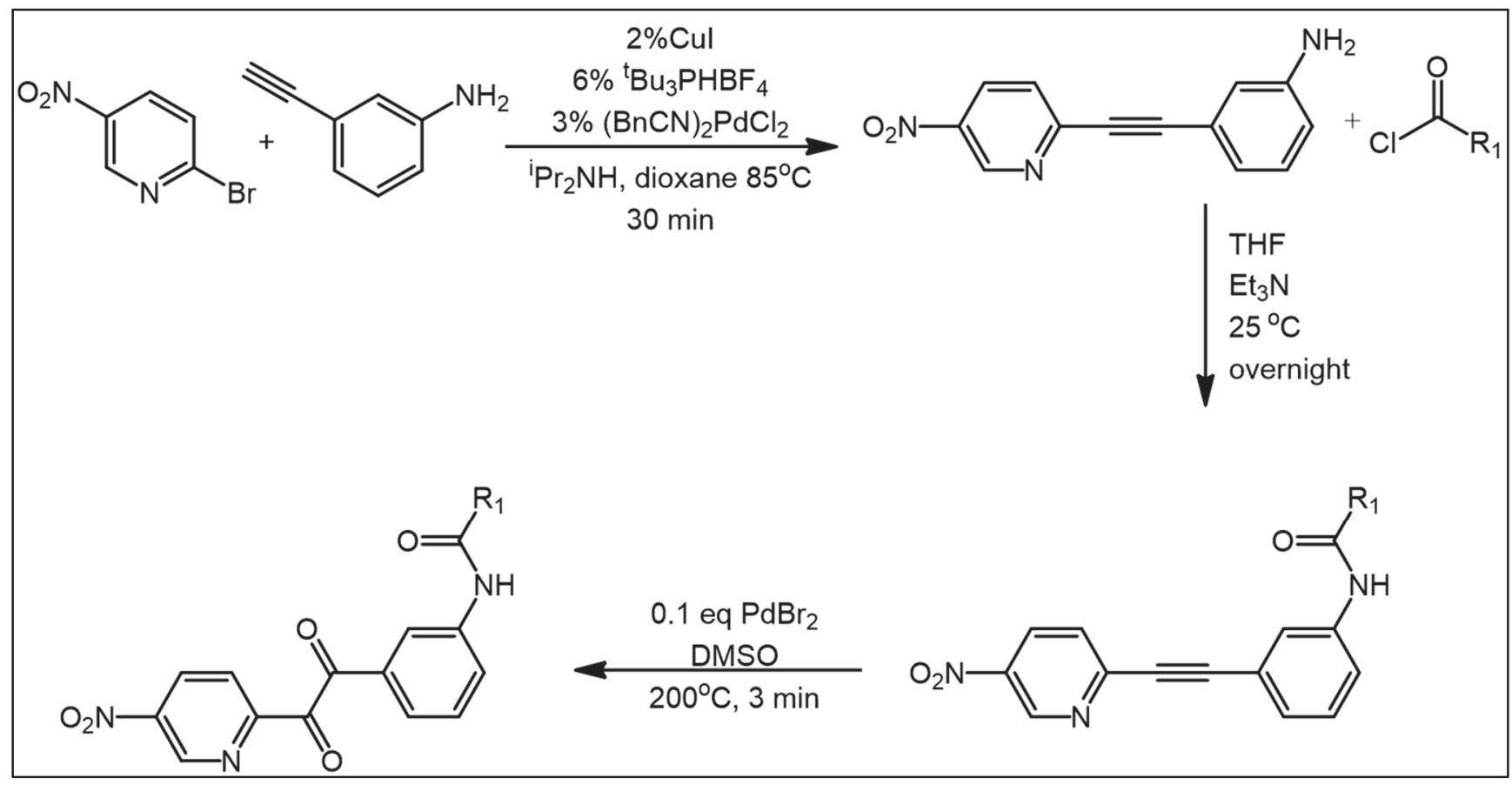

Scheme 2-4. Generic synthesis of phenyl pyridinyl radiosynthetic precursors. Ethynyl-aniline was coupled with the 2-bromo, 5-nitro pyridine through a Sonogashira coupling to give the diarylalkyne. In basic conditions the amide was formed from the acid chloride or acid anhydride in tetrahydrofuran (THF), treated with triethyl amine, at room temperature overnight. The alkyne was oxidized using palladium bromide in DMSO with microwave heating at $200{ }^{\circ} \mathrm{C}$ for 3 minutes.

Data Source: Young, B. M.; Hyatt, J. L.; Bouck, D. C.; Chen, T.; Hanumesh, P.; Price, J.; Boyd, V. A.; Potter, P. M.; Webb, T. R., Structure-activity relationships of substituted 1-pyridyl-2-phenyl-1,2-ethanediones: potent, selective carboxylesterase inhibitors. J Med Chem 2010, 53 (24), 8709-15. 
Table 2-3. Radiochemical yield for $N$-(3-(2-(5- $\left[{ }^{18}\right.$ F]fluoropyridin-2-yl)-2-oxoacetyl)phenyl)acetamide (2ab) using precursor $N$-(3-(2-(5-nitropyridin-2-yl)-2-oxoacetyl)phenyl)propionamide (2q).

\begin{tabular}{|c|c|c|c|c|}
\hline $\begin{array}{c}\text { Run } \\
(n=1)\end{array}$ & $\begin{array}{c}\text { Temperature } \\
\left({ }^{\circ} \mathrm{C}\right)\end{array}$ & $\begin{array}{c}\text { Rate } \\
(\mu \mathrm{L} / \mathrm{min})\end{array}$ & $\begin{array}{l}\text { Precursor to } \\
{ }^{18} \mathrm{~F} \text { ratio }\end{array}$ & $\begin{array}{l}\text { Radiochemical } \\
\text { Yield (\%) }\end{array}$ \\
\hline \multirow{2}{*}{\multicolumn{5}{|c|}{$\begin{array}{l}\text { Precursor } \\
2 q\end{array}$}} \\
\hline & & & & \\
\hline 1 & 140 & 30 & $1: 1$ & 0.0 \\
\hline 2 & 160 & 30 & $1: 1$ & 4.74 \\
\hline 3 & 180 & 30 & $1: 1$ & 8.31 \\
\hline 4 & 200 & 30 & $1: 1$ & 10.8 \\
\hline 5 & 210 & 30 & $1: 1$ & 9.51 \\
\hline 6 & 220 & 30 & $1: 1$ & 10.7 \\
\hline 7 & 200 & 20 & $1: 1$ & 12.9 \\
\hline 8 & 210 & 20 & $1: 1$ & 13.5 \\
\hline 9 & 220 & 20 & $1: 1$ & 10.5 \\
\hline 10 & 200 & 10 & $1: 1$ & 16.5 \\
\hline 11 & 210 & 10 & $1: 1$ & 17.0 \\
\hline 12 & 220 & 10 & $1: 1$ & 15.0 \\
\hline 13 & 200 & 5 & $1: 1$ & 12.9 \\
\hline 14 & 210 & 5 & $1: 1$ & 8.55 \\
\hline 15 & 220 & 5 & $1: 1$ & 8.07 \\
\hline 16 & 200 & 10 & $2: 1$ & 11.4 \\
\hline 17 & 210 & 10 & $2: 1$ & 11.3 \\
\hline 18 & 220 & 10 & $2: 1$ & 12.9 \\
\hline \multicolumn{5}{|l|}{$2 q$} \\
\hline $1^{\mathrm{a}}$ & 130 & $\mathrm{n} / \mathrm{a}$ & $\mathrm{n} / \mathrm{a}$ & 37.1 \\
\hline $2^{\mathrm{b}}$ & 130 & $\mathrm{n} / \mathrm{a}$ & $\mathrm{n} / \mathrm{a}$ & 72.6 \\
\hline
\end{tabular}

Note: a: Conventional heating for 45 minutes on PETChem solutions. b: microwave heating for 7 minutes on PETChem solutions. n/a: not applicable. 


\section{Results and Discussions}

The 4- $\left[{ }^{18} \mathrm{~F}\right]$ fluorobenzil (2aa) is the basic core structure of the library of compounds that could be used to determine the upregulation of the desired CE through NDEPT studies. The 4- $\left[{ }^{18} \mathrm{~F}\right]$ fluorobenzil is not the ideal compound based on its solubility and $\mathrm{IC}_{50}$ data $(15.75 \pm 0.75 \mathrm{nM})$, but it allows the proof of concept for the labeling of future iterations of $\mathrm{CE}$ inhibitors. The radiosynthesis was optimized using both conventional heating methods and microwave-assisted techniques in reproducible yields of 50-60\%. This is a reasonable yield for nucleophilic fluorinations; for comparison, $\left[{ }^{18} \mathrm{~F}\right] \mathrm{FDG}$ is routinely made with radiochemical yields of approximately $60 \%$. ${ }^{18}$ The PETChem Solutions radiochemistry unit, incorporated with the microwave and HPLC makes for a unique, configurable system that could accommodate simple late stage fluorinations typically desired for radiotracer development as well as multi-step reactions and final purification. The Advion NanoTek ${ }^{\circledR}$ is a valuable method development tool that can minimize the consumables needed for repeat synthesis runs, but this instrument yielded a maximum $17 \%$ radiochemical yield compared to the $50-60 \%$ yield that was possible with the large scale, automated radiosynthesis technology.

The phenyl pyridinyl-1,2-dione compounds show better activity and selectivity for the $\mathrm{CE}$, but they also show a greater difficulty in the reproducibility of the radiosynthesis. The radiochemical yield varied from $8-50 \%$, Table $\mathbf{2 - 3}$, when using the optimized conditions for the $4-\left[{ }^{18} \mathrm{~F}\right]$ fluorobenzil.

\section{Overall Conclusions}

The benzil scaffold with a para-substituted electron-withdrawing group is a good precursor for fluorination reactions. Utilizing the benzil core, novel radiotracers were successfully synthesized to target the specific CE used in the NDEPT studies. This study showed that microwave assisted radiolabeling was a viable option to incorporate the ${ }^{18} \mathrm{~F}$ in the non-substituted benzil and the phenyl pyridinyl-1,2-dione. There is a definite problem with the reproducibility of the radiolabeling that was confirmed in the traditional, microwave assisted, and microfluidics development of the phenyl pyridinyl-1,2-dione library of compounds. Although the phenyl pyridinyl-1,2-dione compounds have improved solubility ${ }^{103}$ as compared to the benzil compounds, the problems seen in the variation of the radiochemical yield could be caused by the solubility. This project found that, even in DMSO, the radiosynthetic precursors were difficult to get into solution thus limiting the amount of precursor available to react with the ${ }^{18} \mathrm{~F}$. Future compound libraries that show improved solubility and selectivity for the $\mathrm{CE}$ of interest with low nanomolar $\mathrm{IC}_{50}$ could benefit from the ground work laid out in this project. For example, the para nitro groups on either the pyridine or the phenyl amide of the core structure are valid sites for a $\mathrm{Sn} 2$, nucleophilic attack, attaching the ${ }^{18} \mathrm{~F}$ to the precursor. 


\section{Experimental Section}

\section{Full Synthesis of Radiosynthetic Standards and Precursors}

All the reagents and HPLC grade solvents were purchased from Fisher Scientific (Suwanee, GA). The 4-nitrobenzil compound was generously provided by Dr. Philip M. Potter and the 4-fluorobenzil was purchased commercially from Enamine Ltd. (Kiev, Ukraine). The reactions were monitored by TLC on pre-coated silica gel $60 \mathrm{~F}_{254}$ plates from Merck, KGaA (Darmstadt, Germany) and visualized using UV light with a frequency of $254 \mathrm{~nm}$. Reaction mixtures were purified using a Biotage FLASH (Charlotte, NC) column chromatography purification system and the silica cartridges were purchased from Biotage. HPLC methods were developed using an Agilent Technologies 1200 series system on a DBX-C18 column at room temperature with a flow rate of $1 \mathrm{~mL} / \mathrm{min}$. The HPLC column was purchased from Agilent Technologies (Santa Clara, CA). Mass spectra were determined by a Waters Acquity UPLC-PDA-ELSD-MS. UPLC separations were performed using an Acquity UPLC 2.1 x $50 \mathrm{~mm}$ BEH C18 column $(1.7 \mu \mathrm{m}$, Waters $)$ at $60{ }^{\circ} \mathrm{C}$, and a $1.0 \mathrm{~mL} / \mathrm{min}$ flow rate. The PDA was set to acquire UV data from 200-400 $\mathrm{nm}$ throughout the run. UPLC gradient: solvent A (water with $0.1 \%$ formic acid) and solvent $B$ (acetonitrile with $0.1 \%$ formic acid): $0-0.2$ minutes at $90-70 \%$ A, 0.2-1.6 minutes at 70-5\% A (linear gradient), and 1.6-1.95 minutes at 5\% A.

Synthesis of 3-((5-nitropyridin-2-yl)ethynyl)aniline (2a). In a $25 \mathrm{~mL}$, round bottom flask, copper(I) iodide (5.6 mg, $0.029 \mathrm{mmol}$ ), bis(benzonitrile)palladium(II) chloride (5.82 $\mathrm{mg}, 0.015 \mathrm{mmol})$, and tri-tert-butylphophonium tetrafluoroborate $(9.23 \mathrm{mg}, 0.032$

mmol) were combined and maintained under a nitrogen atmosphere. Next, the mixture was treated with dioxane $(3.0 \mathrm{ml})$ followed by 2-bromo-5-nitropyridine $(101 \mathrm{mg}, 0.498$ mmol) and diisopropylamine $(101 \mathrm{mg}, 1 \mathrm{mmol})$. The reaction stirred at $25{ }^{\circ} \mathrm{C}$ for 30 minutes and then 3 -ethynylaniline $(70 \mathrm{mg}, 0.598 \mathrm{mmol})$ was added to the flask and heated to $80^{\circ} \mathrm{C}$ on a hot plate for 30 minutes. The reaction mixture was maintained at room temperature with stirring overnight. The product formation was monitored by TLC. The completed reaction was diluted with ethyl acetate (EtOAc) and filtered through celite. The filtrate was concentrated in vacuo and the residue purified by crystallization using EtOAc to give the product as a red-orange solid (46\%). TLC $\mathrm{R}_{f}=0.11(70 / 30$ hexanes/EtOAc). MS(ESI), $\mathrm{m} / \mathrm{z}=240.08[(\mathrm{M}+\mathrm{H})]^{+}$.

\section{General procedure for the synthesis of the $N$-substituted 3-((5-nitropyridin-2-yl)ethynyl)aniline (2b-i)}

In a round bottom flask, compound $\mathbf{2 a}$ (1.0 eq) was added and the vessel was maintained under a nitrogen atmosphere and was dissolved in anhydrous solvent and treated with a base (1.5-2.5 eq). Then the reaction was treated with the acid chloride (1.3 eq) drop wise over 5 minutes. The reaction was stirred at $25^{\circ} \mathrm{C}$ overnight. Then the reaction was diluted with EtOAc and washed with sat $\mathrm{NH}_{4} \mathrm{Cl}$. The organic phase was 
washed with saturated $\mathrm{NaCl}$, dried with $\mathrm{MgSO}_{4}$, filtered, and concentrated in vacuo. Finally, the product either formed a precipitate during concentration or was purified using a hexanes/EtOAc gradient on the Biotage FLASH system.

$\mathrm{N}$-(3-((5-nitropyridin-2-yl)ethynyl)phenyl)pentanamide (2b). Using the above general procedure, compound $\mathbf{2 a}(22 \mathrm{mg}, 0.092 \mathrm{mmol})$, THF $(5 \mathrm{~mL})$ potassium phosphate, dibasic (43 $\mathrm{mg}, 0.247 \mathrm{mmol}$ ), and pentanoyl chloride (16 $\mathrm{mg}, 0.13 \mathrm{mmol}$ ) were used to synthesize compound $\mathbf{2 b}$ as a solid (76\%). $\mathrm{MS}(\mathrm{ESI}), \mathrm{m} / \mathrm{z}=324.17[\mathrm{M}+\mathrm{H}]^{+}$.

$\mathrm{N}$-(3-((5-nitropyridin-2-yl)ethynyl)phenyl)acetamide (2c). Using the above general procedure, compound 2a (120 mg, $0.5 \mathrm{mmol})$, dichloromethane $(50 \mathrm{~mL})$, and acetic anhydride (120mg, $0.5 \mathrm{mmol}$ ) were used to synthesize compound $\mathbf{2 c}$ and purified by flash chromatography (61\%). MS(ESI), m/z $=282.13[\mathrm{M}+\mathrm{H}]^{+}$.

N-(3-((5-nitropyridin-2-yl)ethynyl)phenyl)propionamide (2d). Using the above general procedure, compound $\mathbf{2 a}(90 \mathrm{mg}, 0.376 \mathrm{mmol})$, THF $(1 \mathrm{~mL})$, triethylamine (0.079 $\mathrm{mL}, 0.564 \mathrm{mmol}$ ), and propionyl chloride $(45.3 \mathrm{mg}, 0.489 \mathrm{mmol}$ ) were used to synthesize compound $\mathbf{2 d}$ as a solid (97\%). TLC $\mathrm{R}_{f}=0.15(65 / 35$ hexanes/EtOAc). $\mathrm{MS}(\mathrm{ESI}), \mathrm{m} / \mathrm{z}=296.14[\mathrm{M}+\mathrm{H}]^{+}$.

$N$-(3-((5-nitropyridin-2-yl)ethynyl)phenyl)isobutyramide (2e). Using the above general procedure, compound $\mathbf{2 a}(90 \mathrm{mg}, 0.376 \mathrm{mmol})$, THF $(1 \mathrm{~mL})$, triethylamine $(0.079 \mathrm{~mL})$, and isobutyryl chloride $(52.1 \mathrm{mg}, 0.489 \mathrm{mmol})$ were used to synthesize compound $2 \mathrm{e}$ as a solid (74\%). TLC $\mathrm{R}_{f}=0.26$ (65/35 hexanes/EtOAc). MS(ESI), m/z = $310.16[\mathrm{M}+\mathrm{H}]^{+}$.

3-methyl- $N$-(3-((5-nitropyridin-2-yl)ethynyl)phenyl)butanamide (2f). Using the above general procedure, compound $2 \mathbf{a}(90 \mathrm{mg}, 0.376 \mathrm{mmol})$, THF $(1 \mathrm{~mL})$, triethylamine (0.079 mL, $0.564 \mathrm{mmol})$, and 3-methylbutanoyl chloride (59 mg, $0.489 \mathrm{mmol})$ were used to synthesize compound $\mathbf{2 f}$ and purified by flash chromatography $(95 \%)$. TLC $\mathrm{R}_{f}=0.32$ (65/35 hexanes/EtOAc). MS(ESI), m/z = 324.17 [M+H] $]^{+}$.

2-methyl- $N$-(3-((5-nitropyridin-2-yl)ethynyl)phenyl)butanamide (2g). Using the above general procedure, compound $2 \mathbf{a}(90 \mathrm{mg}, 0.376 \mathrm{mmol})$, THF $(1 \mathrm{~mL})$, triethylamine (0.079 mL, $0.564 \mathrm{mmol}$ ), and 2-methylbutanoyl chloride (59 $\mathrm{mg}, 0.489 \mathrm{mmol}$ ) were used to synthesize compound $\mathbf{2 g}$ and purified by flash chromatography $(92 \%)$. TLC $\mathrm{R}_{f}=0.17$ (65/35 hexanes/EtOAc). MS(ESI), m/z = $324.17[\mathrm{M}+\mathrm{H}]^{+}$.

3,4-dichloro- $\mathrm{N}$-(3-((5-nitropyridin-2-yl)ethynyl)phenyl)benzamide (2h). Using the above general procedure, compound $2 \mathbf{a}(75 \mathrm{mg}, 0.314 \mathrm{mmol})$, THF (1 mL), triethylamine (0.066 mL, $0.470 \mathrm{mmol}$ ), and 3,4-dichlorobenzoyl chloride ( $85 \mathrm{mg}, 0.408 \mathrm{mmol}$ ) were used to synthesize compound $\mathbf{2 h}$ as a solid $(35 \%)$. TLC $\mathrm{R}_{f}=0.22(60 / 40$ hexanes/EtOAc). MS(ESI), $\mathrm{m} / \mathrm{z}=413.35[\mathrm{M}+\mathrm{H}]^{+}$.

4-methyl- $N$-(3-((5-nitropyridin-2-yl)ethynyl)phenyl)thiophene-2-carboxamide (2i). Using the above general procedure, compound $\mathbf{2 a}$ (75 mg, $0.314 \mathrm{mmol})$, THF (1 mL), 
triethylamine $(0.066 \mathrm{~mL}, 0.740 \mathrm{mmol})$, and 4-methylthiophene-2-carbonyl chloride $(65.5$ $\mathrm{mg}, 0.408 \mathrm{mmol})$ were used to synthesize compound $\mathbf{2} \mathbf{i}$ as a solid $(74 \%)$. TLC $\mathrm{R}_{f}=0.19$ (60/40 hexanes/EtOAc). $\mathrm{MS}(\mathrm{ESI}), \mathrm{m} / \mathrm{z}=364.17[\mathrm{M}+\mathrm{H}]^{+}$.

Synthesis of 3-((5-fluoropyridin-2-yl)ethynyl)aniline $(\mathbf{2 j})$. In a $25 \mathrm{~mL}$, round bottom flask, copper(I) iodide (2.16 mg, $0.011 \mathrm{mmol})$, bis(benzonitrile)palladium(II) chloride (6.54 mg, $0.017 \mathrm{mmol})$, and tri-tert-butylphosphonium tetrafluoroborate $(9.89 \mathrm{mg}, 0.034$ mmol) were combined and maintained under a nitrogen atmosphere. Next, the mixture was treated with dioxane $(10.0 \mathrm{~mL})$ followed by 2-bromo-5-nitropyridine (100 $\mathrm{mg}, 0.568$ $\mathrm{mmol})$ and diisopropylamine $(0.162 \mathrm{~mL}, 1.14 \mathrm{mmol})$. The reaction stirred at $25^{\circ} \mathrm{C}$ for 30 minutes and then 3 -ethynylaniline $(0.071 \mathrm{~mL}, 0.682 \mathrm{mmol})$ was added to the flask and heated to $80^{\circ} \mathrm{C}$ on a hot plate for 30 minutes. The reaction mixture was maintained at room temperature with stirring overnight. The product formation was monitored by TLC. The completed reaction was diluted with EtOAc and filtered through celite. The filtrate was concentrated in vacuo and the residue purified by crystallization using EtOAc to give the product as a solid (38\%). TLC $\mathrm{R}_{f}=0.22$ (70/30 hexanes/EtOAc). MS(ESI), m/z= $213.12[\mathrm{M}+\mathrm{H}]^{+}$.

General procedure for the synthesis of the $N$-substituted 3-((5-fluoropyridin-2-yl)ethynyl)aniline (2k-n)

In a round bottom flask, compound $\mathbf{2} \mathbf{j}$ (1.0 eq) was added and the vessel was maintained under a nitrogen atmosphere and was dissolved in anhydrous solvent and treated with a base (1.5-2.5 eq). Then the reaction was treated with the acid chloride (1.3 eq) drop wise over 5 minutes. The reaction was stirred at $25^{\circ} \mathrm{C}$ overnight. Then the reaction was diluted with EtOAc and washed with sat $\mathrm{NH}_{4} \mathrm{Cl}$. The organic phase was washed with saturated $\mathrm{NaCl}$, dried with $\mathrm{MgSO}_{4}$, filtered, and concentrated in vacuo. Finally, the product either formed a precipitate during concentration or was purified using a hexanes/EtOAc gradient on the Biotage FLASH system.

$\mathrm{N}$-(3-((5-fluoropyridin-2-yl)ethynyl)phenyl)pentanamide (2k). Using the above general procedure, compound $\mathbf{2} \mathbf{j}(215 \mathrm{mg}, 1.01 \mathrm{mmol})$, dichloromethane $(55 \mathrm{~mL})$, and pentanoyl chloride $(134 \mathrm{mg}, 1.1 \mathrm{mmol})$ were used to synthesize compound $\mathbf{2} \mathbf{k}$ as a solid (57\%). TLC $\mathrm{R}_{f}=0.28$ (60/40 hexanes/EtOAc). MS(ESI), m/z $=297.22[\mathrm{M}+\mathrm{H}]^{+}$.

$\mathrm{N}$-(3-((5-fluoropyridin-2-yl)ethynyl)phenyl)-2-methylbutanamide (2l). Using the above general procedure, compound $\mathbf{2} \mathbf{j}$ ( $75 \mathrm{mg}, 0.353 \mathrm{mmol})$, THF ( $1 \mathrm{~mL})$, triethylamine (0.074 mL, $0.530 \mathrm{mmol})$, and 2-methylbutanoyl chloride $(55.4 \mathrm{mg}, 0.459 \mathrm{mmol})$ were used to synthesize compound $2 \mathrm{l}$ as a solid (70\%). TLC $\mathrm{R}_{f}=0.17(60 / 40$ hexanes/EtOAc). MS(ESI), $\mathrm{m} / \mathrm{z}=297.22[\mathrm{M}+\mathrm{H}]^{+}$.

3,4-dichloro- $N$-(3-((5-fluoropyridin-2-yl)ethynyl)phenyl)benzamide (2m). Using the above general procedure, compound $2 \mathbf{j}$ ( $75 \mathrm{mg}, 0.353 \mathrm{mmol})$, THF (1 mL), triethylamine (0.074 mL, $0.53 \mathrm{mmol}$ ), and 3,4-dichlorobenzoyl chloride (96 mg, $0.459 \mathrm{mmol}$ ) were used to synthesize compound $\mathbf{2 m}$ as a solid (84\%). TLC $\mathrm{R}_{f}=0.26(60 / 40$ hexanes/EtOAc). MS(ESI), $\mathrm{m} / \mathrm{z}=385.14[\mathrm{M}+\mathrm{H}]^{+}$. 
$\mathrm{N}$-(3-((5-fluoropyridin-2-yl)ethynyl)phenyl)-4-methylthiophene-2-carboxamide (2n). Using the above general procedure, compound $2 \mathbf{j}$ ( $75 \mathrm{mg}, 0.353 \mathrm{mmol})$, THF ( $1 \mathrm{~mL}$ ), triethylamine $(0.074 \mathrm{~mL}, 0.53 \mathrm{mmol})$, and 4-methylthiophene-2-carbonyl chloride $(73.8$ $\mathrm{mg}, 0.459 \mathrm{mmol})$ were used to synthesize compound $\mathbf{2 n}$ as a solid $(82 \%)$. TLC $\mathrm{R}_{f}=0.2$ (60/40 hexanes/EtOAc). MS(ESI), m/z $=337.12[\mathrm{M}+\mathrm{H}]^{+}$.

\section{General procedure for the synthesis of the $N$-substituted (4-(2-(5-nitropyridin-2-yl)-2-oxoacetyl)phenyl)amide or (4-(2-(5-fluoropyridin-2-yl)-2-oxoacetyl)phenyl)amide (20-2z)}

In a conical microwave vessel, the desired amide (1 eq) was dissolved in DMSO and treated with a catalytic amount of palladium(II) bromide $\left(\mathrm{PdBr}_{2}\right)$. Next, the vial was capped under ambient atmosphere and brought to $200{ }^{\circ} \mathrm{C}$ for 3 minutes using a Biotage initiator. Once cool, the solution was diluted with $\mathrm{CHCl}_{3}$ and washed with 1:1 sat $\mathrm{NH}_{4} \mathrm{Cl}$ :water. Then, the aqueous phase was washed with an additional amount of $\mathrm{CHCl}_{3}$ and the combined organics were filtered and concentrated in vacuo. Finally, the residue was purified on a silica gel column using a hexane/EtOAc gradient on the Biotage FLASH system yielding the corresponding phenyl pyridinyl-1,2-dione.

$\mathrm{N}$-(3-(2-(5-nitropyridin-2-yl)-2-oxoacetyl)phenyl)pentanamide (20). Using the above general procedure, compound $\mathbf{2 b}(20 \mathrm{mg}, 0.062 \mathrm{mmol})$ in DMSO $(0.619 \mathrm{~mL})$ and $\mathrm{PdBr}_{2}$ $(0.329 \mathrm{mg})$, were used to synthesize compound $\mathbf{2 0}$ and purified by flash chromatography $(45 \%)$. MS(ESI), $\mathrm{m} / \mathrm{z}=356.17[\mathrm{M}+\mathrm{H}]^{+}$.

$\mathrm{N}$-(3-(2-(5-nitropyridin-2-yl)-2-oxoacetyl)phenyl)acetamide (2p). Using the above general procedure, compound $2 \mathrm{c}(100 \mathrm{mg}, 0.356 \mathrm{mmol})$ in DMSO $(3.56 \mathrm{~mL})$ and $\mathrm{PdBr}_{2}$ $(1.9 \mathrm{mg})$ were used to synthesize compound $\mathbf{2 p}$ and purified by flash chromatography (27\%). TLC $\mathrm{R}_{f}=0.31$ (60/40 hexanes/EtOAc). MS(ESI), m/z $=314.33[\mathrm{M}+\mathrm{H}]^{+}$.

N-(3-(2-(5-nitropyridin-2-yl)-2-oxoacetyl)phenyl)propionamide (2q). Using the above general procedure, compound $\mathbf{2 d}(50 \mathrm{mg}, 0.169 \mathrm{mmol})$ in DMSO $(1 \mathrm{~mL})$ and $\mathrm{PdBr}_{2}(4.5 \mathrm{mg})$ were used to synthesize compound $\mathbf{2 q}$ and purified by flash chromatography (24\%). TLC $\mathrm{R}_{f}=0.0$ (65/35 hexanes/EtOAc).

$\mathrm{N}$-(3-(2-(5-nitropyridin-2-yl)-2-oxoacetyl)phenyl)isobutyramide (2r). Using the above general procedure, compound $2 \mathbf{e}(50 \mathrm{mg}, 0.162 \mathrm{mmol})$ in DMSO $(1 \mathrm{~mL})$ and $\mathrm{PdBr}_{2}(4.3 \mathrm{mg})$ were used to synthesize compound $\mathbf{2 r}$ and purified by flash chromatography (18\%). TLC $\mathrm{R}_{f}=0.0$ (65/35 hexanes/EtOAc).

3-methyl- $\mathrm{N}$-(3-(2-(5-nitropyridin-2-yl)-2-oxoacetyl)phenyl)butanamide (2s). Using the above general procedure, compound $2 \mathbf{f}(50 \mathrm{mg}, 0.155 \mathrm{mmol})$ in DMSO (1 mL) and $\mathrm{PdBr}_{2}(4.1 \mathrm{mg})$ were used to synthesize compound $2 \mathrm{~s}$ and purified by flash chromatography (13\%). TLC $\mathrm{R}_{f}=0.0$ (65/35 hexanes/EtOAc). $\mathrm{MS}(\mathrm{ESI}), \mathrm{m} / \mathrm{z}=356.22$ $[\mathrm{M}+\mathrm{H}]^{+}$. 
2-methyl- $\mathrm{N}$-(3-(2-(5-nitropyridin-2-yl)-2-oxoacetyl)phenyl)butanamide (2t). Using the above general procedure, compound $2 \mathrm{~g}(50 \mathrm{mg}, 0.155 \mathrm{mmol})$ in DMSO $(1 \mathrm{~mL})$ and $\mathrm{PdBr}_{2}(4.1 \mathrm{mg}$ ) were used to synthesize compound $\mathbf{2 t}$ and purified by flash chromatography (14\%). TLC $\mathrm{R}_{f}=0.29$ (60/40 hexanes/EtOAc). MS(ESI), $\mathrm{m} / \mathrm{z}=356.13$ $[\mathrm{M}+\mathrm{H}]^{+}$.

3,4-dichloro- $N$-(3-(2-(5-nitropyridin-2-yl)-2-oxoacetyl)phenyl)benzamide (2u). Using the above general procedure, compound $\mathbf{2 h}(40 \mathrm{mg}, 0.097 \mathrm{mmol})$ in DMSO $(1 \mathrm{~mL})$ and $\operatorname{PdBr}_{2}(2.6 \mathrm{mg})$ were used to synthesize compound $\mathbf{2 u}$ and purified by flash chromatography (13\%). TLC $\mathrm{R}_{f}=0.38$ (60/40 hexanes/EtOAc). MS(ESI), $\mathrm{m} / \mathrm{z}=445.21$ $[\mathrm{M}+\mathrm{H}]^{+}$.

4-methyl- $N$-(3-(2-(5-nitropyridin-2-yl)-2-oxoacetyl)phenyl)thiophene-2-carboxamide (2v). Using the above general procedure, compound $2 \mathbf{i}(50 \mathrm{mg}, 0.138 \mathrm{mmol})$ in DMSO $(1 \mathrm{~mL})$ and $\operatorname{PdBr}_{2}(3.7 \mathrm{mg})$ were used to synthesize compound $\mathbf{2} \mathbf{v}$ and purified by flash chromatography (11\%). TLC $\mathrm{R}_{f}=0.32(60 / 40$ hexanes/EtOAc).

$\mathrm{N}$-(3-(2-(5-fluoropyridin-2-yl)-2-oxoacetyl)phenyl)pentanamide (2w). Using the above general procedure, compound $2 \mathbf{k}(50 \mathrm{mg}, 0.169 \mathrm{mmol})$ in DMSO $(1 \mathrm{~mL})$ and $\mathrm{PdBr}_{2}(4.0 \mathrm{mg})$ were used to synthesize compound $\mathbf{2 w}$ and purified by flash chromatography (8\%). TLC $\mathrm{R}_{f}=0.30$ (60/40 hexanes/EtOAc). $\mathrm{MS}(\mathrm{ESI}), \mathrm{m} / \mathrm{z}=329.17$ $[\mathrm{M}+\mathrm{H}]^{+}$.

$\mathrm{N}$-(3-(2-(5-fluoropyridin-2-yl)-2-oxoacetyl)phenyl)-2-methylbutanamide (2x). Using the above general procedure, compound $2 \mathrm{l}(50 \mathrm{mg}, 0.169 \mathrm{mmol})$ in DMSO $(1 \mathrm{~mL})$ and $\mathrm{PdBr}_{2}(4.5 \mathrm{mg}$ ) were used to synthesize compound $\mathbf{2 x}$ and purified by flash chromatography (6\%). TLC $\mathrm{R}_{f}=0.31$ (60/40 hexanes/EtOAc). MS(ESI), $\mathrm{m} / \mathrm{z}=329.26$ $[\mathrm{M}+\mathrm{H}]^{+}$.

3,4-dichloro- $N$-(3-(2-(5-fluoropyridin-2-yl)-2-oxoacetyl)phenyl)benzamide (2y). Using the above general procedure, compound $2 \mathrm{~m}(50 \mathrm{mg}, 130 \mathrm{mmol})$ in DMSO $(1 \mathrm{~mL})$ and $\mathrm{PdBr}_{2}(3.5 \mathrm{mg})$ were used to synthesize compound $2 \mathbf{y}$ and purified by flash chromatography (9\%). TLC $\mathrm{R}_{f}=0.44$ (60/40 hexanes/EtOAc). MS(ESI), $\mathrm{m} / \mathrm{z}=418.2$ $[\mathrm{M}+\mathrm{H}]^{+}$.

$\mathrm{N}$-(3-(2-(5-fluoropyridin-2-yl)-2-oxoacetyl)phenyl)-4-methylthiophene-2carboxamide (2z). Using the above general procedure, compound $\mathbf{2 n}(50 \mathrm{mg}, 0.149$ $\mathrm{mmol})$ in DMSO ( $1 \mathrm{~mL}$ ) and $\mathrm{PdBr}_{2}(4.0 \mathrm{mg})$ were used to synthesize compound $2 \mathrm{z}$ and purified by flash chromatography (2\%). TLC $\mathrm{R}_{f}=0.32$ (60/40 hexanes/EtOAc). $\mathrm{MS}(\mathrm{ESI}), \mathrm{m} / \mathrm{z}=369.16[\mathrm{M}+\mathrm{H}]^{+}$.

\section{Synthesis of Radiolabeled Tracers}

General procedure for the radiosynthesis using ${ }^{18} \mathrm{~F}$ (2aa-af). All the radiochemistry was performed on the PETChem Solutions (Chelsea, MI) radiochemistry unit, a semi- 
automatic nucleophilic fluorination module, under an argon atmosphere. ${ }^{18} \mathrm{~F}$ is produced by proton irradiation of $98 \%{ }^{18} \mathrm{O}$-water in a $(\mathrm{p}, \mathrm{n})$ nuclear reaction using an IBA Cyclone 18/9 cyclotron. Aqueous fluoride is captured using a Waters QMA anion exchange resin and elution of the fluoride ion is accomplished with a mixture of $5 \mathrm{mg}$ Kryptofix $^{\circledR} 2.2 .2$ and $0.5 \mathrm{mg} \mathrm{K}_{2} \mathrm{CO}_{3}$ in 2:1 acetonitrile/water. The resulting acetonitrile/water azeotrope is evaporated at $85{ }^{\circ} \mathrm{C}$ yielding an anhydrous Kryptofix ${ }^{\circledR} 2.2 .2-{ }^{18} \mathrm{~F}-\mathrm{K}$ complex. ${ }^{107}$

The 4-nitrobenzil precursor (1 eq), was dissolved in anhydrous DMSO and added to the room temperature reaction vial with the Kryptofix ${ }^{\circledR} 2.2 .2-{ }^{18} \mathrm{~F}-\mathrm{K}$ complex. The resulting mixture was sealed and either heated by conventional methods at $130{ }^{\circ} \mathrm{C}$ for 45 minutes ${ }^{108}$ or by using microwave heating at $130{ }^{\circ} \mathrm{C}$ for 7 minutes at $100 \mathrm{~W}$, yielding the desired radiotracer. The key results are listed in Tables 2-2 and 2-3.

1-(4-[ $\left[{ }^{18}\right.$ F]fluorophenyl)-2-phenylethane-1,2-dione (2aa). Using the above general procedure, 1-(4-nitrophenyl)-2-phenylethane-1,2-dione (10 mg, $0.04 \mathrm{mmol})$ in DMSO $(0.125 \mathrm{~mL})$, was reacted with the Kryptofix ${ }^{\circledR} 2.2 .2-{ }^{18} \mathrm{~F}-\mathrm{K}$ complex to yield the radiotracer compound 2aa. The reaction yielded $20-25 \%$ labeled compound by traditional heating and $50-65 \%$ by microwave heating as determined by TLC with radiation detection. The radioactivity TLC profile for $4-\left[{ }^{18} \mathrm{~F}\right]$ fluorobenzil $\mathrm{R}_{f}=0.53(70 / 30$ hexanes/EtOAc) was compared to the UV-TLC profile for 4-nitrobenzil $\mathrm{R}_{f}=0.47(70 / 30$ hexanes/EtOAc).

$\mathrm{N}$-(3-(2-(5-[ ${ }^{18}$ F]fluoropyridin-2-yl)-2-oxoacetyl)phenyl)acetamide (2ab). Using the above general procedure, compound $\mathbf{2 q}(11.7 \mathrm{mg}, 0.037 \mathrm{mmol})$ in DMSO $(0.1 \mathrm{~mL})$, was reacted with the Kryptofix ${ }^{\circledR} 2.2 .2-{ }^{18} \mathrm{~F}-\mathrm{K}$ complex using microwave heating of $130{ }^{\circ} \mathrm{C}$ for 7 minutes at $100 \mathrm{~W}$ to yield the compound $\mathbf{2 a b}$ radiotracer $(73 \%)$. Radio $\mathrm{TLC} \mathrm{R}_{f}=0.54$ (70/30 hexanes/EtOAc).

$\mathrm{N}$-(3-(2-(5-[ ${ }^{18}$ F]fluoropyridin-2-yl)-2-oxoacetyl)phenyl)isobutyramide (2ac). Using the above general procedure, compound $2 \mathrm{r}(5 \mathrm{mg}, 0.01 \mathrm{mmol})$ in DMSO $(0.1 \mathrm{~mL})$, was reacted with the Kryptofix ${ }^{\circledR} 2.2 .2-{ }^{18} \mathrm{~F}-\mathrm{K}$ complex using microwave heating of $130{ }^{\circ} \mathrm{C}$ for 7 minutes at $100 \mathrm{~W}$ to yield the compound 2 ac radiotracer $(3 \%)$. Radio TLC $\mathrm{R}_{f}=0.33$ (70/30 hexanes/EtOAc).

$\mathrm{N}$-(3-(2-(5-[18F]fluoropyridin-2-yl)-2-oxoacetyl)phenyl)-2-methylbutanamide (2ad). Using the above general procedure, compound $2 \mathrm{t}(5 \mathrm{mg}, 0.01 \mathrm{mmol})$ in DMSO $(0.1 \mathrm{~mL})$, was reacted with the Kryptofix ${ }^{\circledR} 2.2 .2-{ }^{18} \mathrm{~F}-\mathrm{K}$ complex using microwave heating of $130{ }^{\circ} \mathrm{C}$ for 7 minutes at $100 \mathrm{~W}$ did not yield the compound 2 ad radiotracer $(0 \%)$.

$N$-(3-(2-(5-[ ${ }^{18}$ F]fluoropyridin-2-yl)-2-oxoacetyl)phenyl)-3-methylbutanamide (2ae). Using the above general procedure, compound $2 \mathrm{~s}(5 \mathrm{mg}, 0.01 \mathrm{mmol})$ in DMSO $(0.1 \mathrm{~mL})$, was reacted with the Kryptofix ${ }^{\circledR} 2.2 .2{ }^{18} \mathrm{~F}-\mathrm{K}$ complex using microwave heating of $130{ }^{\circ} \mathrm{C}$ for 7 minutes at $100 \mathrm{~W}$ did not yield the compound 2 ae radiotracer $(0 \%)$.

$\mathrm{N}$-(3-(2-(5-[ ${ }^{18}$ F]fluoropyridin-2-yl)-2-oxoacetyl)phenyl)-4-methylthiophene-2carboxamide (2af). Using the above general procedure, compound $2 \mathbf{v}$ ( $5 \mathrm{mg}, 0.01$ $\mathrm{mmol})$ in DMSO $(0.1 \mathrm{~mL})$, was reacted with the Kryptofix ${ }^{\circledR} 2.2 .2-{ }^{18} \mathrm{~F}-\mathrm{K}$ complex heated 
to $130{ }^{\circ} \mathrm{C}$ for 45 minutes to yield the compound 2 af radiotracer $(2 \%)$. Radio TLC $\mathrm{R}_{f}=$ 0.3 (70/30 hexanes/EtOAc). 


\section{CHAPTER 3. DESIGN OF A TRKB SELECTIVE IMAGING AGENT FOR NEUROBLASTOMA AND ITS POTENTIAL USE IN DIRECTING THERAPY}

\section{Introduction}

As discussed in Chapter 1, NB originates from neural crest cells that normally differentiate to form the sympathetic ganglia, adrenal medulla and other paraspinal sites where sympathetic nervous system tissue is present. ${ }^{1}$ Retrospective studies have shown the presence of TrkB, in patients with poor prognosis. The reason for this is not completely understood yet, but it is known that TrkB is not normally found in sympathetic nervous tissue ${ }^{1}$ and thus is a potential target for imaging and therapy.

The presence of TrkB and its NT, BDNF, have been reported to protect NB tumor cells from chemotherapy-induced apoptosis via the phosphatidylinositol 3'-kinase pathway. ${ }^{81}$ A PET radiotracer that could determine the presence or absence of TrkB in NB tumor cells early on in diagnosis could be useful in determining the most beneficial therapeutic course for patients. These PET scans could be cross-referenced to the normal standard of care mIBG scan to verify that the TrkB density corresponds with NB tissue.

\section{Targeting TrkB}

There are three distinct, yet similar, Trks to consider when investigating NB patients. Each Trk is activated by the presence of a specific NT and the presence of each is associated with a different prognosis. Since there is evidence that TrkB and its NT, BDNF, can be expressed in patients that have a poor prognosis, and their presence is associated with tumor differentiation and proliferation ${ }^{28}$ as well as drug resistance, ${ }^{109-112}$ TrkB became the target of this study, see previous Figure 1-3.

It is generally accepted that early diagnosis and treatment lead to improved outcomes of patients suffering from any form of cancer. ${ }^{9,97-98}$ There is some debate as to whether earlier diagnosis of NB is truly of any benefit since the cases with the earliest development tend to fall in the low risk category and may spontaneously regress..$^{9,39,84}$, 113 Therefore, outcomes have not improved with earlier diagnosis. The accepted chemotherapy options for treatment of NB have been described in the previous chapter, but it is important to recall that there are numerous side effects associated with those therapies. The current literature indicates that the presence of TrkB and BDNF can impart chemoresistance to multiple DNA-damaging reagents ${ }^{109,111-112,114}$ or rescue cells from chemotherapy-induced apoptosis. ${ }^{81}$ Targeting TrkB would provide a form of image guided therapy to prevent exposing patients to unnecessary chemotherapeutic agents, thus avoiding the agent-specific side effects and allowing effective treatment to start earlier. 


\section{Pharmacophore}

For this project, the focus and purpose was to develop, synthesize, and evaluate radiotracers based on compounds that were reported in the literature to find possible candidates that could be synthesized with a radionuclide to be used as an imaging agent, Figure 3-1. The preferred radiosynthetic precursor would be one that could be radiolabeled with a direct replacement of $\mathrm{a}^{12} \mathrm{C}$ with a ${ }^{11} \mathrm{C}$ or a ${ }^{19} \mathrm{~F}$ for a ${ }^{18} \mathrm{~F}$. This would allow us to utilize the reported data of all pharmacologic, pharmacokinetic, and chemical properties of potential tracers. The literature evaluation offered several options.

One option was to look at the interaction with the extracellular binding site of NT with the Trk. As stated earlier, the NTs are selective for the specific Trks ${ }^{115}$ and researchers have looked at compounds like ANA-12 that block the interaction of the NT at the external binding site ${ }^{89}$ or 7,8-dihydroxyflavone ${ }^{116}$ that is an agonist of TrkB. These compounds have the same general issues as some proteins, namely they have very short half-lives of minutes or less and minimal oral bioavailability, ${ }^{29}$ and generally are not selective, thus interfering with other beneficial receptors or in the case of 7,8dihydroxyflavone, it provokes TrkB activation and protects neurons from apoptosis. ${ }^{116}$ The greatest concern for this project though is the need to alter the core compound through the addition of the radionuclide. This addition may change any number of the properties of the compound and would then require extensive evaluation to see if any of the desirable properties are still present after radiolabeling. One option would be to develop a full medicinal chemistry project that would elucidate the SAR of the compounds and offer new derivatives that allow for incorporation of the radionuclide without altering the properties of the compound. However, such an undertaking is beyond the scope and the focus of this radiochemistry project. This path would be a standalone project that could utilize the radiochemistry developments reported in this project. Therefore, these compounds were not investigated further.

Next, there are pan-Trk inhibitors currently in clinical trials, like TSR-011 (NCT02048488), LOXO-101 (NCT02637687), and RXDX-101 (NCT02097810) that are showing positive results on patient therapy in various cancers but they all are showing that cancers cells can develop rapid resistance through point mutations resulting in limited function in long-term therapy. ${ }^{117}$ These compounds have the potential to be radiolabeled without alteration of the core compound thus potentially maintaining all properties, but the compounds are pan-Trk inhibitors. The issue here is that the presence of TrkA would complicate the images and is an indication of a favorable prognosis and has been found to benefit NB patients. ${ }^{1}$ If these compounds are utilized then the data gathered would not differentiate between TrkA and TrkB, thus providing no useful data that could help direct patient therapy.

There is the class of staurosporine derivative Trk inhibitors like K-252a, CEP-701, and CEP-751. ${ }^{71,118}$ These glycosylated indolocarbazole alkaloids could be labeled with $\left[{ }^{11} \mathrm{C}\right]$ methyl by replacing the methoxy of the tetrahydrofuran ring, but demethylation in the liver would cleave the radionuclide from the compound negating the effectiveness of it as an imaging agent. The nitrogen of the pyrrolidine ring could be 
Figure 3-1. Current compounds targeting Trk.

Selection of Trk compounds that were evaluated for radiotracer development. Sources: Cazorla, M.; Premont, J.; Mann, A.; Girard, N.; Kellendonk, C.; Rognan, D., Identification of a low-molecular weight TrkB antagonist with anxiolytic and antidepressant activity in mice. J Clin Invest 2011, 121 (5), 1846-57. Jang, S. W.; Liu, X.; Yepes, M.; Shepherd, K. R.; Miller, G. W.; Liu, Y.; Wilson, W. D.; Xiao, G.; Blanchi, B.; Sun, Y. E.; Ye, K., A selective TrkB agonist with potent neurotrophic activities by 7,8-dihydroxyflavone. Proc Natl Acad Sci U S A 2010, 107 (6), 2687-92. Yang, Q.; Modi, P.; Newcomb, T.; Queva, C.; Gandhi, V., Idelalisib: First-in-Class PI3K Delta Inhibitor for the Treatment of Chronic Lymphocytic Leukemia, Small Lymphocytic Leukemia, and Follicular Lymphoma. Clin Cancer Res 2015, 21 (7), 1537-42. Russo, M.; Misale, S.; Wei, G.; Siravegna, G.; Crisafulli, G.; Lazzari, L.; Corti, G.; Rospo, G.; Novara, L.; Mussolin, B.; Bartolini, A.; Cam, N.; Patel, R.; Yan, S.; Shoemaker, R.; Wild, R.; Di Nicolantonio, F.; Bianchi, A. S.; Li, G.; Siena, S.; Bardelli, A., Acquired Resistance to the TRK Inhibitor Entrectinib in Colorectal Cancer. Cancer Discov 2016, 6 (1), 36-44. Ruggeri, B. A.; Miknyoczki, S. J.; Singh, J.; Hudkins, R. L., Role of neurotrophin-trk interactions in oncology: the anti-tumor efficacy of potent and selective trk tyrosine kinase inhibitors in pre-clinical tumor models. Curr Med Chem 1999, 6 (9), 845-57. Ho, R.; Eggert, A.; Hishiki, T.; Minturn, J. E.; Ikegaki, N.; Foster, P.; Camoratto, A. M.; Evans, A. E.; Brodeur, G. M., Resistance to chemotherapy mediated by TrkB in neuroblastomas. Cancer Res 2002, 62 (22), 6462-6. Baindur, N.; Gaul, M.; Kreutter, K.; Baumann, C.; Kim, A.; Xu, G.; Zhao, B. P., Aminoquinoline and aminoquinazoline kinase modulators. Patent: US20070004763 A1. Bernard-Gauthier, V.; Aliaga, A.; Aliaga, A.; Boudjemeline, M.; Hopewell, R.; Kostikov, A.; Rosa-Neto, P.; Thiel, A.; Schirrmacher, R., Syntheses and evaluation of carbon-11- and fluorine-18radiolabeled pan-tropomyosin receptor kinase (Trk) inhibitors: exploration of the 4-aza2-oxindole scaffold as Trk PET imaging agents. ACS Chem Neurosci 2015, 6 (2), 260-76. Clinical trials NCT02637687, NCT02048488, and NCT02097810 available at clinicaltrials.gov. 

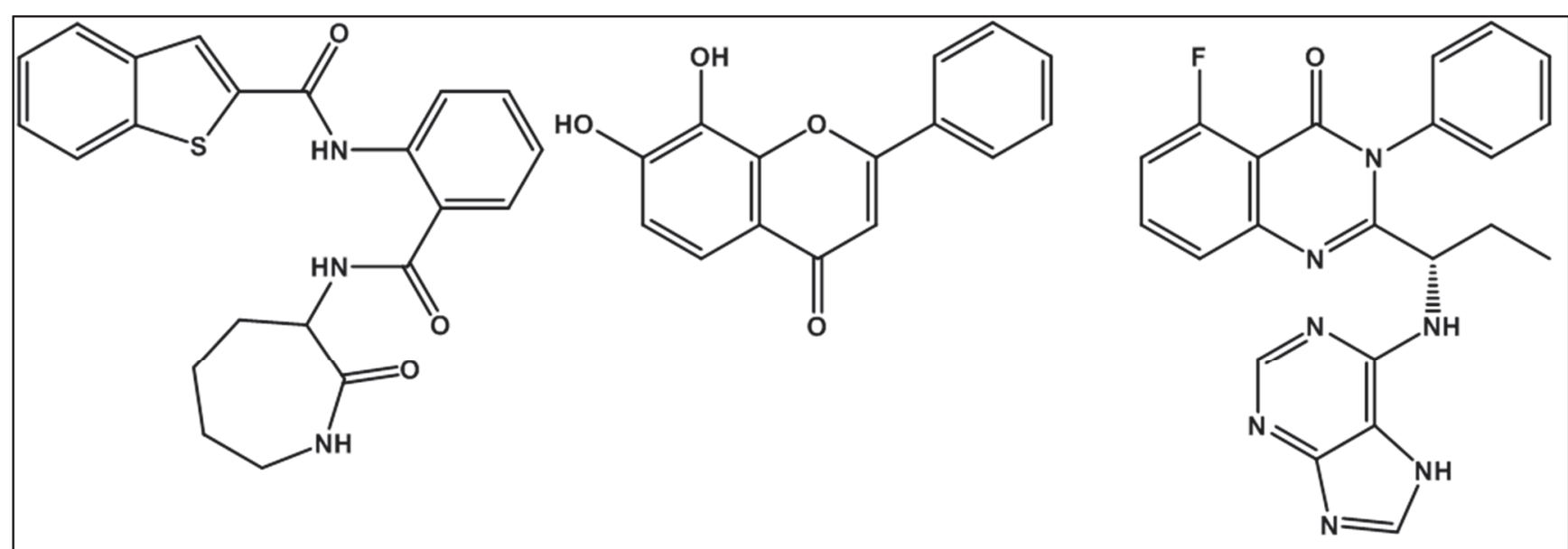

ANA-12

7,8-dihydroxyflavone

GS-1101
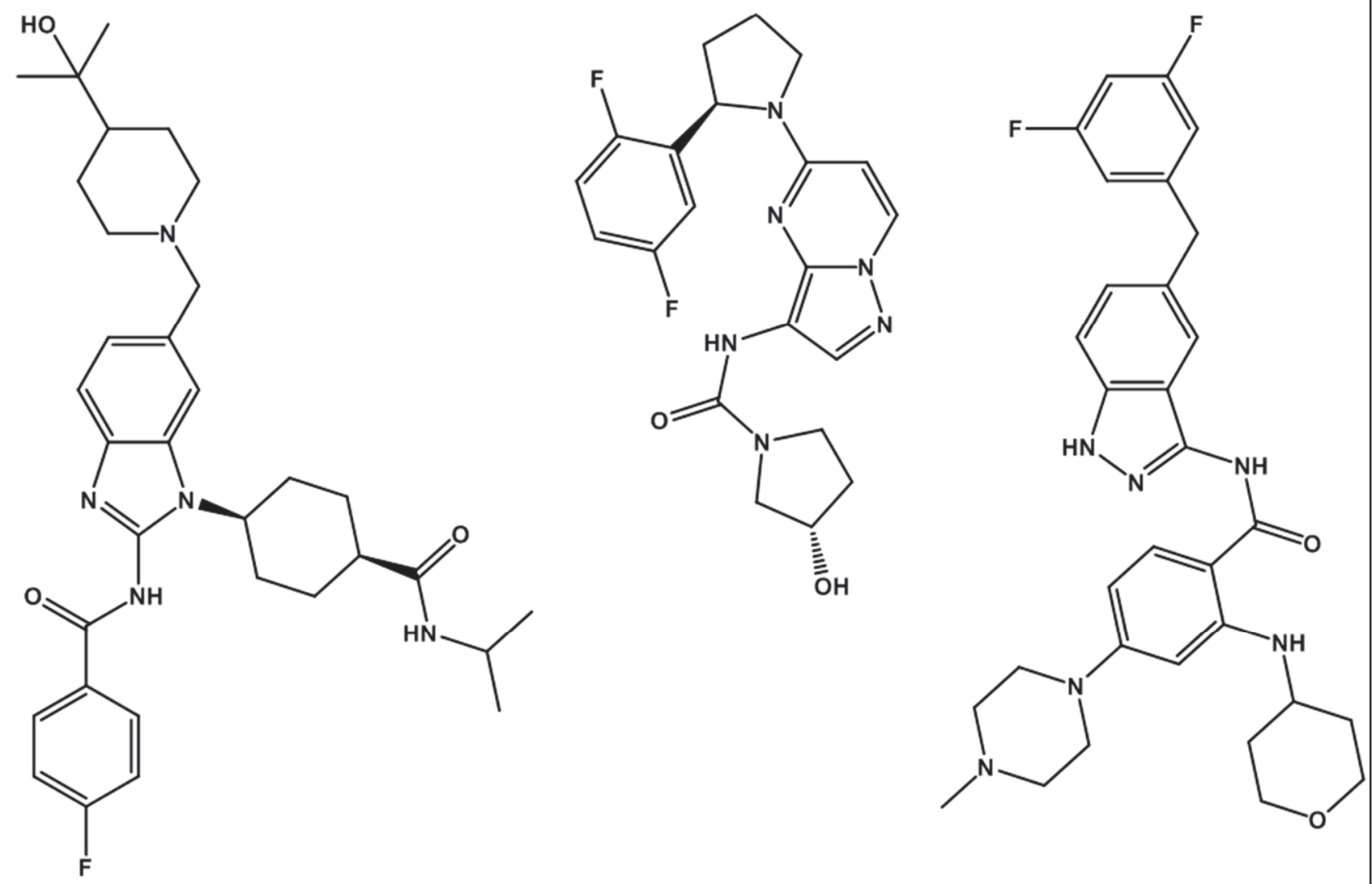

TSR-011 


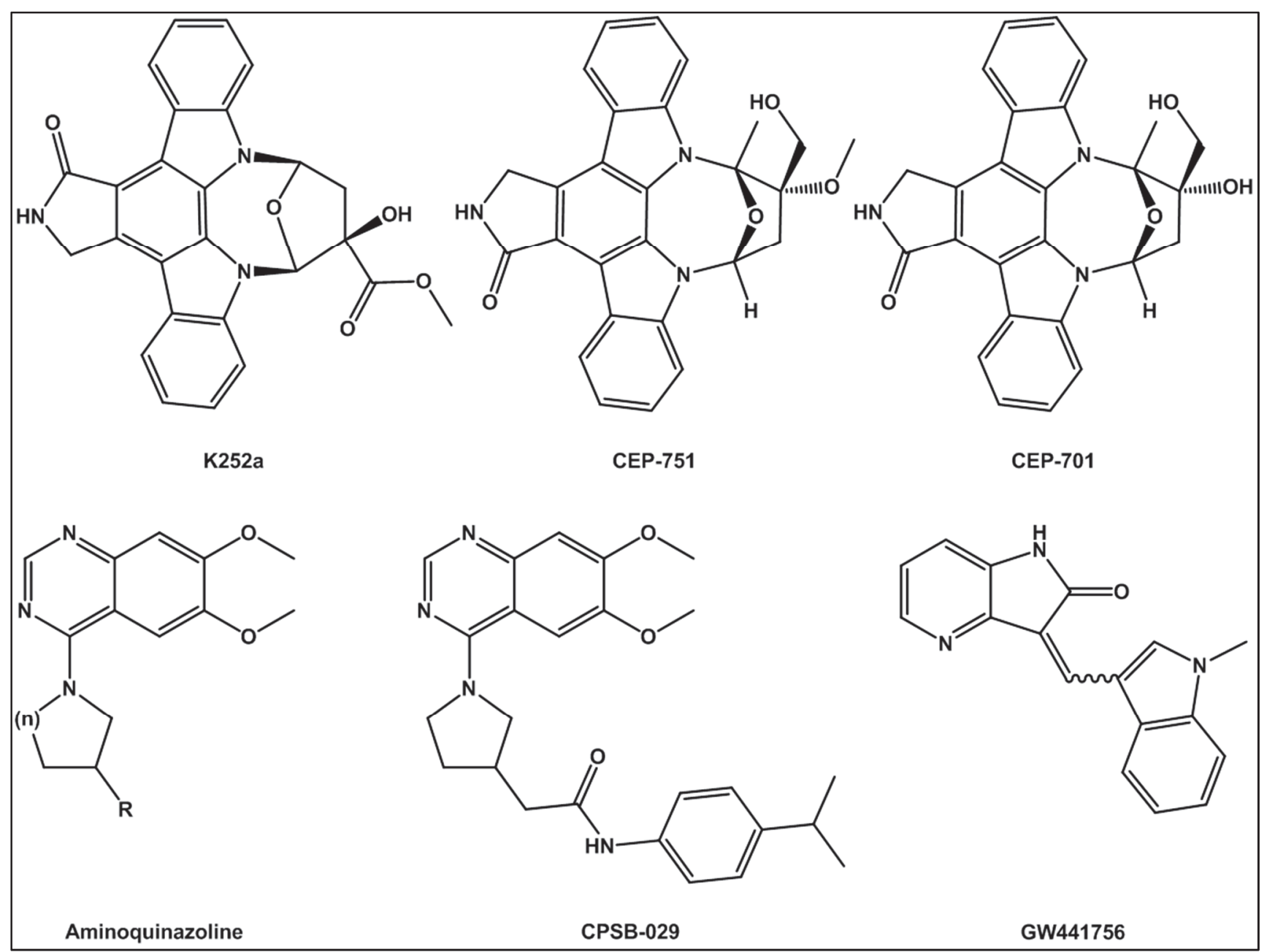

Figure 3-1. Continued. 
substituted with various radionuclides but again would probably change some properties of the compound requiring evaluation to determine if the compound maintains any antiTrk activity and TrkB specifically. Possibly, ${ }^{11} \mathrm{C}$ could be incorporated into the oxodiazepane ring during the synthesis of the final compound but this is difficult and the synthesis would need to be optimized to incorporate the radionuclide at the latest stages to maintain any activity of the radionuclide to be used as an imaging agent.

Finally, we investigated the aminoquinazoline derivatives. The reported compounds are claimed to be selective for TrkB with low nanomolar activity (100 $\mathrm{nM}) .{ }^{119}$ These compounds have the potential to be radiolabeled with ${ }^{11} \mathrm{C}$ on the quinazoline structure in two positions that may survive demethylation in the liver, the replacement with ${ }^{11} \mathrm{C}$ should not alter the properties of the compound in any way, and the desmethyl radiosynthetic precursor would allow for the radiolabeling to be the last step in the synthetic process. Although the activity is not the ideal range for a radiotracer (100 $\mathrm{nM}$ vs $<10 \mathrm{nM}$ ), it provided a starting point and a proof of concept for this class of compounds. Any developments and optimization could be applied to future compounds in this class designed in another project.

In late October 2014, long after initiation of this project and just after the radiolabeling of the aminoquinazolines proved possible in August 2014, BernardGauthier and colleagues published an article on the radiolabeling of the 4-aza-2-oxindole scaffold of pan-Trk inhibitors. ${ }^{120}$ While Bernard-Gauthier's radiotracer showed promise, it was decided not to backtrack at this point. Optimization of the aminoquinazolines continued through July 2015 and our first-in-animal studies began in March of 2016.

\section{Synthesis of Radiosynthetic Standards and Precursors}

The synthetic development of the aminoquinazoline was previously described by Baindur, ${ }^{119}$ presenting trivial initial chemistry schemes. This study intended to synthesize an aminoquinazoline derivative with nanomolar activity and then selectively demethylate the quinazoline to create the desmethyl precursor for addition of the $\left[{ }^{11} \mathrm{C}\right]$ methyl group. The commercially available 4-chloro-6,7-dimethoxyquinazoline was reacted with the prepared $N$-(4-isopropylphenyl)-2-(pyrrolidin-3-yl)acetamide (3a), Scheme 3-1, in anhydrous 2-propanol and DIEA. This mixture was stirred overnight at $100{ }^{\circ} \mathrm{C}$ yielding the desired 2-(1-(6,7-dimethoxyquinazolin-4-yl)-pyrrolidin-3-yl)- $N$-(4isopropylphenyl)acetamide (3d), Scheme 3-2. Controlling the demethylation and the subsequent purification of the 6- or 7- desmethyl quinazoline yielded inconsistent results and was further complicated by the presence of 5-15\% catechol formed from the complete demethylated quinazoline Scheme 3-3A, B, C. Whether dodecanethiol with sodium hydroxide in $\mathrm{N}$-methyl-2-pyrrolidone, ${ }^{121}$ boron tribromide in chloroform, ${ }^{122}$ or neat methane sulfonic acid ${ }^{123}$ was used, the reaction suffered from the presence of the catechol and the mono-desmethyl products would coelute on the TLC. The most successful option was refluxing $\mathrm{BBr}_{3}$ in chloroform overnight which provided an $18 \%$ yield of compound $\mathbf{3 x}$ in $91 \%$ purity. 


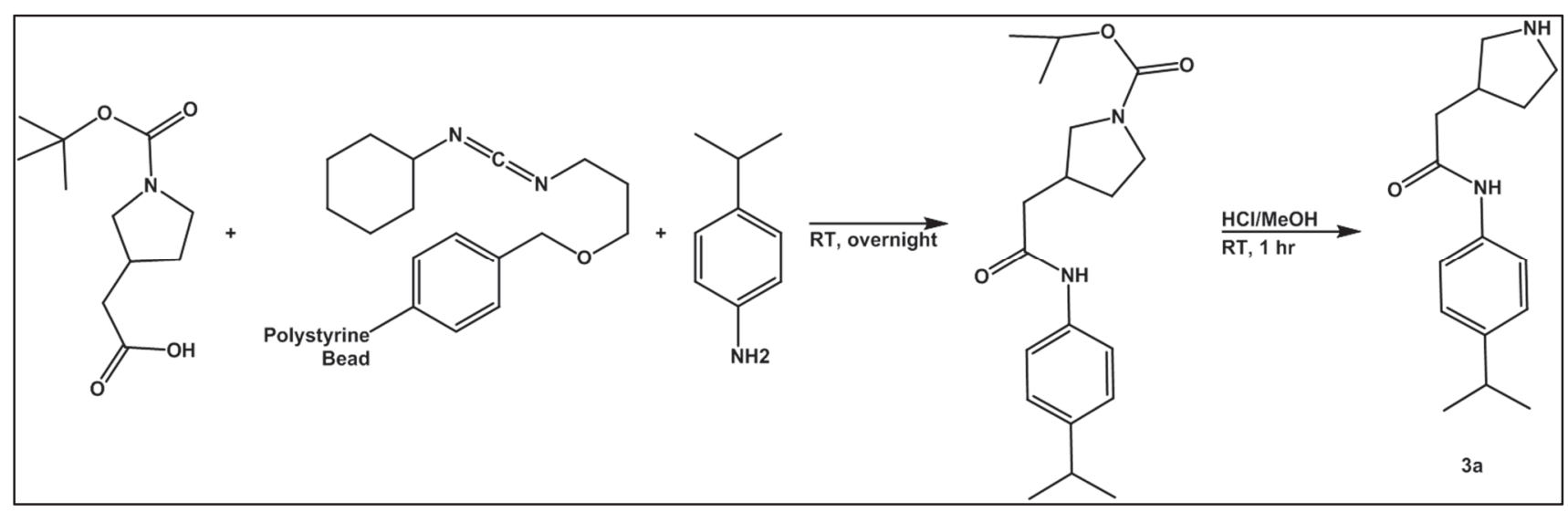

\section{Scheme 3-1. Synthesis of pyrrolidine acetamide 3 a.}

Commercially available 2-(1-(tert-butoxycarbonyl)pyrrolidin-3-yl)acetic acid was dissolved in anhydrous DCM and PS-carbodiimide beads were added and stirred for 1560 minutes. 4-isopropylaniline was then added to the mixture and the mixture was stirred overnight to yield the tert-butyl 3-(2-((4-isopropylphenyl)-amino)-2-

oxoethyl)pyrrolidine-1-carboxylate. The crude product was then dissolved in a $3 \mathrm{M}$ $\mathrm{HCl} / \mathrm{MeOH}$ solution and stirred at room temperature for 1 hour to yield the $\mathrm{HCl}$ salt.

Data Source: Baindur, N.; Gaul, M.; Kreutter, K.; Baumann, C.; Kim, A.; Xu, G.; Zhao, B. P., Aminoquinoline and aminoquinazoline kinase modulators. Patent:

US20070004763 A1. 


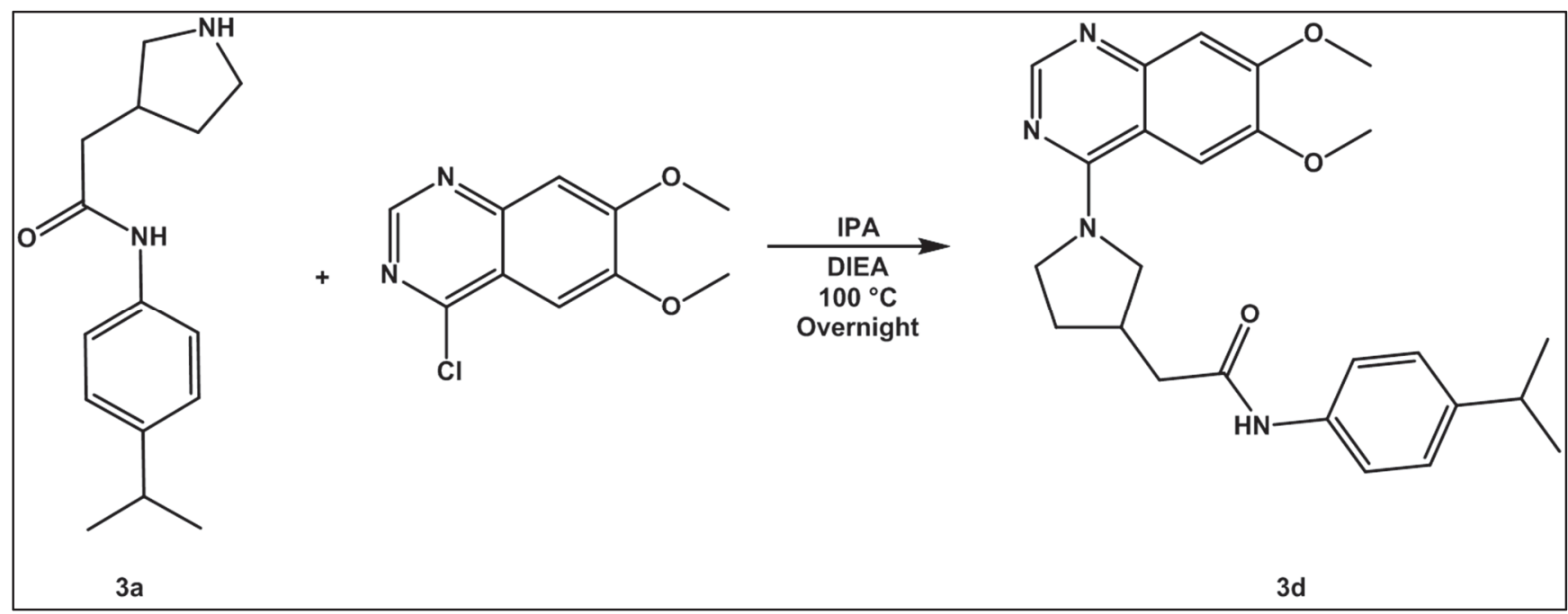

\section{Scheme 3-2. Synthesis of radiosynthetic standard 3d.}

Compound 3a was dissolved in anhydrous 2-propanol, and the commercially available quinazoline was added followed by DIEA and stirred overnight at $100{ }^{\circ} \mathrm{C}$ to yield $3 \mathbf{d}$. Data Source: Baindur, N.; Gaul, M.; Kreutter, K.; Baumann, C.; Kim, A.; Xu, G.; Zhao, B. P., Aminoquinoline and aminoquinazoline kinase modulators. Patent: US20070004763 A1. 


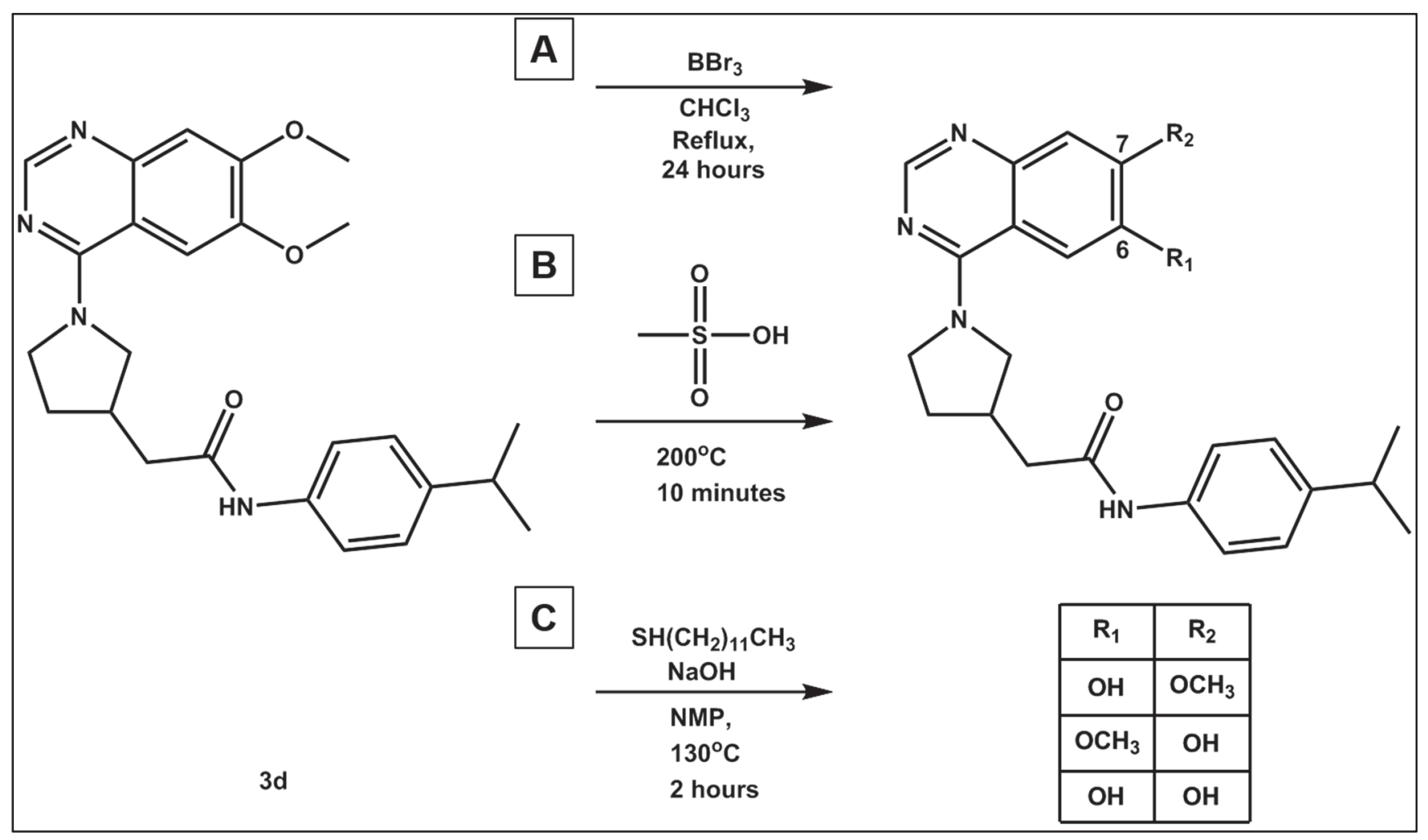

Scheme 3-3. Methods investigated for the demethylation of the radiosynthetic standard 3d.

Each method yielded a complex mixture of the catechol and the mono-desmethyl quinazoline. A: Compound $\mathbf{3 d}$ was dissolved in $\mathrm{CHCl}_{3}$ and cooled to $0{ }^{\circ} \mathrm{C}$. $\mathrm{BBr}_{3}$ was added drop-wise under a nitrogen atmosphere. The reaction refluxed for 24 hours. B: Compound 3d was dissolved in methanesulfonic acid and heated at $200{ }^{\circ} \mathrm{C}$ for 10 minutes. C: Compound 3d and sodium hydroxide were maintained under a nitrogen atmosphere while anhydrous NMP was added to the reaction mixture followed by dodecane-1-thiol. The reaction mixture was stirred at $130^{\circ} \mathrm{C}$ for 2 hours.

Sources: A: Johnstrom, P.; Fredriksson, A.; Thorell, J. O.; Stone-Elander, S., Synthesis of [methoxy- $\left.{ }^{11} \mathrm{C}\right] \mathrm{PD} 153035$, a selective EGF receptor tyrosine kinase inhibitor. Journal of Labelled Compounds and Radiopharmaceuticals 1998, 41 (7), 623-629. B:

Fredriksson, A.; Stone-Elander, S., Rapid microwave-assisted cleavage of methyl phenyl ethers: new method for synthesizing desmethyl precursors and for removing protecting groups. Journal of Labelled Compounds and Radiopharmaceuticals 2002, 2002 (45), 529-538. C: Chae, J., Practical demethylation of aryl methyl ethers using an odorless thiol reagent. Arch Pharm Res 2008, 31 (3), 305-9. 
The initial radiolabeling attempts of $\mathbf{3 x}$ failed. The major radiolabeled peak correlated to an impurity and not the desired aminoquinazoline, Figure 3-2. It was not clear at this point whether this failure resulted from either poor reactivity of the precursor phenol, competition for radiolabel by the $9 \%$ impurity still present in the precursor, or decomposition of the precursor during radiolabeling or some combination of the three. It was decided, therefore, to utilize the simpler model aminoquinazoline 6,7-dimethoxy-4(pyrrolidin-1-yl)quinazoline (3e) to eliminate any possible contribution of side-chain instability and hopefully to aid efficient purification of the radiolabeling precursor. Unfortunately, the demethylation and purification options were attempted as described above with no improvement. Based on the resulting purity of the precursor $(89 \%)$, there was concern that the major radiolabeled product would not be the intended final compound of 6-methoxy-7-[ $\left[{ }^{11} \mathrm{C}\right]$ methoxy-4-(pyrrolidin-1-yl)quinazoline (3ar), resulting in an unusable radiotracer; a new strategy was formulated.

It was evident that a protected quinazoline in the desired radiolabeling position (3al-am) would be required to achieve a workable radiosynthetic precursor.

Commercially available vanillic acid was dibenzylated followed by nitration with nitric acid, Scheme 3-4. The nitroester intermediate was then reduced with tin chloride and cyclized with formamide to form the quinazolinone ring, followed by chlorination with thionyl chloride, to afford the protected quinazoline intermediate. ${ }^{124}$

The workup of the nitro reduction using tin chloride produced a thick foam that rapidly clogged the Kontes fritted glass funnel when filtered with either a grade 1 or 5 qualitative filter paper. This caused a substantial delay in the filtering process and left the yields between $22-69 \%$. The decision was to try iron(II) acetate as a different reducing agent, Scheme 3-5, that would provide a less problematic workup. The workup was slightly improved with a yield of 50\%. However, the addition of a thin layer of sand over celite was used to filter the tin chloride allowing for a smother filtration that improved the yield to $95 \%$.

The coupling of the pyrrolidine to the halogenated quinazoline was achieved as previously described in Scheme 3-2. A new development was that one of the side products was identified as the benzyl protected quinazolinone (3ak) that was not present at the beginning of the reaction, which introduced an unwanted product, and decreased the yield. Instead of directly halogenating the quinazolinone, tosylate was introduced as a better leaving group, Scheme 3-6, but this method created the quinazolinone and the tosylated pyrrolidine in greater yields than the desired 7-(benzyloxy)-6-methoxy-4(pyrrolidin-1-yl)quinazoline (3h).

Maintaining the synthesis set forth in the patent, ${ }^{124}$ 2-(1-(7-(benzyloxy)-6methoxyquinazolin-4-yl)pyrrolidin-3-yl)- $N$-(4-isopropylphenyl)acetamide (3i) was synthesized followed by removal of the benzyl protecting group from the quinazoline (3ap-aq), Scheme 3-7A, B. This deprotection was attempted by palladium catalyzed hydrogenation using a gas balloon attached to the vessel that contained the 2-(1-(7(benzyloxy)-6-methoxyquinazolin-4-yl)pyrrolidin-3-yl)- $N$-(4-isopropylphenyl)acetamide (3i) and 10\% palladium on carbon in EtOAc. The reaction was monitored for up to 3 


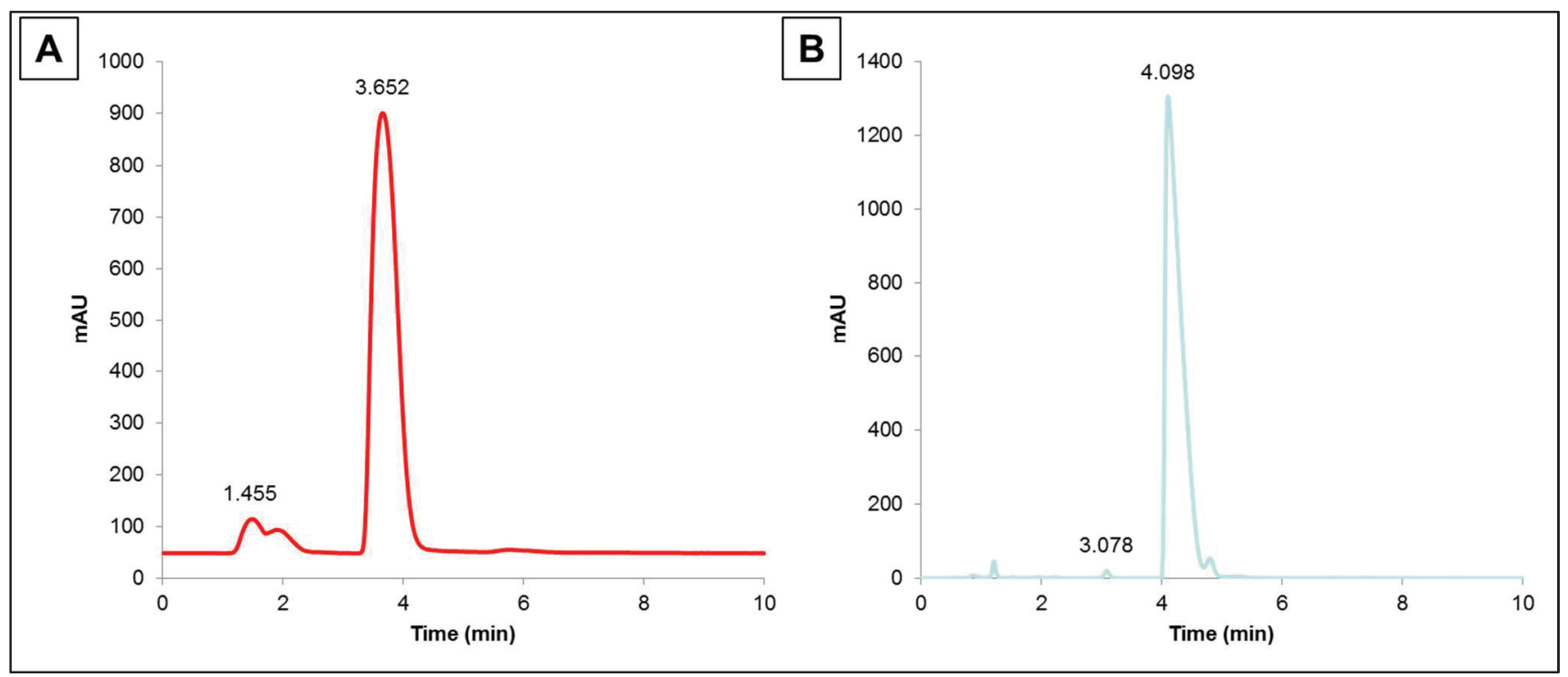

Figure 3-2. HPLC chromatogram of radiotracer 3ar using $\left[{ }^{11} \mathrm{C}\right]$ methyl iodide. A: Radioactivity signal of $\left[{ }^{11} \mathrm{C}\right]$ radio-contaminate $\left(t_{R}=3.652\right)$. B: UV signal $(254 \mathrm{~nm})$ of 4-nitrobenzil $\left(\mathrm{t}_{\mathrm{R}}=4.098 \mathrm{~min}\right.$.). Conditions: radiolabeled using $\left[{ }^{11} \mathrm{C}\right] \mathrm{methyl}$ iodide, $\mathrm{NaOH} / \mathrm{DMF}$, heated at $70{ }^{\circ} \mathrm{C}$ for 7 minutes. HPLC: mobile phase of $55 \% 50 \mathrm{mM}$ ammonium acetate with acetonitrile $\mathrm{pH}$ adjusted to 3.8 with a flow rate of $0.45 \mathrm{~mL} / \mathrm{min}$ on an Agilent ZORBAX SB-C18 analytical column, 3.0 x $100 \mathrm{~mm}, 3.5 \mu \mathrm{m}$ particle size.

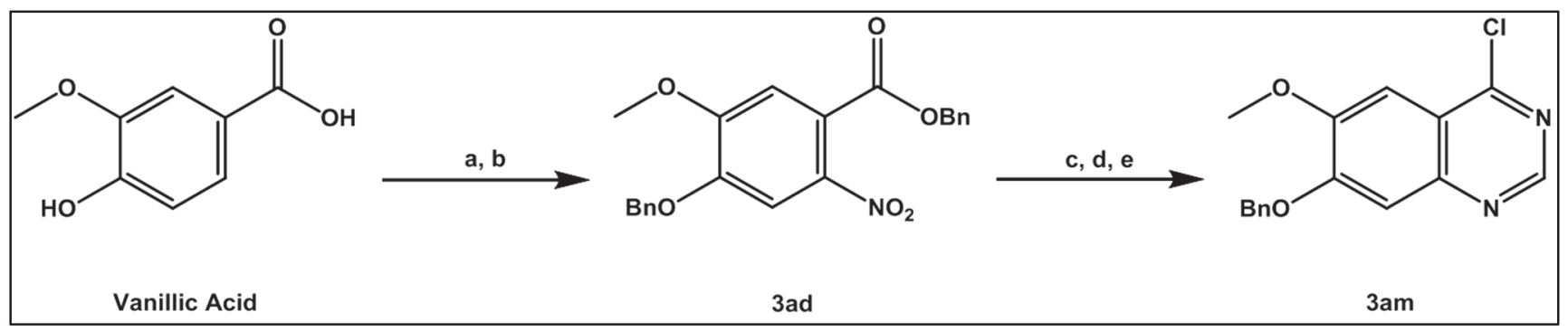

Scheme 3-4. Synthesis of protected quinazoline.

(a) $\mathrm{BnBr}, \mathrm{K}_{2} \mathrm{CO}_{3}, \mathrm{DMF}$, RT. (b) $\mathrm{HNO}_{3}, \mathrm{AcOH}, 0-100{ }^{\circ} \mathrm{C}, \mathrm{o} / \mathrm{n}$. (c) $\mathrm{SnCl}_{2}, 2 \mathrm{H}_{2} \mathrm{O}, \mathrm{EtOAc}$, $50{ }^{\circ} \mathrm{C}, \mathrm{o} / \mathrm{n}$. (d) $\mathrm{HCONH}_{2}, \mathrm{HCO}_{2} \mathrm{NH}_{4}, 145{ }^{\circ} \mathrm{C}, 12$ h. (e) $\mathrm{SOCl}_{2}$, catalytic DMF, toluene, reflux.

Source: Pandey, A.; Scarborough, R. M.; Matsuno, K.; Ichimura, M.; Nomoto, Y.; Ide, S.; Tsukuda, E.; Irie, J.; Oda, S., Quinazoline derivatives as kinase inhibitors. Patent: EP1964839 A2. 


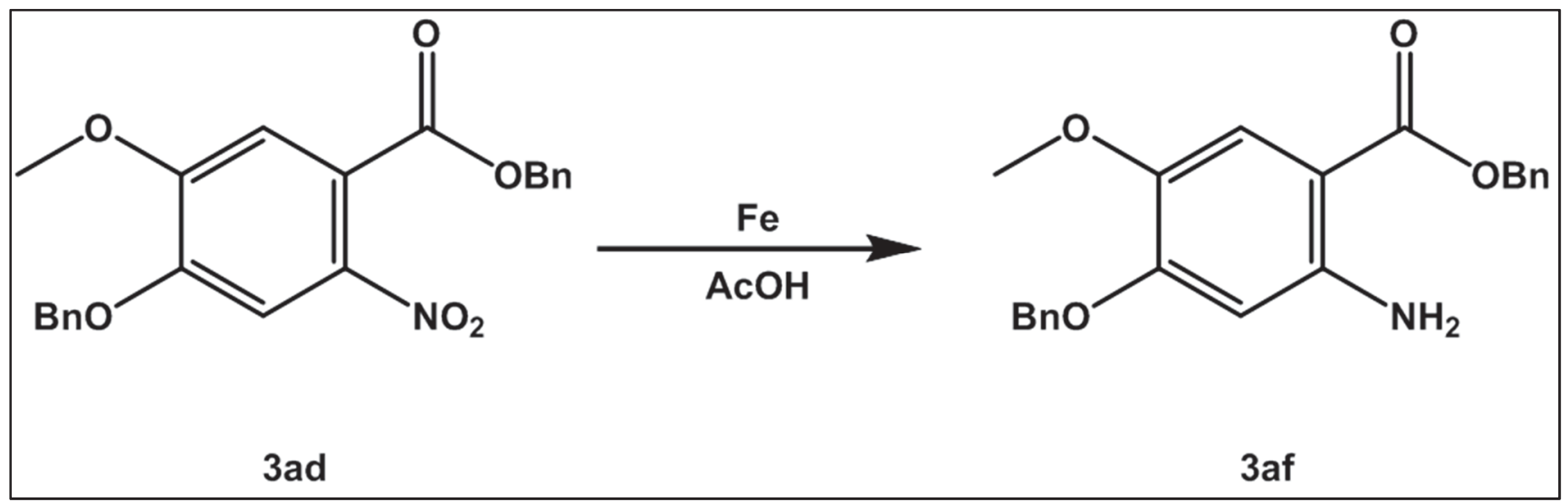

Scheme 3-5. Reduction of 3ad with iron(II) acetate.

Compound $\mathbf{3 a d}$ and iron in acetic acid were heated at $100{ }^{\circ} \mathrm{C}$ for 1 hour to yield $\mathbf{3 a f}$.

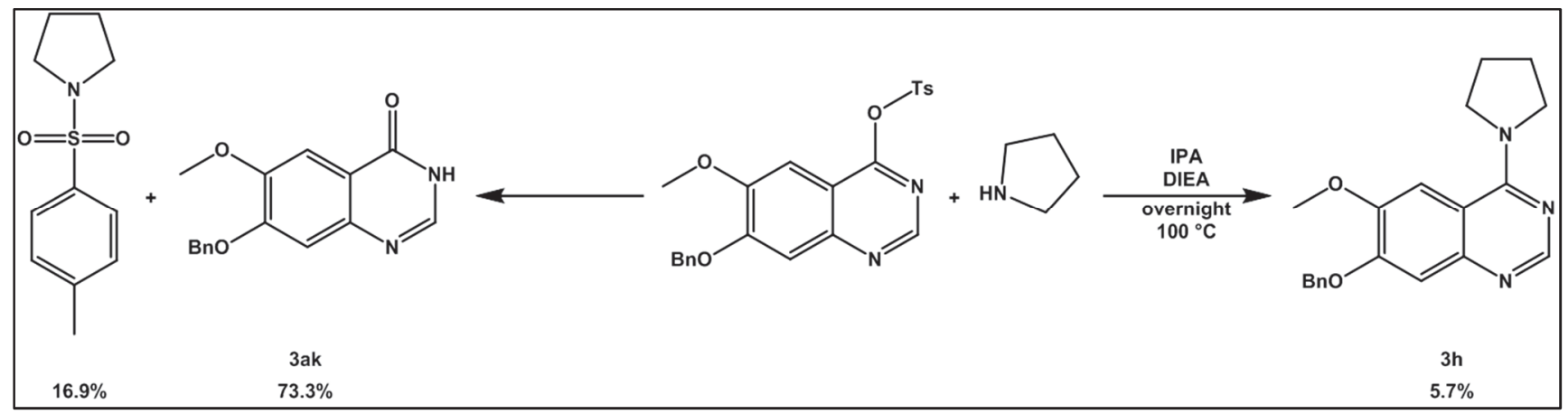

Scheme 3-6. Attempted coupling of the tosyl protected quinazolinone with pyrrolidine.

Pyrrolidine was dissolved in anhydrous 2-propanol and 7-(benzyloxy)-6methoxyquinazolin-4-yl-4-methylbenzenesulfonate was added followed by DIEA and stirred overnight at $100{ }^{\circ} \mathrm{C}$ to yield $\mathbf{3 h}(5.7 \%)$ and $\mathbf{3 a k}(73.3 \%)$. 


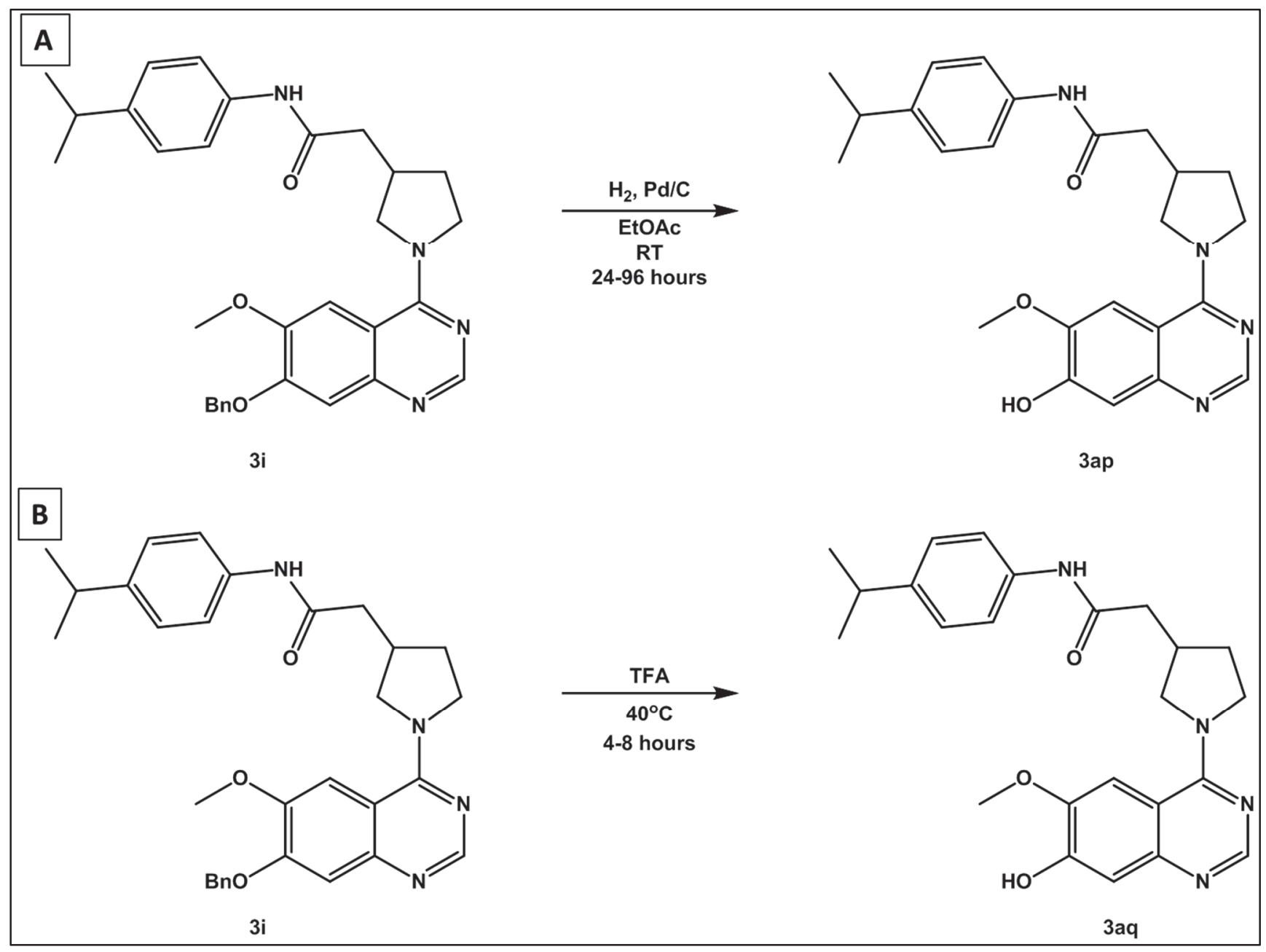

Scheme 3-7. Methods investigated for the debenzylation of 3i.

A: A catalytic amount of $10 \%$ palladium on carbon under nitrogen was used. EtOAc was then added and a balloon filled with hydrogen gas was attached. 3i in EtOAc was added. The reaction mixture was stirred at room temperature for 96 hours. B: In a 5-mL microwave vessel with a stir bar, $\mathbf{3 i}$ was added followed by TFA. The vessel was sealed and heated to $40{ }^{\circ} \mathrm{C}$ for 4 hours. 
days with the greatest yield being $11.28 \%$. Use of trifluoroacetic acid (TFA) has also been reported for $o$-debenzylations with greater than $90 \%$ yields. ${ }^{125}$ The first attempt gave $55 \%$ yield after 4 hours and $>98 \%$ after 8 hours by dissolving the benzyl protected aminoquinazoline in straight TFA and heating to $40^{\circ} \mathrm{C}$.

\section{Microwave Assisted Organic Synthesis}

After determining the optimal synthesis of the aminoquinazolines, microwave assisted organic synthesis was investigated to improve the synthetic scheme, Scheme 3-8 by taking advantage of the key aspects of microwave assistance, namely decreased reaction times, cleaner product, and reduced use of solvents. ${ }^{104-106}$ The changes improved the benzylation, the nitro reduction, the quinazoline cyclization, and the pyrrolidine addition times from hours to minutes.

\section{Radiolabeling}

The aminoquinazoline precursor and standards were successfully synthesized with optimized synthetic schemes utilizing microwave assistance and other alterations to improve yield and purity. Radiolabeling options were then pursued. Traditionally, production of $\left[{ }^{11} \mathrm{C}\right]$ methyl iodide is used as the reactive group to add a radioactive methyl group to precursors. ${ }^{126-129}$

${ }^{11} \mathrm{C}$ is produced by proton irradiation of nitrogen gas that has a trace amount of oxygen mixed with it in a $(p, \alpha)$ nuclear reaction producing $\left[{ }^{11} \mathrm{C}\right]$ carbon dioxide, Scheme 3-9. This reactive gas is bubbled through a mixture of lithium aluminum hydride (LAH) and THF to give $\left[{ }^{11} \mathrm{C}\right]$ methoxide salts. The THF is then evaporated to prevent decomposition during radiolabeling to yield multiple radioactive ethers. The dry $\left[{ }^{11} \mathrm{C}\right]$ methoxide salt is then acidified with phosphoric acid to give the volatile $\left[{ }^{11} \mathrm{C}\right]$ methanol species. This is then bubbled through a concentrated solution of hydroiodic acid at an elevated temperature, creating $\left[{ }^{11} \mathrm{C}\right]$ methyl iodide which is then distilled directly into a reaction vial containing the precursor in a continuous flowthrough process. ${ }^{130}$ The $\left[{ }^{11} \mathrm{C}\right]$ methyl iodide was reacted with the precursor dissolved in DMSO with potassium carbonate at $70{ }^{\circ} \mathrm{C}$ for 7 minutes. ${ }^{122}$

Methyl iodide is the most versatile carbon-11 labeling precursor and the "wet" $\left[{ }^{11} \mathrm{C}\right]$ methyl iodide production method described above is universally used. ${ }^{130}$ Methyl triflate is a methylating agent that is more reactive by a factor of about $10^{4}$ than methyl iodide and has been reported to provide the advantages of decreasing the amount of the desmethyl precursor needed, decreasing the reaction time, and allowing reaction at lower temperatures. ${ }^{126-129}$ The synthesis of methyl triflate is performed in sequence after the production of methyl iodide on the automated radiosynthesis equipment. The $\left[{ }^{11} \mathrm{C}\right]$ methyl iodide is passed through a short, glass column containing silver triflate on graphitized carbon spheres that is heated to $200{ }^{\circ} \mathrm{C}$. This is a minor modification to the 


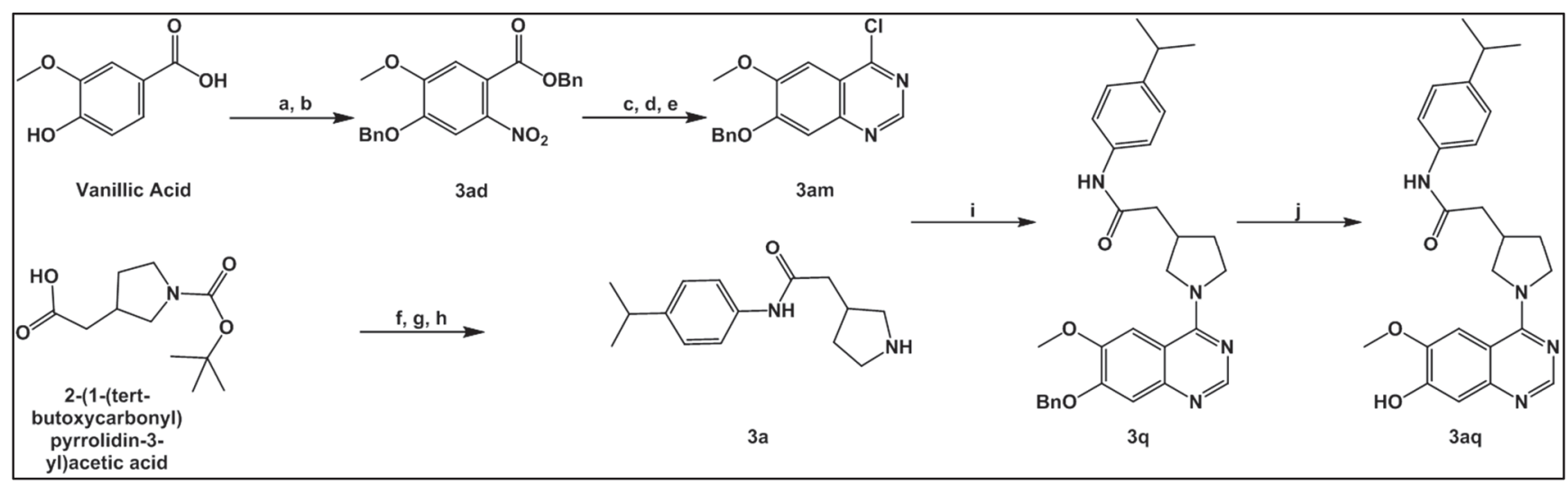

Scheme 3-8. Optimized synthesis conditions for the radiosynthetic precursor.

(a) $\mathrm{BnBr}, \mathrm{K}_{2} \mathrm{CO}_{3}$, DMF, microwave: $95{ }^{\circ} \mathrm{C}, 5.6 \mathrm{~min}$. 3aa (b) $\mathrm{HNO}_{3}, \mathrm{AcOH}, 0-100{ }^{\circ} \mathrm{C}$, overnight. (c) $\mathrm{SnCl}_{2}, 2 \mathrm{H}_{2} \mathrm{O}$, EtOAc, $50{ }^{\circ} \mathrm{C}$, overnight. (d) $\mathrm{HCONH}_{2}, \mathrm{HCO}_{2} \mathrm{NH}_{4}$, microwave: $220^{\circ} \mathrm{C}, 5.6 \mathrm{~min}$. 3ak (e) $\mathrm{SOCl}_{2}$, catalytic DMF, toluene, reflux. (f) PSCarbodiimide, DCM, RT, 15 min. (g) Isopropylaniline, RT, overnight. (h) $\mathrm{HCl} / \mathrm{MeOH}$, RT, 1 hour. (i) DMF, microwave: $170^{\circ} \mathrm{C}, 5.6$ min. (j) TFA, $40^{\circ} \mathrm{C}, 4 \mathrm{hr}$. 


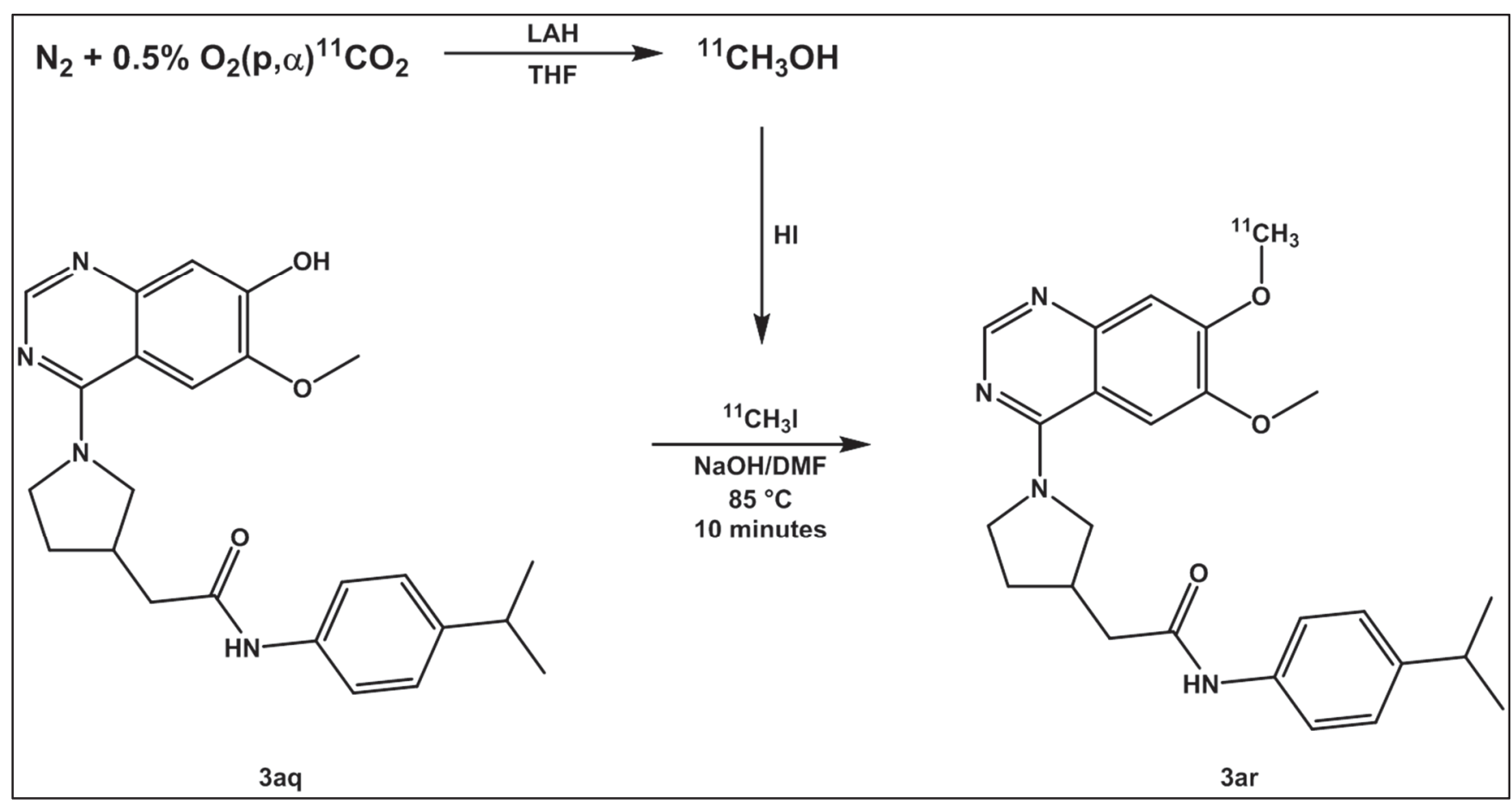

\section{Scheme 3-9. Radiosynthesis of 3aq using $\left[{ }^{11} \mathrm{C}\right]$ methyl iodide.}

${ }^{11} \mathrm{C}$ is produced by proton irradiation of $\mathrm{N}_{2}$ gas with $0.5 \% \mathrm{O}_{2}$ in a $(\mathrm{p}, \alpha)$ nuclear reaction producing $\left[{ }^{11} \mathrm{C}\right]$ carbon dioxide. This reactive gas is bubbled through a mixture of LAH and THF to give the volatile $\left[{ }^{11} \mathrm{C}\right]$ methanol species. This is then passed through a solution of hydroiodic acid creating $\left[{ }^{11} \mathrm{C}\right]$ methyl iodide. The $\left[{ }^{11} \mathrm{C}\right]$ methyl iodide is reacted with 3aq in $\mathrm{DMF}$ and $\mathrm{NaOH}$ to yield 3 ar. 
PETChem Solutions radiochemistry unit and allows for the trapping of $\left[{ }^{11} \mathrm{C}\right]$ methyl triflate, Scheme 3-10, into the reactor vessel containing a small volume of solvent and base. When $\left[{ }^{11} \mathrm{C}\right]$ methyl triflate was used with approximately $0.5 \mathrm{mg}$ of the desmethyl precursor, the reaction was instantaneous at room temperature, and improved the yield from approximately $15 \%$ to approximately $23 \%$.

Researchers must be cautious with the use of LAH because it can lead to a decrease in specific radioactivity of the final radiotracer since carbon dioxide readily adsorbs to LAH and is difficult to remove without extended heating under a constant inert gas flow. Thus the LAH is the leading source of non-radioactive carbon during the production of $\left[{ }^{11} \mathrm{C}\right]$ methyl iodide and $\left[{ }^{11} \mathrm{C}\right]$ methyl triflate. ${ }^{130}$ Use of LAH in typical dry ether solvents like THF can also lead to rapid deterioration of the tubing and valves of the automated synthesizer. The use of caustic solvents and reagents like LAH, required extensive cleaning and drying protocols to maintain the equipment after each radiosynthetic procedure, which affects the number of procedures that are achievable in a single day. The alternative to using LAH would be to use the "gas" phase method utilizing the bromination of $\left[{ }^{11} \mathrm{C}\right]$ methane to $\left[{ }^{11} \mathrm{C}\right]$ methyl bromide. ${ }^{130}$ This method requires different equipment than the current configuration of the PETChem solutions radiochemistry unit.

\section{Method Development}

The radiolabeling methods of the desmethyl precursor 3aq were evaluated to reduce the amount of precursor used, temperature, reaction time, and both radiochemical and organic impurities. Using the least amount of precursor possible minimized the need to remove excess unreacted organic compounds from the final product. Reactions were carried out with $0.1,1.0,1.3,1.5,1.6,2.0$, and $5.0 \mathrm{mg}$ of the precursor. The crude reaction mixture was evaluated and using $0.5 \mathrm{mg}$ provided $80 \%$ radiochemical purity and 23-33\% radiochemical yield, Table 3-1. Even at amounts less than $1.0 \mathrm{mg}$, the desmethyl precursor is in a unique stoichiometric relationship with $\left[{ }^{11} \mathrm{C}\right]$ methyl triflate of a factor of approximately 10,000:1, creating a pseudo-first order kinetics ${ }^{131}$ of heteroatom methylation reactions. ${ }^{130}$

Temperature evaluation was conducted at $85^{\circ} \mathrm{C}$ and at $20^{\circ} \mathrm{C}$ with the lower temperature providing larger radiochemical yield, $8.6 \pm 0.2 \%$ and $12.4 \pm 1.9 \%$ respectively. Next, the time for the reaction was tested at $0,1,2,3,5,10$, and 15 minutes yielding comparable results, $79.8 \pm 0.94 \%$ radiochemical purity. The optimal time was determined to be immediately after the maximum activity was noted in the reaction vessel during $\left[{ }^{11} \mathrm{C}\right]$ methyl triflate transfer.

The synthesized aminoquinazoline compounds are soluble in polar aprotic solvents used for ${ }^{11} \mathrm{C}$ methylation reactions. These solvents include DMSO, DMF, and acetone, all of which have limits set by the United States Pharmacopeia (USP) as to how much can be in the final product administered to a patient. The solvents were tested with either potassium carbonate $\left(\mathrm{K}_{2} \mathrm{CO}_{3}\right)$ or tetrabutylammonium hydroxide (TBAOH) as the 


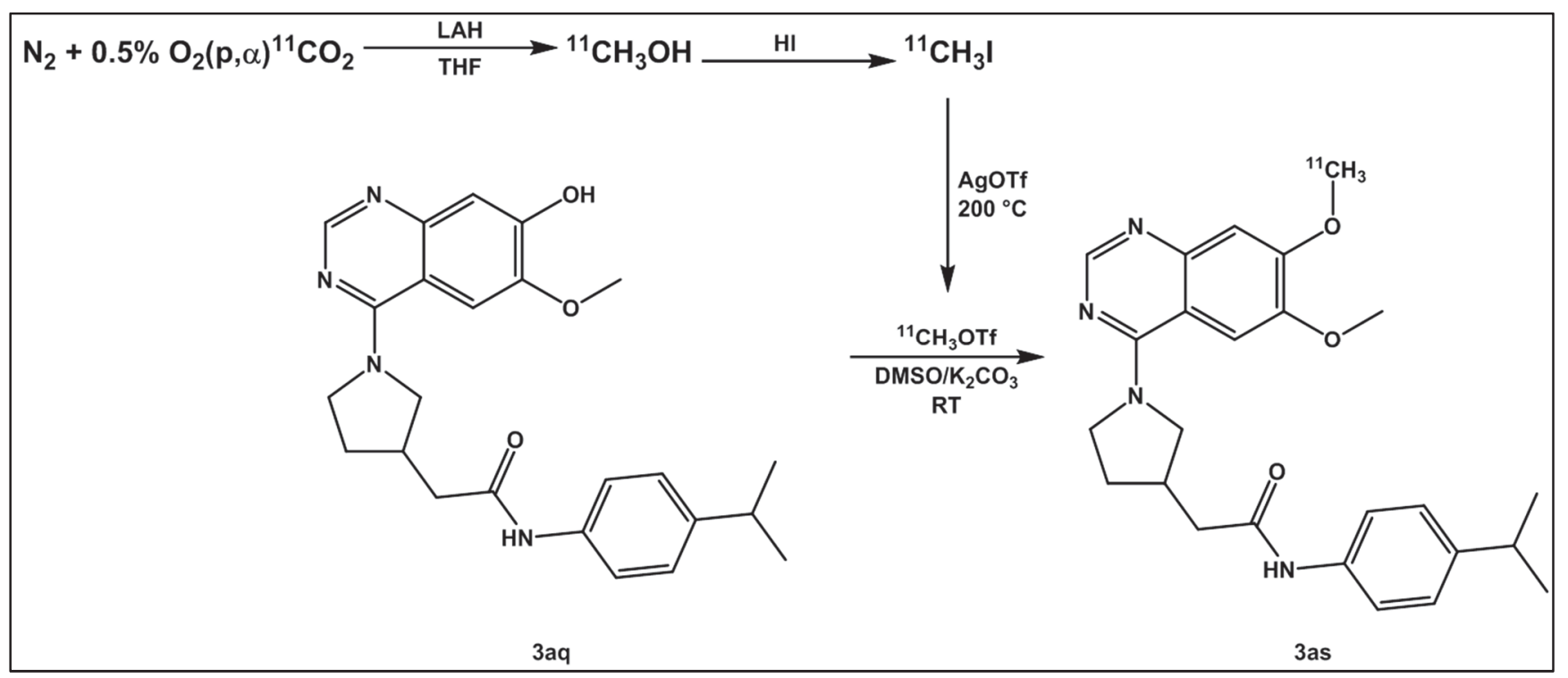

\section{Scheme 3-10. Radiosynthesis of 3aq using $\left[{ }^{11} \mathrm{C}\right]$ methyl triflate.}

${ }^{11} \mathrm{C}$ is produced by proton irradiation of $\mathrm{N}_{2}$ gas with $0.5 \% \mathrm{O}_{2}$ in a $(\mathrm{p}, \alpha)$ nuclear reaction producing $\left[{ }^{11} \mathrm{C}\right]$ carbon dioxide. This reactive gas is bubbled through a mixture of LAH and THF to give the volatile $\left[{ }^{11} \mathrm{C}\right]$ methanol species. This is then passed through a solution of hydroiodic acid creating $\left[{ }^{11} \mathrm{C}\right]$ methyl iodide. The $\left[{ }^{11} \mathrm{C}\right]$ methyl iodide is passed over the silver triflate column to produce $\left[{ }^{11} \mathrm{C}\right]$ methyl triflate, which is then reacted with 3aq in DMSO and $\mathrm{K}_{2} \mathrm{CO}_{3}$ to yield 3as. 
Table 3-1. Radiolabeling reaction condition optimizations for 2-(1-(6-methoxy-7-[ $\left[{ }^{11} \mathrm{C}\right]$-methoxyquinazolin-4-yl)pyrrolidin-3-yl)- $\mathrm{N}$ (4-isopropylphenyl)acetamide (3as).

\begin{tabular}{|c|c|c|c|}
\hline \multirow{2}{*}{$\begin{array}{c}\text { Condition } \\
(\mathrm{n}=1)\end{array}$} & \multicolumn{3}{|c|}{ Radiochemical Purity (\%) } \\
\hline & DMSO & DMF & Acetone \\
\hline \multicolumn{4}{|l|}{ Precursor (mg) } \\
\hline 0.1 & 36.9 & nd & nd \\
\hline 0.5 & 76.6 & nd & nd \\
\hline 1.0 & 81.1 & nd & nd \\
\hline 1.3 & 80.6 & nd & nd \\
\hline 1.5 & 78.4 & nd & nd \\
\hline 1.6 & 78.6 & nd & nd \\
\hline 2.0 & 90.8 & nd & nd \\
\hline 5.0 & 79.0 & nd & nd \\
\hline \multicolumn{4}{|l|}{ Time (min) } \\
\hline 0 & 78.6 & 0 & 0 \\
\hline 1 & 80.3 & nd & nd \\
\hline 2 & 79.1 & nd & nd \\
\hline 3 & 79.7 & nd & nd \\
\hline 5 & 80.4 & 0 & 0 \\
\hline 10 & 79.1 & 0 & 0 \\
\hline 15 & 81.3 & 0 & 0 \\
\hline 20 & nd & 0 & 0 \\
\hline \multicolumn{4}{|l|}{ Temperature $\left({ }^{\circ} \mathrm{C}\right)$} \\
\hline 20 & 78.4 & nd & nd \\
\hline 70 & nd & 75.0 & nd \\
\hline 85 & 61.0 & nd & nd \\
\hline \multicolumn{4}{|l|}{ Base } \\
\hline Potassium Carbonate & 76.6 & 0 & 0 \\
\hline Tetrabutylammonium Hydroxide & 0 & 0 & 0 \\
\hline
\end{tabular}

Note: nd: not determined. 
base for depotonation of the precursor phenol. Every combination failed to react after 20 minutes except for DMSO or DMF with $\mathrm{K}_{2} \mathrm{CO}_{3}$, Table 3-1. These solvents cannot be removed by purging with inert gas, therefore, the solvents were removed through the purification and reformulation portion of the radiosynthesis procedure.

Solid phase extraction cartridges like the Sep-Pak ${ }^{\circledR}$ cartridges offered by Waters (Milford, MA) are commonly used to remove impurities and solvents. A classic C18 cartridge was utilized to adsorb the radiolabeled aminoquinazoline on the cartridge and remove the DMSO through dilution. The radiolabeled compound was then released from the cartridge for analysis with a different mobile phase. The Classic short C18 variety of Sep-Pak ${ }^{\circledR}$ cartridge caused backpressure that prohibited the transfer of the solutions through the PETChem Solutions radiochemistry unit. The C18 Plus Long version required 2-3 $\mathrm{mL}$ of ethanol to remove the radiotracer from the cartridge, which led the final product to contain 10-15\% ethanol. The tC18 Plus short cartridge Sep-Pak ${ }^{\circledR}$ avoided these issues. The crude reaction mixture could be diluted with $18-22 \%$ acetonitrile $/ 50 \mathrm{mM}$ ammonium acetate mixture, passed through the cartridge, flushed with water, and released with $1 \mathrm{~mL}$ of ethanol. This successfully removed the solvents but did not yield purity above $90 \%$ for the final product. Therefore, HPLC was required and utilized immediately prior to the Sep-Pak ${ }^{\circledR}$.

The HPLC purification was optimized using a ZORBAX SB-C18 column and the 1200 series Agilent system. A mobile phase of $50 \mathrm{mM}$ ammonium acetate with acetonitrile, $\mathrm{pH}$ adjusted to 3.8, was used. The percentage of the organic solvent was increased until the retention time of the desired compound and potential impurities had base line separation and the full chromatogram could be completed in 10 minutes. This was achieved with a final mobile phase concentration of 55\% ammonium acetate and $45 \%$ acetonitrile. The analytical column $(3.0 \times 100 \mathrm{~mm}, 3.5 \mu \mathrm{m})$ flow rate was 0.45 $\mathrm{mL} / \mathrm{min}$ and the semi-prep column $(9.4 \times 250 \mathrm{~mm}, 5 \mu \mathrm{m})$ flow was $4 \mathrm{~mL} / \mathrm{min}$.

With the HPLC conditions finalized the purified radiotracer needed to be reformulated into an injectable solution. Therefore, the HPLC eluent was diluted with 50 $\mathrm{mM}$ ammonium acetate, $\mathrm{pH}$ adjusted to 3.8, and passed through the Sep-Pak ${ }^{\circledR}$ to trap the radiotracer and flush off the organic solvent. Next, pure water was passed over the Sep-Pak ${ }^{\circledR}$ to remove the solvents as described above. The radiotracer was then eluted from the Sep-Pak ${ }^{\circledR}$ with $1 \mathrm{~mL}$ of ethanol into a $30 \mathrm{~mL}$, vial containing $19 \mathrm{~mL}$ of $50 \mathrm{mM}$ ammonium acetate that was $\mathrm{pH}$ adjusted to 5.5. This presented a final product solution of $5 \%$ ethanol at a $\mathrm{pH}$ that could be safely injected. The optimized results and conditions are summarized in Table 3-2.

\section{Results and Discussions}

This project focused on developing a radiotracer that could be used to identify the presence of the TrkB in a patient diagnosed with NB. The aminoquinazolines were synthesized and radiolabeled at the 6 or 7 position of the quinazoline as reported in this study. A clone of SH-SY5Y cell line (BR6) that was transfected with a pLNCX vector 
Table 3-2. Results of optimized conditions for 2-(1-(6-methoxy-7-[ $\left.{ }^{11} \mathrm{C}\right]$-methoxyquinazolin-4-yl)pyrrolidin-3-yl)- $\mathrm{N}$ (4-isopropylphenyl)acetamide (3as).

\begin{tabular}{ll}
\hline \multicolumn{1}{c}{ Parameter } & \multicolumn{1}{c}{ Results } \\
\hline Solvent/Base & $\mathrm{DMSO} / \mathrm{K}_{2} \mathrm{CO}_{3}$ \\
Precursor & $0.5 \mathrm{mg}$ \\
Radiolabeling Method & $\mathrm{MeOTf}$ \\
Temperature & $20{ }^{\circ} \mathrm{C}$ \\
Purification & $\mathrm{HPLC}$ \\
& $\mathrm{Sep}-\mathrm{Pak}{ }^{\circledR} \mathrm{tC} 18$ Short plus \\
Formulation & $5 \% \mathrm{EtOH}$ \\
& $50 \mathrm{mM} \mathrm{Ammonium} \mathrm{Acetate}$ \\
pH & 5.5 \\
Yield, uncorrected & $8.8 \pm 1.9 \%$ \\
& $4.5 \pm 1.3 \mathrm{mCi} / \mathrm{mL}$ \\
Specific Activity & $>3 \mathrm{Ci} / \mu \mathrm{mol}$ \\
Reaction Time & $30 \mathrm{minutes}$ \\
\hline
\end{tabular}


expressing TrkB ${ }^{132}$ was graciously provided from the Brodeur lab at Children's Hospital of Philadelphia (CHOP). These BR6 cells have been stable for years with a high TrkB expression as compared to the SJCRH repository of NB cell lines (personal communication with Dr. David Finkelstein, 3/31/2016). The SH-SY5Y is a human NB neuronal sub-clone of SK-N-SH started from thoracic NB cells. ${ }^{133}$ The SH-SY5Y parent cell line does not express TrkB, thus the parent cell line was used for the controls in the following experiments.

A cell association protocol was performed with the radiotracer, Figure 3-3. The BR6 cells had $5.97 \pm 0.39 \%$ uptake and the parent SH-SY5Y cells had $4.65 \pm 0.36 \%$ uptake. The difference in radiotracer uptake between these cell lines was expected to be more significant, thus the presence of TrkB in the cell samples and tumor lysate from the in vivo tumors was confirmed by a Bio-Rad Western blot kit, Figure 3-4. There was a 10 -fold increased TrkB expression in the TrkB positive BR6 cells of both the in vitro and in vivo lanes as compared to the TrkB negative parent cells.

An in vitro adsorption, distribution, metabolism, and excretion (ADME) analysis panel was performed on the radiosynthetic standard, compound 3d, Table 3-3. The compound is very slightly soluble ${ }^{134}$ with the solubility reported as $0.22 \pm 0.05 \mu \mathrm{g} / \mathrm{mL}$. This solubility limitation was noted during the reformulation portion and found a need for ethanol to keep the radiotracer in solution. The Caco-2 permeability reported that the efflux ratio was 0.6 , this indicates that the radiotracer may not be subject to active efflux. ${ }^{135}$ The radiosynthetic standard has $98.8 \pm 0.1 \%$ plasma binding in the mouse model with a $t_{1} / 2$ of $27 \pm 1.2$ minutes and an intrinsic clearance of $126.55 \mathrm{~mL} / \mathrm{min} / \mathrm{kg}$ as identified by a liver microsomal assay in mice. Using the physical half-life time and the biological half-life time, the calculated effective half-life of the radiotracer is 11.62 minutes. While the limited aqueous solubility and possible plasma protein sequestration of the radiotracer were obvious issues, the in vitro ADME data did not completely exclude the radiotracer compound 3as as a viable option. For this reason, animal tumor models were developed to test the radiotracer.

Using athymic nude $(n u / n u)$ mice, bilateral TrkB+ (right flank) and TrkB- (left flank) tumors were grown. Once the tumors were of sufficient size $(>200 \mathrm{mg})$ the animals were injected retro-orbitally with $200 \mu \mathrm{Ci}$ of the radiotracer, 2-(1-(6-methoxy-7$\left[{ }^{11} \mathrm{C}\right]$ methoxyquinazolin-4-yl)-pyrrolidin-3-yl)- $N$-(4-isopropylphenyl)acetamide (3as), and dynamically imaged on a Siemens (Malvern, PA) Inveon PET/CT small animal imaging resource, Figure 3-5, under isoflurane (1.5\%) anesthesia. The terminal studies collected biodistribution data at 2, 10, and 30-minute post-injection times, Figure 3-5.

The final radiotracer of this project, compound 3as, was shown to have hepatic (48.2 $\pm 15.7 \%$ injected dose/g of tissue), renal (47.2 $\pm 12.1 \%$ injected dose/g of tissue), lung $(27.8 \pm 8.2 \%$ injected dose/g of tissue), and heart (33.9 $\pm 7.3 \%$ injected dose/g of tissue) radioactivity uptake, Figure 3-6. with minimal uptake in the brain $(0.76 \pm 0.16 \%$ injected dose/g of tissue). There was also minimal activity seen in the NB tumors, $1.21 \pm 0.21 \%$ injected dose $/ g$ of tissue TrkB + tumor versus $0.956 \pm 0.16 \%$ injected dose/g of tissue TrkB- tumor at 30 minutes. In comparison, the 4-aza-2-oxindole pan-Trk 


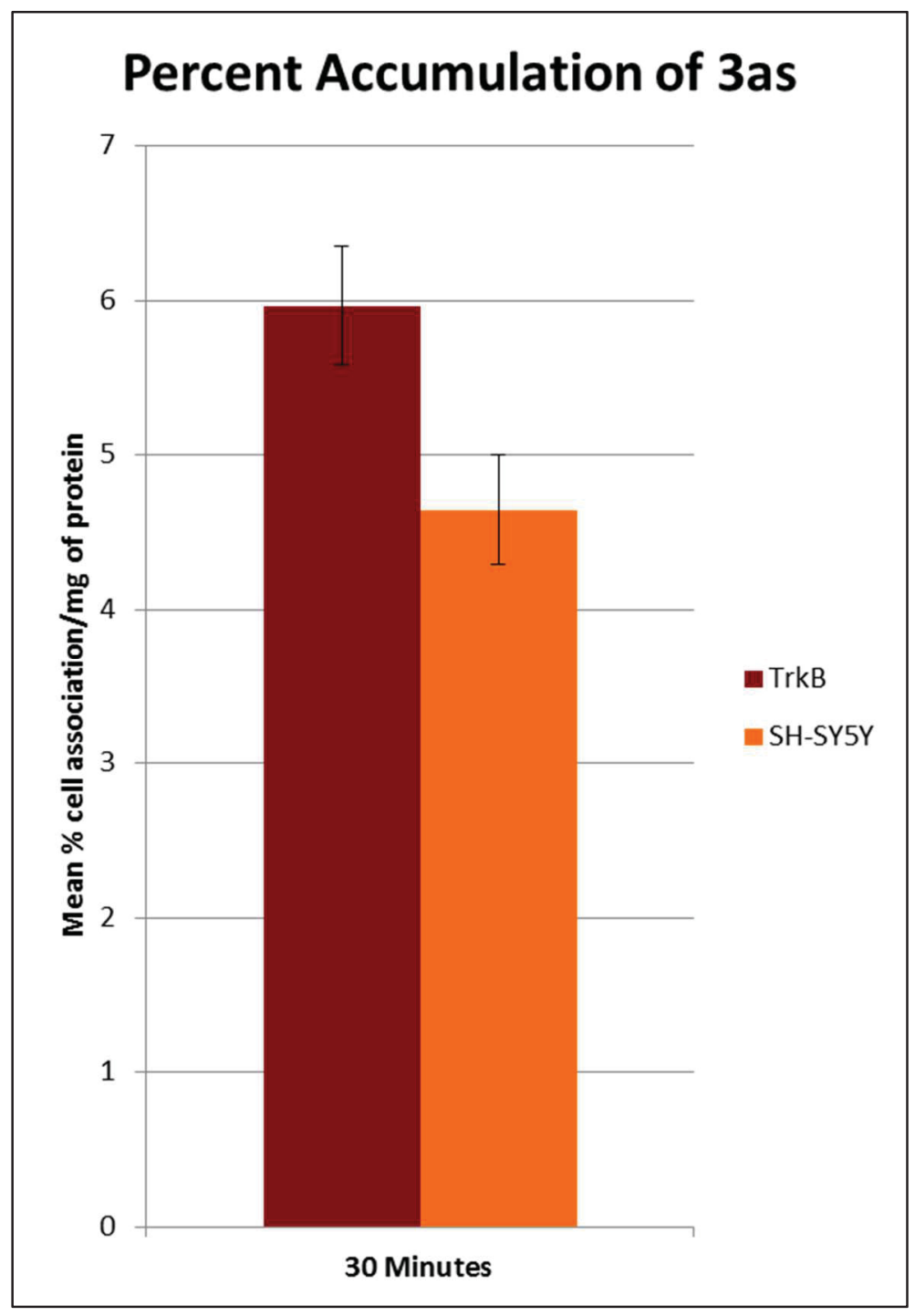

Figure 3-3. Cell uptake of 3as.

Accumulation of 3as in TrkB-transfected and parent SH-SY5Y cells determined after 30 minutes of exposure. Cell-associated radioactivity data were normalized for the amount of protein in each sample. The percentage of cell-associated radioactivity was based on total radioactivity initially added to each well. 


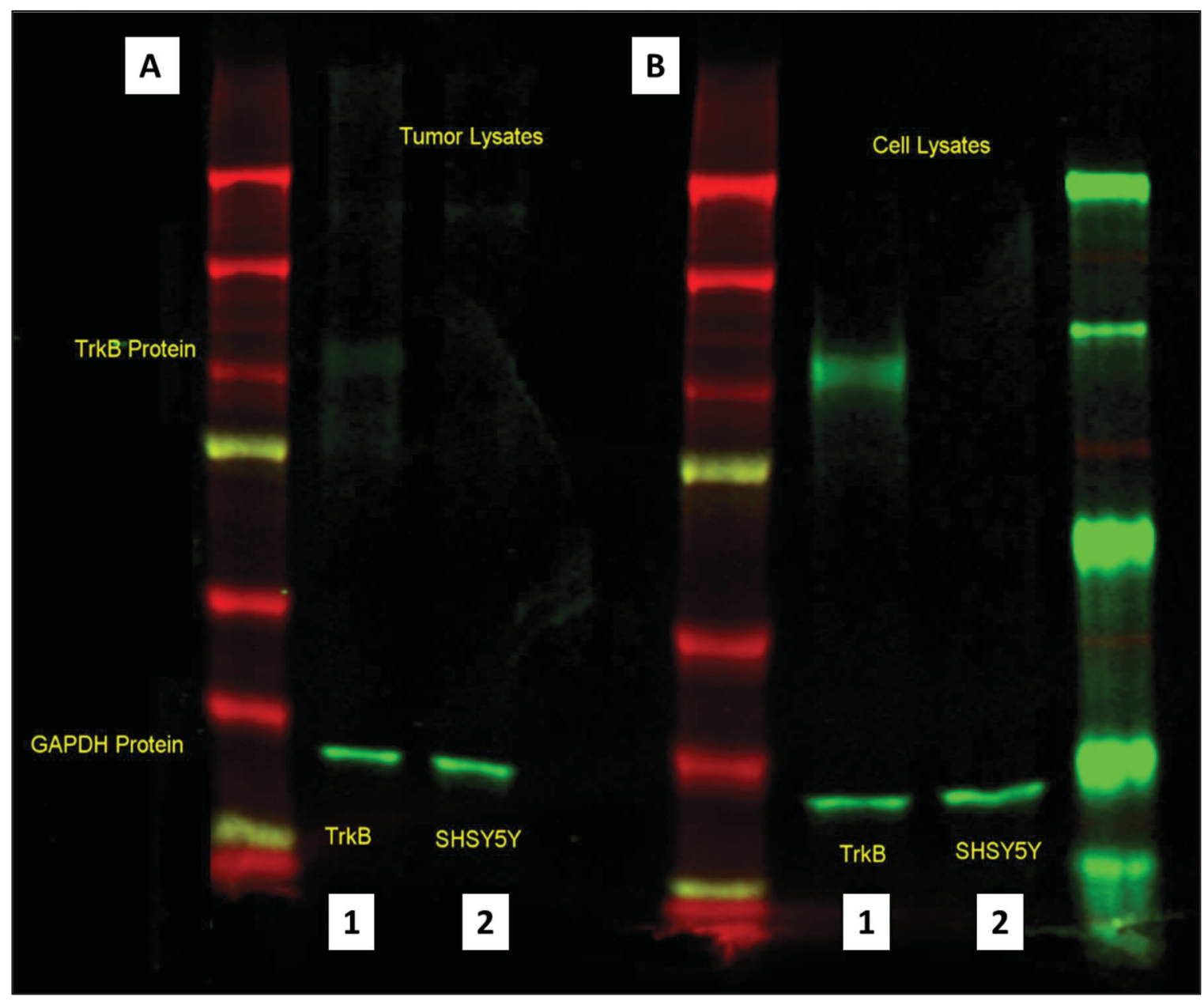

Figure 3-4. TrkB protein as detected by Western blot analysis of tumor and cell lysates.

The primary antibody, TrkB (80E3) Rabbit mAb was used to detect levels of TrkB protein, with the secondary antibody, IRDye ${ }^{\circledR} 800 \mathrm{CW}$ Goat anti-Rabbit $\operatorname{IgG}(\mathrm{H}+\mathrm{L})$. GAPDH protein was used as the loading control for the experiment. A: Tumor lysates (1) the TrkB-positive and (2) the TrkB-negative. B: Cell lysates (1) the TrkB-positive and (2) the TrkB-negative. 
Table 3-3. ADME testing for radiosynthetic standard 2-(1-(6,7-dimethoxyquinazolin-4-yl)pyrrolidin-3-yl)- $N$-(4-isopropylphenyl)acetamide (3d).

\begin{tabular}{cc}
\hline \multicolumn{1}{c}{ Parameter } & Result \\
\hline Biomek Solubility & \\
Average Solubility $(\mu \mathrm{g} / \mathrm{mL})$ & $0.22 \pm 0.05$ \\
Solubility $(\%)$ & $0.5 \%$ \\
& \\
CACO-2 Permeability & $245.3 \pm 1.9$ \\
Average PAPP A/B (nm/s) & $145.6 \pm 2.7$ \\
Average PAPP B/A (nm/s) & 0.6 \\
Efflux Ratio & \\
& \\
Mouse Plasma Protein Binding $(\%)$ & $98.8 \pm 0.1 \%$ \\
& \\
Stability (microsomal; mouse) & $27 \pm 1.2$ \\
Half-life (min) & 126.55 \\
Clint (mL/min/kg)
\end{tabular}




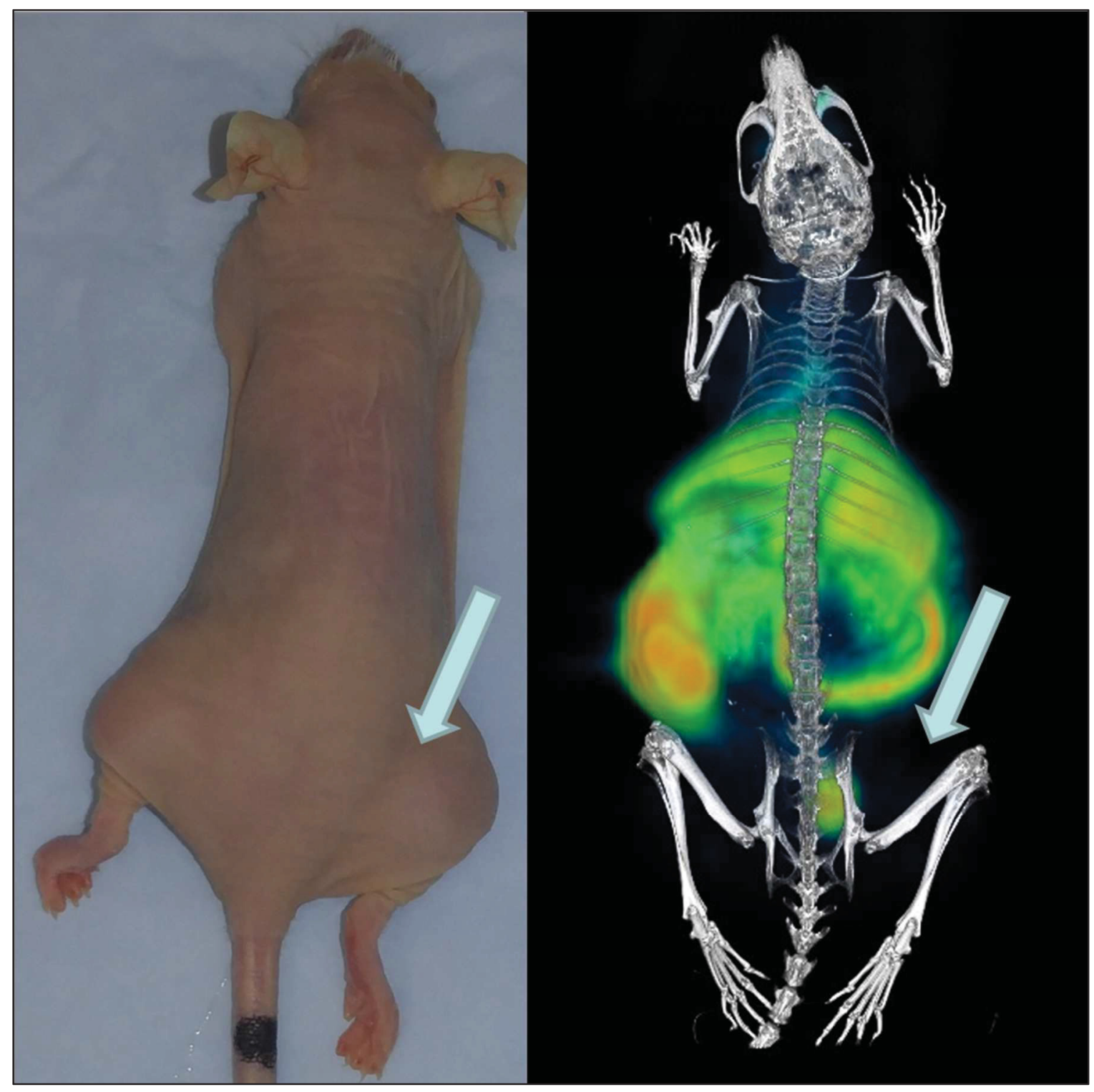

Figure 3-5. Small animal PET/CT image of the biodistribution of 3as.

Static co-registered PET-CT image (summed 0-30 min.) of an athymic nude ( $\mathrm{nu} / \mathrm{nu}$ ) mouse bearing bilateral TrkB+ (right flank, arrow) and TrkB- (left flank) tumors. Animal was injected r.o. with $200 \mu \mathrm{Ci}$ of radiotracer 3as and imaged under isoflurane $(1.5 \%)$ anesthesia. 


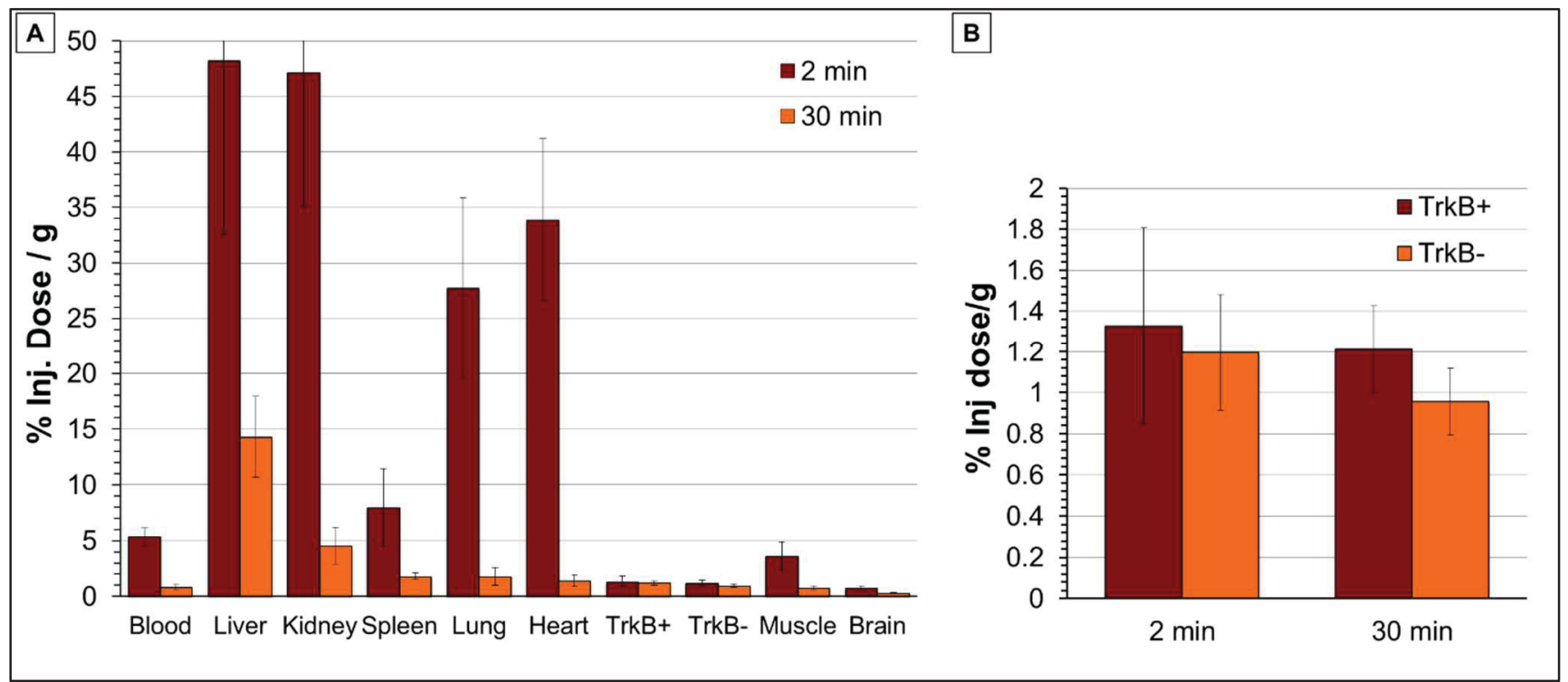

Figure 3-6. In vivo biodistribution of 3as.

A: In vivo biodistribution of radiotracer 3 as in athymic nude $(\mathrm{nu} / \mathrm{nu})$ mice bearing bilateral TrkB+ (right flank) and TrkB- (left flank) tumors. Animals were injected r.o. with 100-200 mCi of radiotracer 3as and sacrificed at 2 and $30 \mathrm{~min}$. post-injection. B: In vivo accumulation of radiotracer 3 as in TrkB + and TrkB- NB tumors in athymic nude (nu/nu) mice. 
inhibitor reported by Bernard-Gauthier has good brain penetration $\left(\mathrm{SUV}_{\max }=2.0\right)$ and is of interest for the imaging of neuronal disorders. ${ }^{120}$ Like radiotracer 3as, their compound was shown to have uptake in the lungs and is cleared through the hepatobiliary system with the radiotracer being metabolized at the 1-methylindole carbon which is the site of radionuclide addition.

The required time for the distribution of radiotracer 3as to achieve a signal that is visible on the subject image may be outside the parameters based on the effective halflife. This would indicate that a longer-lived radionuclide, such as ${ }^{18} \mathrm{~F}$, should be incorporated into a specific TrkB inhibitor. There is also the possibility that the ${ }^{11} \mathrm{C}$ radionuclide is being metabolized during first pass metabolism via O-demethylation in the liver. Compound 3d could be radiolabeled in the 6 position of the quinazoline structure (compound $\mathbf{3 I}$ and $\mathbf{3 0}$ ) which may avert the liver metabolism, making the quinazoline structure a key element for radiolabeling, which could improve delivery of the radiotracer to the tumor and thus improve imaging.

Although the aminoquinazoline was purported to be selective for $\operatorname{TrkB},{ }^{119}$ and the mice had developed tumors as designed, the TrkB tumor could not be visualized. The PET images were similar to most of the data reported for the 4-aza-2-oxindole scaffold ${ }^{120}$ compounds which are pan-Trk inhibitors suggesting that the aminoquinazolines are not intra-Trk selective.

From the aminoquinazoline PET images, there could be other kinases activated by the radiotracer. To verify the reported activity of the radiosynthetic standard, the half maximal inhibitory concentration ( $\left.\mathrm{IC}_{50}\right)$, Table $3-4$, and a kinase activity profile, Table 3-5, was contracted with Reaction Biology Corp. (Malvern, PA). The kinase profile data revealed other kinases to be a target of the aminoquinazoline compound causing secondary targets to be imaged that can confound the diagnostic data gathered. Significant probe development work will be required for image guided therapy for NB patients using a selective TrkB inhibitor to become a reality.

The racemate of compound 3as was used as the initial compound for radiosynthetic optimization, but isomerically pure compounds could be more potent. ${ }^{136}$ There is evidence that an individual isomer of ligands for many biological molecules may be more active, more selective, or even more toxic. ${ }^{136}$ The pharmaceutical industry has pursued pure isomers as both an improvement to patient care and the company's bottom line through patent extensions. The next step of the study was to determine if one isomer was more potent and selective than the other. The isomerically pure radiosynthetic standards were synthesized per the chemistry elucidated above, compound $\mathbf{3 j}$ and $\mathbf{3 m}$.

The $\mathrm{IC}_{50}$ of the $R$ and $S$ isomerically pure compounds $\mathbf{3} \mathbf{j}$ and $\mathbf{3} \mathbf{m}$ were performed by Reaction Biology Corp, Table 3-4. The data shows that $R$ isomer is more potent than the $S$ isomer for all Trk isoforms ( $152 \mathrm{nM}$ vs $1400 \mathrm{nM}$ respectively for TrkB), but not as potent as the racemic mixture at $71.5 \mathrm{nM}$. The racemate was a $51: 49$ as determined by HPLC (RegisPack, $250 \mathrm{~mm} \times 4.6 \mathrm{~mm}, 5 \mu \mathrm{m}$; 50/50 Hexane/Ethanol + 0.1\% DEA at 1.5 $\mathrm{mL} / \mathrm{min}$ ) with an optical rotation of $-9.06 \pm 2.6$ while the $R$ isomer had an optical rotation 
Table 3-4. IC50 against Trks for radiosynthetic standard 2-(1-(6,7-dimethoxyquinazolin-4-yl)pyrrolidin-3-yl)- $N$-(4-isopropylphenyl)acetamide (3d).

\begin{tabular}{lccc}
\hline Compound & \multicolumn{3}{c}{ Kinase $\mathbf{I C}_{\mathbf{5 0}}(\mathbf{n M})$} \\
\cline { 2 - 4 } & TrkA & TrkB & TrkC \\
\hline Racemate & 256 & 71.5 & 74 \\
$R$ isomer & 567 & 152 & 73.5 \\
$S$ isomer & 6540 & 1400 & 617 \\
\hline
\end{tabular}

Table 3-5. Abbreviated kinase profiling report for radiosynthetic standard 2-(1-(6,7-dimethoxyquinazolin-4-yl)pyrrolidin-3-yl)- $N$-(4-isopropylphenyl)acetamide (3d).

\begin{tabular}{lccl}
\hline Kinase & $\begin{array}{c}\text { Enzyme Activity } \\
\text { (\% relative to DMSO } \\
\text { controls) }\end{array}$ & $\begin{array}{c}\text { Control Compound } \\
\text { IC } \mathbf{5 0}(\mathbf{n M})\end{array}$ & Control Compound ID \\
\hline TrkB & 7.55 & 0.0914 & Staurosporine \\
TrkC & 15.12 & 0.19 & Staurosporine \\
RAF1 & 27.92 & 9.39 & GW5074 \\
TrkA & 32.84 & 1.51 & Staurosporine \\
EPHA7 & 33.25 & 49.2 & Staurosporine \\
FMS & 41.88 & 2.02 & Staurosporine \\
FLT3 & 52.69 & 2.19 & Staurosporine \\
HIPK4 & 59.60 & 446.0 & Staurosporine \\
c-Kit & 61.53 & 54.6 & Staurosporine \\
ARAF & 63.49 & 27.1 & GW5074 \\
IRAK1 & 67.24 & 27.8 & Staurosporine \\
DDR1 & 72.50 & 2.31 & Staurosporine \\
Aurora B & 76.43 & 9.24 & Staurosporine \\
PDGFRb & 77.93 & 2.92 & Staurosporine \\
ACK1 & 77.54 & 31.8 & Staurosporine \\
\hline
\end{tabular}

Tested against 369 kinases. Conditions: compound concentration of $1 \mu \mathrm{M}$. Control compound staurosporine was tested in 10-dose $\mathrm{IC}_{50}$ mode with 4-fold serial dilution starting at 20 or $100 \mu \mathrm{M}$. Reactions were carried out at $10 \mu \mathrm{M}$ ATP. 
of $-92.9 \pm 6.3$ and the $S$ isomer was $+94.6 \pm 7.5$ as expected. Although a reputable company was used for the $\mathrm{IC}_{50}$ determinations, the data of the racemate was collected on different days than the isomers, therefore, there may be possible inter-to intra-day variability affecting the data and causing the appearance of the isomers being worse than the racemate. The data for the isomers was collected on the same day and does clearly show that the $R$ isomer is more potent than the $S$ isomer. The results were used to select the $R$ isomer for repeat studies of the cell uptake, biodistribution at 30 minutes, and a kinetic image spanning one hour. The data indicated no change from the racemate in the PET images and biodistribution, (data not shown).

\section{Overall Conclusions}

Novel aminoquinazoline radiotracers were synthesized. The activity reported by Baindur (100 nM) was similar to the lab results obtained from the Reaction Biology Corp $(71.5 \mathrm{nM})$ for the TrkB $\mathrm{IC}_{50}$, but the isomerically pure data and the in vivo imaging data yielded confounding results. This may be due to the metabolism of the radiotracer, the preparation of the compound, or that the overall uptake time of these compounds is

greater than what can be imaged with ${ }^{11} \mathrm{C}$. Changing to another PET radionuclide like ${ }^{18} \mathrm{~F}$ could provide a superior uptake time without the meaningful loss of radioactivity. The aminoquinazoline pharmacophore is viable for radiolabeling with ${ }^{11} \mathrm{C}$ but an extensive SAR study is required to see if there is a more suitable compound to selectively target TrkB with higher affinity and improved solubility. The compounds radiolabeled in this study would also benefit from a targeted reformulation investigation that may address the solubility, lipophilicity, and stability issues noted during the experiments. Ultimately, this project has provided a glimpse into the possibility of designing a compound that could be used to provide image guided therapy for a group of patients that has a lot of room for improvement in the overall survival.

\section{Experimental Section}

\section{Synthesis of Radiosynthetic Standards and Precursors}

All the reagents and HPLC grade solvents were purchased from Fisher Scientific (Suwanee, GA). The reactions were monitored by TLC on pre-coated silica gel $60 \mathrm{~F}_{254}$ plates from Merck, KGaA (Darmstadt, Germany) and visualized using UV light with a frequency of $254 \mathrm{~nm}$. Reaction mixtures were purified using a Biotage FLASH (Charlotte, NC) column chromatography purification system and the silica cartridges were purchased from Biotage. HPLC methods were developed using an Agilent Technologies 1200 series system on a SB-C18 column at room temperature with a flow rate of $0.45 \mathrm{~mL} / \mathrm{min}$. The HPLC column was purchased from Agilent Technologies (Santa Clara, CA). Mass spectra were determined by a Waters Acquity UPLC-PDAELSD-MS. UPLC separations were performed using an Acquity UPLC $2.1 \times 50 \mathrm{~mm}$ BEH C18 column $(1.7 \mu \mathrm{m}$, Waters $)$ at $60^{\circ} \mathrm{C}$, and a $1.0 \mathrm{~mL} / \mathrm{min}$ flow rate. The PDA was 
set to acquire UV data from 200-400 nm throughout the run. UPLC gradient: solvent A (water with $0.1 \%$ formic acid) and solvent $\mathrm{B}$ (acetonitrile with $0.1 \%$ formic acid): $0-0.2$ minutes at 90-70\% A, 0.2-1.6 minutes at 70-5\% A (linear gradient), and 1.6-1.95 minutes at 5\% A. The optical rotation was determined using a Jasco P-1010 polarimeter from Jasco Inc. (Easton, MD); all samples were prepared in chloroform.

The 4-chloro-6,7-dimethoxyquinazoline is commercially available from Alfa Aesar (Tewksbury, MA), the 2-(1-(tertbutoxycarbonyl)-pyrrolidin3-yl)acetic acid was purchased from Asta Tech (Bristol, PA), the 4-isopropylaniline is commercially available from Acros Organics (New Jersey, USA), and the polystyrene (PS) carbodiimide beads are commercially available from Biotage (Charlotte, NC).

\section{General procedure for the synthesis of $N$-(4-isopropylphenyl)-2-(pyrrolidin- 3-yl)acetamide (3a-c)}

An appropriate sized round bottom flask was used to dissolve 2-(1-(tertbutoxycarbonyl)pyrrolidin-3-yl)acetic acid (1.5 eq) in anhydrous dichloromethane (DCM) and PS-carbodiimide beads (2 eq) were added and stirred for 15-60 minutes. 4isopropylaniline (1 eq) was then added to the mixture and the mixture was stirred overnight. The crude product was filtered and the resin was washed with DCM twice and the combined filtrate and washings were concentrated to yield the tert-butyl 3-(2-((4isopropylphenyl)-amino)-2-oxoethyl)pyrrolidine-1-carboxylate. The crude product was then dissolved in $3 \mathrm{M} \mathrm{HCl} / \mathrm{MeOH}$ solution and stirred at room temperature for 1 hour. Completion of the reaction was determined by UPLC-MS and/or TLC chromatography. The product was concentrated under reduced pressure to obtain the crude product as the $\mathrm{HCl}$ salt in sufficient purity for the next step.

N-(4-isopropylphenyl)-2-(pyrrolidin-3-yl)acetamide (3a). Using the above general procedure, 2-(1-(tert-butoxycarbonyl)pyrrolidin-3-yl)acetic acid $(2.04 \mathrm{~g}, 8.88 \mathrm{mmol})$ in DCM (100 mL) with PS-carbodiimide beads $(9.17 \mathrm{~g}, 11.8 \mathrm{mmol})$ and 4-isopropylaniline $(0.81 \mathrm{~mL}, 5.92 \mathrm{mmol})$ were used to synthesize tert-butyl 3-(2-((4-isopropylphenyl)amino)-2-oxoethyl)pyrrolidine-1-carboxylate. Next, 3M $\mathrm{HCl} / \mathrm{MeOH}(100 \mathrm{~mL})$ solution was used to yield compound $\mathbf{3 a}$ as a salt (99\%). MS(ESI), $\mathrm{m} / \mathrm{z}=247.3[\mathrm{M}+\mathrm{H}]^{+}$.

(R)- $N$-(4-isopropylphenyl)-2-(pyrrolidin-3-yl)acetamide (3b). Using the above general procedure, $(R)$-2-(1-(tert-butoxycarbonyl)pyrrolidin-3-yl)acetic acid (0.5 mg, 2.2 $\mathrm{mmol})$ in DCM $(50 \mathrm{~mL})$ with PS-carbodiimide beads $(3.1 \mathrm{~g}, 4 \mathrm{mmol})$ and $4-$ isopropylaniline $(0.27 \mathrm{~mL}, 2 \mathrm{mmol})$ were used to synthesize $(R)$-tert-butyl 3-(2-((4-isopropylphenyl)amino)-2-oxoethyl)pyrrolidine-1-carboxylate. Next, 3M $\mathrm{HCl} / \mathrm{MeOH}(500 \mathrm{~mL})$ solution was used to yield compound $\mathbf{3 b}$ as a salt $(98 \%) . \mathrm{MS}(\mathrm{ESI})$, $\mathrm{m} / \mathrm{z}=247.23[\mathrm{M}+\mathrm{H}]^{+}$.

(S)-N-(4-isopropylphenyl)-2-(pyrrolidin-3-yl)acetamide (3c). Using the above general procedure, $(S)-2-(1-($ tert-butoxycarbonyl)pyrrolidin-3-yl)acetic acid $(0.5 \mathrm{mg}, 2.2 \mathrm{mmol})$ in DCM $(50 \mathrm{~mL})$ with PS-carbodiimide beads $(3.0 \mathrm{~g}, 3.9 \mathrm{mmol})$ and 4-isopropylaniline 
$(0.27 \mathrm{~mL}, 2 \mathrm{mmol})$ were used to synthesize (S)-tert-butyl

3-(2-((4-isopropylphenyl)amino)-2-oxoethyl)pyrrolidine-1-carboxylate. Next, 3M

$\mathrm{HCl} / \mathrm{MeOH}(500 \mathrm{~mL})$ solution was used to yield compound $\mathbf{3 c}$ as a salt $(98 \%) . \mathrm{MS}(\mathrm{ESI})$, $\mathrm{m} / \mathrm{z}=247.23[\mathrm{M}+\mathrm{H}]^{+}$.

\section{General procedure for the coupling of the quinazoline and pyrrolidine (3d-o)}

The pyrrolidine (1 eq) was dissolved in anhydrous 2-propanol and the quinazoline (1 eq) was added followed by $N$,- $N$-diisopropylethylamine (DIEA) (2 eq) and stirred overnight at $100{ }^{\circ} \mathrm{C}$. The reaction mixture was cooled to room temperature, concentrated in vacuo, and purified by reverse phase chromatography with a gradient mobile phase of acetonitrile and water with $0.1 \%$ ammonium bicarbonate using a Biotage FLASH system with a $\mathrm{C} 18$ column cartridge. The desired compound was identified by UPLC-MS.

2-(1-(6,7-dimethoxyquinazolin-4-yl)pyrrolidin-3-yl)- $N$-(4-isopropylphenyl)acetamide (3d). Using the above general procedure, compound 3a (1 g, $4.1 \mathrm{mmol})$, 2-propanol (80 $\mathrm{mL})$, 4-chloro-6,7-dimethoxyquinazoline $(1.5 \mathrm{~g}, 6.5 \mathrm{mmol})$, and DIEA $(1.5 \mathrm{~mL})$ were used to synthesize compound $\mathbf{3 d}$ as a solid $(25 \%)$. MS(ESI), $\mathrm{m} / \mathrm{z}=435.40[\mathrm{M}+\mathrm{H}]^{+}$.

6,7-dimethoxy-4-(pyrrolidin-1-yl)quinazoline (3e). Using the above general procedure, pyrrolidine $(0.12 \mathrm{~mL}, 1.41 \mathrm{mmol})$, 2-propanol $(8 \mathrm{~mL})$,

4-chloro-6,7-dimethoxyquinazoline (316 mg, $1.41 \mathrm{mmol})$, and DIEA $(0.5 \mathrm{~mL})$ were used to synthesize compound $\mathbf{3 e}$ and purified by flash chromatography (35\%). MS(ESI), $\mathrm{m} / \mathrm{z}$ $=260.30[\mathrm{M}+\mathrm{H}]^{+}$.

6-(benzyloxy)-7-methoxy-4-(pyrrolidin-1-yl)quinazoline (3f). Using the above general procedure, pyrrolidine $(0.03 \mathrm{~mL}, 0.4 \mathrm{mmol}), 2$-propanol $(8 \mathrm{~mL})$,

6-(benzyloxy)-4-chloro-7-methoxyquinazoline (110 $\mathrm{mg}, 0.37 \mathrm{mmol})$, and DIEA $(0.5 \mathrm{~mL})$ were used to synthesize compound $\mathbf{3}$ f and purified by flash chromatography (39\%).

$\operatorname{MS}(\mathrm{ESI}), \mathrm{m} / \mathrm{z}=336.94[\mathrm{M}+\mathrm{H}]^{+}$.

7-(benzyloxy)-6-methoxy-4-(pyrrolidin-1-yl)quinazoline (3g). Using the above general procedure, pyrrolidine $(0.27 \mathrm{~mL}, 3.33 \mathrm{mmol})$, 2-propanol $(8 \mathrm{~mL})$, 7-(benzyloxy)-4-chloro-6-methoxyquinazoline $(1 \mathrm{~g}, 3.33 \mathrm{mmol})$ and DIEA $(0.5 \mathrm{~mL})$ were used to synthesize compound $\mathbf{3 g}$ and purified by flash chromatography $(33 \%)$. $\mathrm{MS}(\mathrm{ESI}), \mathrm{m} / \mathrm{z}=336.36[\mathrm{M}+\mathrm{H}]^{+}$.

7-(benzyloxy)-6-methoxy-4-(pyrrolidin-1-yl)quinazoline (3h). Using the above general procedure, pyrrolidine ( $0.4 \mathrm{~mL}, 0.5 \mathrm{mmol})$, 2-propanol $(12.5 \mathrm{~mL})$, 7-(benzyloxy)-6-methoxyquinazolin-4-yl 4-methylbenzenesulfonate (190 mg, $0.5 \mathrm{mmol}$ ), and DIEA $(0.2 \mathrm{~mL})$ were used to synthesize compound $\mathbf{3 h}$ and purified by flash chromatography (3\%). MS(ESI), $\mathrm{m} / \mathrm{z}=336.46[\mathrm{M}+\mathrm{H}]^{+}$.

2-(1-(7-(benzyloxy)-6-methoxyquinazolin-4-yl)pyrrolidin-3-yl)- $N$-(4-

isopropylphenyl)acetamide (3i). Using the above general procedure, compound 3a (411 $\mathrm{mg}, 1.67 \mathrm{mmol}$ ), 2-propanol (40 mL), 7-(benzyloxy)-4-chloro-6-methoxyquinazoline 
(502 $\mathrm{mg}, 1.67 \mathrm{mmol})$ and DIEA $(0.5 \mathrm{~mL})$ were used to synthesize compound $\mathbf{3 i}$ and purified by flash chromatography $(35 \%)$. MS(ESI), $\mathrm{m} / \mathrm{z}=511.5[\mathrm{M}+\mathrm{H}]^{+}$.

(R)-2-(1-(6,7-dimethoxyquinazolin-4-yl)pyrrolidin-3-yl)- $N$-(4isopropylphenyl)acetamide (3j). Using the above general procedure, compound $\mathbf{3 b}$ (160 mg, $0.65 \mathrm{mmol}), 2$-propanol (80 mL), 4-chloro-6,7-dimethoxyquinazoline (233 mg, $1.04 \mathrm{mmol})$, and DIEA $(1.5 \mathrm{~mL})$ were used to synthesize compound $\mathbf{3} \mathbf{j}$ and purified by flash chromatography (44\%). $\mathrm{MS}(\mathrm{ESI}), \mathrm{m} / \mathrm{z}=435.33[\mathrm{M}+\mathrm{H}]^{+}$. Optical rotation: $-92.88 \pm 6.28$.

(R)-2-(1-(7-(benzyloxy)-6-methoxyquinazolin-4-yl)pyrrolidin-3-yl)- $\mathrm{N}-(4-$ isopropylphenyl)acetamide (3k). Using the above general procedure, compound $\mathbf{3 b}$ (160 mg, $0.65 \mathrm{mmol}), 2$-propanol $(80 \mathrm{~mL})$, 7-(benzyloxy)-4-chloro-6-methoxyquinazoline (313 mg, $1.04 \mathrm{mmol})$, and DIEA (1.5 mL) were used to synthesize compound $\mathbf{3 k}$ and purified by flash chromatography (38\%). $\mathrm{MS}(\mathrm{ESI}), \mathrm{m} / \mathrm{z}=511.29[\mathrm{M}+\mathrm{H}]^{+}$.

(R)-2-(1-(6-(benzyloxy)-7-methoxyquinazolin-4-yl)pyrrolidin-3-yl)- $N$-(4isopropylphenyl)acetamide (3l). Using the above general procedure, compound $\mathbf{3 b}$ (160 mg, $0.65 \mathrm{mmol}), 2$-propanol $(80 \mathrm{~mL})$, 6-(benzyloxy)-4-chloro-7-methoxyquinazoline (313 mg, $1.04 \mathrm{mmol})$, and DIEA (1.5 mL) were used to synthesize compound $\mathbf{3 I}$ and purified by flash chromatography (38\%). $\mathrm{MS}(\mathrm{ESI}), \mathrm{m} / \mathrm{z}=511.38[\mathrm{M}+\mathrm{H}]^{+}$.

(S)-2-(1-(6,7-dimethoxyquinazolin-4-yl)pyrrolidin-3-yl)- $\mathrm{N}-(4-$

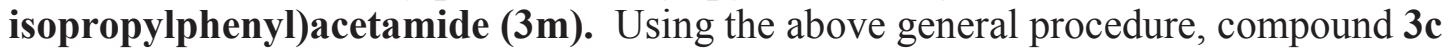
(150 mg, $0.61 \mathrm{mmol}), 2$-propanol (80 mL), 4-chloro-6,7-dimethoxyquinazoline (219 mg, $0.97 \mathrm{mmol}$ ), and DIEA were used to synthesize compound $\mathbf{3 m}$ and purified by flash chromatography (47\%). MS(ESI), $\mathrm{m} / \mathrm{z}=435.42[\mathrm{M}+\mathrm{H}]^{+}$. Optical rotation: $94.6 \pm 7.5$.

(S)-2-(1-(7-(benzyloxy)-6-methoxyquinazolin-4-yl)pyrrolidin-3-yl)- $\mathrm{N}$-(4isopropylphenyl)acetamide (3n). Using the above general procedure, compound 3c (150 mg, $0.61 \mathrm{mmol}), 2$-propanol (80 mL), 7-(benzyloxy)-4-chloro-6-methoxyquinazoline (293 mg, $0.97 \mathrm{mmol}$ ) and DIEA (1.5 mL) were used to synthesize compound $\mathbf{3 n}$ and purified by flash chromatography $(40 \%)$. $\mathrm{MS}(\mathrm{ESI}), \mathrm{m} / \mathrm{z}=511.38[\mathrm{M}+\mathrm{H}]^{+}$.

(S)-2-(1-(6-(benzyloxy)-7-methoxyquinazolin-4-yl)pyrrolidin-3-yl)- $\mathrm{N}-(4-$ isopropylphenyl)acetamide (3o). Using the above general procedure, compound 3c (150 mg, $0.61 \mathrm{mmol}), 2$-propanol (80 mL), 6-(benzyloxy)-4-chloro-7-methoxyquinazoline (293 $\mathrm{mg}, 0.97 \mathrm{mmol})$, and DIEA were used to synthesize compound 30 and purified by flash chromatography (40\%). MS(ESI), $\mathrm{m} / \mathrm{z}=511.29[\mathrm{M}+\mathrm{H}]^{+}$. 


\section{General procedure for the coupling of the quinazoline and pyrrolidine using microwave synthetic technology (3p-u)}

In a microwave tube with a stir bar, the pyrrolidine ( 1 eq), the quinazoline ( 1 eq) and DIEA were dissolved in solvent. The vessel was sealed and purged with nitrogen. Next the vessel was inserted into the microwave instrument and the reaction was initiated. The reaction mixture was cooled to room temperature, concentrated in vacuo, and purified by reverse phase chromatography with a gradient mobile phase of acetonitrile and water with $0.1 \%$ ammonium bicarbonate using a Biotage FLASH system with a $\mathrm{C} 18$ column cartridge. The desired compound was identified by UPLC-MS.

7-(benzyloxy)-6-methoxy-4-(pyrrolidin-1-yl)quinazoline (3p). Using the above general procedure, pyrrolidine $(1.0 \mathrm{~mL}, 12.2 \mathrm{mmol})$ and 7-(benzyloxy)-4-chloro-6-methoxyquinazoline $(1 \mathrm{~g}, 3.3 \mathrm{mmol})$ were heated at $170{ }^{\circ} \mathrm{C}$ for 5.6 minutes at normal intensity to synthesize compound $\mathbf{3 p}$ and purified by flash chromatography (41\%). MS(ESI), $\mathrm{m} / \mathrm{z}=336.2[\mathrm{M}+\mathrm{H}]^{+}$.

2-(1-(7-(benzyloxy)-6-methoxyquinazolin-4-yl)pyrrolidin-3-yl)- $\mathrm{N}-(4-$ isopropylphenyl)acetamide (3q). Using the above general procedure, compound 3a (87 $\mathrm{mg}, 0.35 \mathrm{mmol}$ ) and 7-(benzyloxy)-4-chloro-6-methoxyquinazoline (107 $\mathrm{mg}, 0.35 \mathrm{mmol}$ ) in DMF $(2 \mathrm{~mL})$ were heated at $170{ }^{\circ} \mathrm{C}$ for 5.6 minutes at normal intensity to synthesize compound $\mathbf{3 q}$ and purified by flash chromatography (41\%). MS(ESI), m/z = 511.4 $[\mathrm{M}+\mathrm{H}]^{+}$.

(R)-2-(1-(7-(benzyloxy)-6-methoxyquinazolin-4-yl)pyrrolidin-3-yl)- $\mathrm{N}$-(4isopropylphenyl)acetamide (3r). Using the above general procedure, compound $\mathbf{3 b}$ (106 mg, $0.43 \mathrm{mmol}$ ), 7-(benzyloxy)-4-chloro-6-methoxyquinazoline (130 mg, 0.43 mmol) and DIEA $(0.151 \mathrm{~mL}, 0.87 \mathrm{mmol})$ in DMF $(2 \mathrm{~mL})$ were heated at $170^{\circ} \mathrm{C}$ for 5.6 minutes at normal intensity to synthesize compound $\mathbf{3 r}$ and purified by flash chromatography (43\%). MS(ESI), m/z $=511.36[\mathrm{M}+\mathrm{H}]^{+}$.

(R)-2-(1-(6-(benzyloxy)-7-methoxyquinazolin-4-yl)pyrrolidin-3-yl)- $N$-(4isopropylphenyl)acetamide (3s). Using the above general procedure, compound $\mathbf{3 b}$ (168 mg, $0.68 \mathrm{mmol}$ ), 6-(benzyloxy)-4-chloro-7-methoxyquinazoline (205 mg, 0.68 mmol), and DIEA $(0.24 \mathrm{~mL}, 1.36 \mathrm{mmol})$ in DMF $(3 \mathrm{~mL})$ were heated at $170{ }^{\circ} \mathrm{C}$ for 5.6 minutes at normal intensity to synthesize compound $\mathbf{3 s}$ and purified by flash chromatography (43\%). MS(ESI), m/z $=511.36[\mathrm{M}+\mathrm{H}]^{+}$.

(R)-2-(1-(6,7-dimethoxyquinazolin-4-yl)pyrrolidin-3-yl)- $\mathrm{N}-(4-$ isopropylphenyl)acetamide (3t). Using the above general procedure, compound $\mathbf{3 b}$ (160 mg, $0.65 \mathrm{mmol}$ ), 4-chloro-6,7-dimethoxyquinazoline (146 mg, $0.65 \mathrm{mmol}$ ) and DIEA $(0.23 \mathrm{~mL}, 1.3 \mathrm{mmol})$ in DMF $(3 \mathrm{~mL})$ were heated at $170{ }^{\circ} \mathrm{C}$ for 5.6 minutes at normal intensity to synthesize compound $3 \mathrm{t}$ and purified by flash chromatography $(43 \%)$. $\mathrm{MS}(\mathrm{ESI}), \mathrm{m} / \mathrm{z}=435.31[\mathrm{M}+\mathrm{H}]^{+}$. 
2-(1-(6,7-dimethoxyquinazolin-4-yl)pyrrolidin-3-yl)- $N$-(4-isopropylphenyl)acetamide (3u). Using the above general procedure, compound 3a (170 $\mathrm{mg}, 0.69 \mathrm{mmol})$, 4-chloro-6,7-dimethoxyquinazoline (250 mg, $1.1 \mathrm{mmol})$, and DIEA (0.24 mL, $1.4 \mathrm{mmol})$ in DMF $(3 \mathrm{~mL})$ were heated at $170{ }^{\circ} \mathrm{C}$ for 5.6 minutes at normal intensity to synthesize compound $3 \mathbf{u}$ and purified by flash chromatography (46\%). MS(ESI), $\mathrm{m} / \mathrm{z}=435.4$ $[\mathrm{M}+\mathrm{H}]^{+}$.

\section{zoline}

Synthetic options for demethylation of the 6 or 7 position of the aminoquina-

Synthesis of 2-(1-(6-hydroxy-7-methoxyquinazolin-4-yl)pyrrolidin-3-yl)- $\mathrm{N}$ (4-isopropylphenyl)acetamide (3x). Compound 3d (100 mg, $0.230 \mathrm{mmol}$ ) and sodium hydroxide (13.8 $\mathrm{mg}, 0.345 \mathrm{mmol})$ were put in a reaction vessel. The vessel was maintained under a nitrogen atmosphere. Anhydrous $N$-methyl-2-pyrrolidone (NMP) (2 $\mathrm{mL})$ was added to the reaction mixture followed by dodecane-1-thiol $(0.164 \mathrm{~mL}, 0.69$ mmol). The reaction mixture was stirred at $130{ }^{\circ} \mathrm{C}$ for 2 hours. The crude mixture was acidified using $1 \mathrm{~N} \mathrm{HCl}$ and diluted with EtOAc. The aqueous phase was extracted with EtOAc and the combined organic layers were washed with water and brine, dried over $\mathrm{MgSO}_{4}$ and concentrated in vacuo. Compound $\mathbf{3 x}$ was purified by flash chromatography $(49 \%)$.

Synthesis of 2-(1-(6-hydroxy-7-methoxyquinazolin-4-yl)pyrrolidin-3-yl)- $\mathrm{N}$ (4-isopropylphenyl)acetamide (3x). Compound 3d (100 mg, $0.230 \mathrm{mmol}$ ) was dissolved in methanesulfonic acid $(1.5 \mathrm{~mL}, 23 \mathrm{mmol})$ and heated at $200{ }^{\circ} \mathrm{C}$ for 10 minutes. The reaction mixture was allowed to cool to room temperature and then was treated with sodium bicarbonate solution and then extracted with EtOAc. TLC R $\mathrm{R}_{f}=0$. (89/11 DCM/methanol).

Synthesis of 2-(1-(6-hydroxy-7-methoxyquinazolin-4-yl)pyrrolidin-3-yl)- $N$ (4-isopropylphenyl)acetamide (3x). Compound 3d (108 mg, $0.249 \mathrm{mmol}$ ) was dissolved in $\mathrm{CHCl}_{3}(25 \mathrm{ml})$ and cooled to $0{ }^{\circ} \mathrm{C}$. Then tribromoborane $(0.836 \mathrm{ml}, 4.87$ mmol) was added drop wise under a nitrogen atmosphere and allowed to come to room temperature. The reaction was refluxed for 24 hours. The reaction mixture was allowed to cool to room temperature and then was treated with sodium bicarbonate solution and then extracted with methanol. TLC $\mathrm{R}_{f}=0$. $(89 / 11 \mathrm{DCM} /$ methanol $)$.

Synthesis of 7-methoxy-4-(pyrrolidin-1-yl)quinazolin-6-ol (3y). Compound 3e (50 $\mathrm{mg}, 0.19 \mathrm{mmol})$ was dissolved in $\mathrm{CHCl}_{3}(5 \mathrm{ml})$ and cooled to $0{ }^{\circ} \mathrm{C}$. Then tribromoborane $(0.65 \mathrm{ml}, 3.8 \mathrm{mmol})$ was added drop wise under a nitrogen atmosphere and allowed to come to room temperature. The reaction temperature was increased to $65^{\circ} \mathrm{C}$ for 60 minutes. The reaction mixture was allowed to cool to room temperature and then was treated with sodium bicarbonate solution and then extracted with methanol. TLC $\mathrm{R}_{f}=0$. (89/11 DCM/methanol). 


\section{General procedure for the synthesis of the benzyl protected 6 or 7 position aminoquinazoline (3z-am)}

Step 1: The hydroxy substituted methoxybenzoic acid (1 eq) was dissolved in DMF. Then potassium carbonate ( $5 \mathrm{eq})$ and benzyl bromide $(2.5 \mathrm{eq})$ were added to the reaction vessel. The reaction mixture was stirred overnight at room temperature. The reaction mixture was filtered, EtOAc was added and the solution was washed with brine, dried with $\mathrm{MgSO}_{4}$, and concentrated in vacuo. Purification by crystallization gave benzyl protected methoxybenzoate. Step 2: The benzyl protected methoxybenzoate (1 eq) from Step 1 was dissolved in DCM at $-10^{\circ} \mathrm{C}$ and acetic acid (35 eq) was slowly added followed by nitric acid (10 eq). The reaction mixture warmed to room temperature and then refluxed at $100{ }^{\circ} \mathrm{C}$ overnight. The completed reaction mixture was poured into ice, extracted with EtOAc, washed with brine, dried with $\mathrm{MgSO}_{4}$, filtered, and concentrated in vacuo. Step 3: The benzyl protected nitrobenzoate (1 eq) was dissolved in EtOAc and tin(II) chloride dihydrate (3.1 eq) was added. The reaction mixture was heated at $50{ }^{\circ} \mathrm{C}$ overnight. The reaction mixture was cooled, filtered through celite, washed with $10 \%$ $\mathrm{NaHCO}_{3}$, extracted with EtOAc, dried with $\mathrm{MgSO}_{4}$, and concentrated in vacuo. Step 4: The benzyl protected amino methoxybenzoate (1 eq) was dissolved in formamide followed by ammonium formate $(1.5 \mathrm{eq})$. The reaction mixture was heated at $150{ }^{\circ} \mathrm{C}$ for 12 hours. The reaction mixture was cooled to room temperature, poured into water, and filtered, yielding the quinazolinone. Step 5: The quinazolinone (1 eq), thionyl chloride (19 eq), and 5 drops of DMF were added to toluene and refluxed for 4 hours. The reaction mixture cooled to room temperature and concentrated in vacuo yielding the halogenated quinazoline as a solid.

benzyl 3-(benzyloxy)-4-methoxybenzoate (3z). Using Step 1 of the above general procedure, isovanillic acid $(2.5 \mathrm{~g}, 15 \mathrm{mmol})$, potassium carbonate $(10.3 \mathrm{~g}, 74.3 \mathrm{mmol})$, and benzyl bromide $(4.4 \mathrm{~mL}, 37 \mathrm{mmol})$ in DMF $(130 \mathrm{~mL})$ were used to synthesize compound $\mathbf{3 z}$ as a solid (68\%). MS(ESI), $\mathrm{m} / \mathrm{z}=349.22[\mathrm{M}+\mathrm{H}]^{+}$.

benzyl 4-(benzyloxy)-3-methoxybenzoate (3aa). Using Step 1 of the above general procedure, vanillic acid $(2.5 \mathrm{~g}, 15 \mathrm{mmol})$, potassium carbonate $(10.3 \mathrm{~g}, 74.3 \mathrm{mmol})$, and benzyl bromide $(4.4 \mathrm{~mL}, 37 \mathrm{mmol})$ in DMF $(130 \mathrm{~mL})$ were used to synthesize compound 3aa as a solid (70\%). MS(ESI), $\mathrm{m} / \mathrm{z}=349.23[\mathrm{M}+\mathrm{H}]^{+}$.

benzyl 4-(benzyloxy)-3-methoxybenzoate (3aa). Using Step 1 of the above general procedure, vanillic acid $(100 \mathrm{mg}, 0.6 \mathrm{mmol})$, potassium carbonate $(410 \mathrm{mg}, 6.8 \mathrm{mmol})$, and benzyl bromide $(0.35 \mathrm{~mL}, 37 \mathrm{mmol})$ in DMF $(2 \mathrm{~mL})$ were heated in a microwave reactor at $95{ }^{\circ} \mathrm{C}$ for 5.6 minutes at normal intensity to synthesize compound 3aa as a solid (51\%). MS(ESI), $\mathrm{m} / \mathrm{z}=349.32[\mathrm{M}+\mathrm{H}]^{+}$.

benzyl 5-(benzyloxy)-4-methoxy-2-nitrobenzoate (3ac). Using Step 2 of the above general procedure, compound $\mathbf{3 z}(3 \mathrm{~g}, 8.6 \mathrm{mmol})$, acetic acid $(17.3 \mathrm{~mL}, 301 \mathrm{mmol})$, and nitric acid $(3.9 \mathrm{~mL}, 86 \mathrm{mmol})$ in DCM $(17 \mathrm{~mL})$ were used to synthesize compound 3ac as an oil $(89 \%)$. MS(ESI), $\mathrm{m} / \mathrm{z}=394.08[\mathrm{M}+\mathrm{H}]^{+}$. 
benzyl 4-(benzyloxy)-5-methoxy-2-nitrobenzoate (3ad). Using Step 2 of the above general procedure, compound 3aa $(3 \mathrm{~g}, 8.6 \mathrm{mmol})$, acetic acid $(27.1 \mathrm{~mL}, 474 \mathrm{mmol})$, and nitric acid $(6.1 \mathrm{~mL}, 136 \mathrm{mmol})$ in DCM $(28 \mathrm{~mL})$ were used to synthesize compound 3ad as a solid (78\%). MS(ESI), $\mathrm{m} / \mathrm{z}=394.49[\mathrm{M}+\mathrm{H}]^{+}$.

benzyl 2-amino-5-(benzyloxy)-4-methoxybenzoate (3ae). Using Step 3 of the above general procedure, compound 3ac $(3 \mathrm{~g}, 7.6 \mathrm{mmol})$ and tin(II) chloride dihydrate $(5.4 \mathrm{~g}$, $24 \mathrm{mmol})$ in EtOAc $(32 \mathrm{~mL})$ were used to synthesize compound 3ae as a brown solid $(23 \%)$. MS(ESI), $\mathrm{m} / \mathrm{z}=364.39[\mathrm{M}+\mathrm{H}]^{+}$.

benzyl 2-amino-4-(benzyloxy)-5-methoxybenzoate (3af). Using Step 3 of the above general procedure, compound 3ad $(2 \mathrm{~g}, 5.1 \mathrm{mmol})$ and tin(II) chloride dihydrate $(3.4 \mathrm{~g}$, $15 \mathrm{mmol})$ in EtOAc $(20 \mathrm{~mL})$ were used to synthesize compound 3af as a brown solid (44\%). $\mathrm{MS}(\mathrm{ESI}), \mathrm{m} / \mathrm{z}=364.14[\mathrm{M}+\mathrm{H}]^{+}$.

benzyl 2-amino-4-(benzyloxy)-5-methoxybenzoate (3af). Using Step 3 of the above general procedure, compound 3ad (400 mg, $1 \mathrm{mmol}$ ) and tin(II) chloride dihydrate (688 $\mathrm{mg}, 3.1 \mathrm{mmol})$ in EtOAc $(3.7 \mathrm{~mL})$ were heated in a microwave reactor at $120^{\circ} \mathrm{C}$ for 5.6 minutes at normal intensity to synthesize compound 3 af as a brown solid (48\%). $\mathrm{MS}(\mathrm{ESI}), \mathrm{m} / \mathrm{z}=364.32[\mathrm{M}+\mathrm{H}]^{+}$.

benzyl 2-amino-4-(benzyloxy)-5-methoxybenzoate (3af). Using a modified Step 3 of the above general procedure, compound 3ad (367.6 $\mathrm{mg}, 0.935 \mathrm{mmol})$ and iron $(52.2 \mathrm{mg}$, $0.935 \mathrm{mmol})$ in acetic acid $(5 \mathrm{~mL})$ were heated at $100{ }^{\circ} \mathrm{C}$ for 1 hour to synthesize compound 3af as a brown solid (50\%). MS(ESI), $\mathrm{m} / \mathrm{z}=364.3[\mathrm{M}+\mathrm{H}]^{+}$.

6-(benzyloxy)-7-methoxyquinazolin-4(3H)-one (3ai). Using Step 4 of the above general procedure, compound 3ae $(500 \mathrm{mg}, 1.38 \mathrm{mmol})$, formamide $(3.3 \mathrm{~mL}, 83 \mathrm{mmol})$, and ammonium formate $(130 \mathrm{mg}, 2.1 \mathrm{mmol})$ were used to synthesize compound 3ai as a solid $(73 \%)$. MS(ESI), $\mathrm{m} / \mathrm{z}=283.04[\mathrm{M}+\mathrm{H}]^{+}$.

7-(benzyloxy)-6-methoxyquinazolin-4(3H)-one (3ak). Using Step 4 of the above general procedure, compound 3af $(4.5 \mathrm{~g}, 12.4 \mathrm{mmol})$, formamide $(29.8 \mathrm{~mL}, 748 \mathrm{mmol})$, and ammonium formate $(1.17 \mathrm{~g}, 18.6 \mathrm{mmol})$ were used to synthesize compound 3ak as a solid (86\%). MS(ESI), $\mathrm{m} / \mathrm{z}=283.12[\mathrm{M}+\mathrm{H}]^{+}$.

7-(benzyloxy)-6-methoxyquinazolin-4(3H)-one (3ak). Using Step 4 of the above general procedure, compound 3 af $(750 \mathrm{mg}, 2.06 \mathrm{mmol})$, formamide $(2.5 \mathrm{~mL}, 63 \mathrm{mmol})$, and ammonium formate $(195 \mathrm{mg}, 3.1 \mathrm{mmol})$ were heated in a microwave reactor at 220 ${ }^{\circ} \mathrm{C}$ for 5.6 minutes at normal intensity to synthesize compound 3ak as a solid (68\%). $\mathrm{MS}(\mathrm{ESI}), \mathrm{m} / \mathrm{z}=282.8[\mathrm{M}+\mathrm{H}]^{+}$.

6-(benzyloxy)-4-chloro-7-methoxyquinazoline (3al). Using Step 5 of the above general procedure, compound 3ai $(250 \mathrm{mg}, 0.89 \mathrm{mmol})$, thionyl chloride $(1.27 \mathrm{~mL}, 17.3 \mathrm{mmol})$, and a catalytic amount of DMF in toluene $(25 \mathrm{~mL})$ were used to synthesize compound 3al as a solid (92\%). MS(ESI), $\mathrm{m} / \mathrm{z}=301.2[\mathrm{M}+\mathrm{H}]^{+}$. 
7-(benzyloxy)-4-chloro-6-methoxyquinazoline (3am). Using Step 5 of the above general procedure, compound 3ak $(360 \mathrm{mg}, 1.3 \mathrm{mmol})$, thionyl chloride $(1.8 \mathrm{~mL}, 25$ $\mathrm{mmol})$, and a catalytic amount of DMF in toluene $(25 \mathrm{~mL})$ were used to synthesize compound 3am as a solid (62\%). MS(ESI), $\mathrm{m} / \mathrm{z}=300.87[\mathrm{M}+\mathrm{H}]^{+}$.

\section{quinazoline}

Synthetic options for debenzylation of the 6 or 7 position of the 4-substituted

General procedure for the removal of the benzyl protecting group of the quinazoline (3an-ap). Using a 3-neck, round bottom flask, a catalytic amount of 10\% palladium on carbon was added and the flask was purged with nitrogen. EtOAc was then added and the flask was maintained under a nitrogen atmosphere continually fed through the flask neck. A balloon filled with hydrogen gas was attached to a stop-cock apparatus and affixed to the second flask neck. The substituted quinazoline (1 eq) was dissolved in EtOAc and added through the septum of the third neck. The nitrogen flow was stopped, the hydrogen purged the flask, and finally the vent needle was removed to maintain a positive pressure with hydrogen. The reaction mixture was stirred at room temperature for 96 hours. The reaction mixture was filtered and the concentrated in vacuo to yield the desired product.

7-methoxy-4-(pyrrolidin-1-yl)quinazolin-6-ol (3an). Using the above general procedure, compound $\mathbf{3 f}$ ( $40 \mathrm{mg}, 0.12 \mathrm{mmol}$ ), 10\% palladium on carbon (15.9 $\mathrm{mg}, 0.149$ $\mathrm{mmol})$ in EtOAc $(20 \mathrm{~mL})$ were used to synthesize compound 3an as a solid (4\%). $\mathrm{MS}(\mathrm{ESI}), \mathrm{m} / \mathrm{z}=246.38[\mathrm{M}+\mathrm{H}]^{+}$.

6-methoxy-4-(pyrrolidin-1-yl)quinazolin-7-ol (3ao). Using the above general procedure, compound $\mathbf{3 g}$ (40 mg, $0.12 \mathrm{mmol}$ ), 10\% palladium on carbon (15.9 $\mathrm{mg}, 0.149$ mmol) in EtOAc $(20 \mathrm{~mL})$ were used to synthesize compound 3ao as a solid (11\%). $\mathrm{MS}(\mathrm{ESI}), \mathrm{m} / \mathrm{z}=246.3[\mathrm{M}+\mathrm{H}]^{+}$.

2-(1-(7-hydroxy-6-methoxyquinazolin-4-yl)pyrrolidin-3-yl)- $\mathrm{N}-(4-$ isopropylphenyl)acetamide (3ap). Using the above general procedure, compound 3i ( $80 \mathrm{mg}, 0.16 \mathrm{mmol}), 10 \%$ palladium on carbon $(20.8 \mathrm{mg}, 0.196 \mathrm{mmol})$ in EtOAc $(25 \mathrm{~mL})$ were used to synthesize compound 3ap as a solid (2\%). MS(ESI), m/z $=421.4[\mathrm{M}+\mathrm{H}]^{+}$.

Synthesis of 2-(1-(7-hydroxy-6-methoxyquinazolin-4-yl)pyrrolidin-3-yl)-N-(4isopropylphenyl)acetamide (3aq). In a 5-mL microwave vessel with a stir bar, compound $3 \mathbf{i}$ ( $50 \mathrm{mg}, 0.1 \mathrm{mmol})$ was added followed by TFA $(2 \mathrm{~mL})$. The vessel was sealed and heated to $40{ }^{\circ} \mathrm{C}$ for 4 hours. The solution was diluted with acetonitrile and concentrated in vacuo yielding the desired deprotected quinazoline. The product was purified by flash chromatography as a solid (97\%). MS(ESI), m/z $=421.4[\mathrm{M}+\mathrm{H}]^{+}$. 


\section{Synthesis of Radiolabeled Tracers}

General procedure for radiosynthesis using ${ }^{11} \mathrm{C}$ (3ar-as). All the radiochemistry was performed on the PETChem Solutions (Chelsea, MI) radiochemistry unit, a semiautomatic ${ }^{11} \mathrm{C}$ methylation module using the "wet" method under an argon atmosphere. ${ }^{11} \mathrm{C}$ is produced by proton irradiation of nitrogen gas with $0.5 \%$ oxygen mixed with it in a $(\mathrm{p}, \alpha)$ nuclear reaction producing $\left[{ }^{11} \mathrm{C}\right]$ carbon dioxide. This reactive gas is bubbled through a mixture of LAH and THF to give the volatile $\left[{ }^{11} \mathrm{C}\right]$ methanol species. This is then passed through a solution of hydroiodic acid creating $\left[{ }^{11} \mathrm{C}\right]$ methyl iodide. The $\left[{ }^{11} \mathrm{C}\right]$ methyl iodide is either reacted with the desmethyl precursor dissolved in DMSO with potassium carbonate or passed over the silver triflate column to produce $\left[{ }^{11} \mathrm{C}\right]$ methyl triflate, which is then reacted with the desmethyl precursor in the same manner as $\left[{ }^{11} \mathrm{C}\right]$ methyl iodide.

The radiolabeled tracer was purified by HPLC using a SB-C18 column with a mobile phase of 55\% $50 \mathrm{mM}$ ammonium acetate and acetonitrile, $\mathrm{pH}$ adjusted to 3.8 at a flow of $4 \mathrm{~mL} / \mathrm{min}$. Removal of the solvents was achieved through filtration and adsorption on a tC18 Sep-Pak ${ }^{\circledR}$ and eluted with $1 \mathrm{~mL}$ of EtOH into a final solution of 50 $\mathrm{mM}$ ammonium acetate that is $\mathrm{pH}$ adjusted to 5.5. Total synthesis time is $30-33$ minutes. The key results are listed in Table 3-1.

6-methoxy-7-[ $\left.{ }^{11} \mathrm{C}\right]$ methoxy-4-(pyrrolidin-1-yl)quinazoline (3ar). Using the above general procedure, compound 3ao $(1 \mathrm{mg}, 0.004 \mathrm{mmol})$ and potassium carbonate $(3.75$ $\mathrm{mg}, 0.271 \mathrm{mmol})$ in DMF $(0.15 \mathrm{~mL})$ were reacted with $\left[{ }^{11} \mathrm{C}\right]$ methyl iodide at $85{ }^{\circ} \mathrm{C}$ for 10 minutes to yield the crude compound 3ar radiotracer $(15 \%)$.

\section{2-(1-(6-methoxy-7-[11C]methoxyquinazolin-4-yl)pyrrolidin-3-yl)- $N-(4-$} isopropylphenyl)acetamide (3as). Using the above general procedure, compound 3aq (1 mg, $0.002 \mathrm{mmol})$ and potassium carbonate $(3.75 \mathrm{mg}, 0.271 \mathrm{mmol})$ in DMSO $(0.15$ $\mathrm{mL})$ were reacted with $\left[{ }^{11} \mathrm{C}\right]$ methyl triflate at room temperature to yield the crude compound 3as radiotracer (26\%). 


\section{CHAPTER 4. OVERALL DISCUSSION OF RESEARCH PROJECTS}

\section{Introduction}

The work discussed in this dissertation involved the development of novel radiotracers through the incorporation of PET radionuclides that may provide a way to aid in the therapy planning of NB patients. NB is a childhood disease that has an overall survival rate that could be improved and the high-risk group is the most in need with a 5year event-free survival of $<50 \% .^{2-3}$

The design and development of new radiotracers for specific enzymes or receptors to identify disease states has been the topic of discussion in the molecular imaging community for years. The projects discussed in Chapters $\mathbf{2}$ and $\mathbf{3}$ provide a way to image a target that could be intentionally expressed to increase the activation of a prodrug at a desired location or to examine the entire body for the presence of a receptor that would indicate what therapy path the clinicians should pursue in that individual patient. The focus of both projects was to synthesize novel radiotracers that could help the therapy planning by targeting the $\mathrm{CE}$ and TrkB. This was a multi-disciplinary undertaking, using techniques from organic chemistry, nuclear medicine, radiochemistry, biochemistry, pharmacokinetic (PK), and veterinary sciences to design and test the radiotracers.

\section{Imaging Carboxylesterase Project}

The project discussed in Chapter 2 covered the design of novel radiotracers targeted to CE. The previous work by colleagues at SJCRH had an opportunity to improve their method of monitoring the upregulation of a specific CE through $\mathrm{NDEPT}^{19}$, 23, 25-26 at NB tumors. The current method was through immunohistochemical staining of the dissected tumor. The benefit of PET radiotracers is that it is administered at a subpharmacological $^{12}$ dose that allows clinicians to observe the physiologic process without the imaging agent perturbing the process or causing a therapeutic effect. These radiotracers are biologically active, so the biological process can be monitored in real time with PET imaging technology.

Analysis of the selective CE inhibitors led to a library of compounds that could be designed with a radionuclide as a substituent or substituted for the non-radioactive isotope. The radiosynthetic precursors and standards of the benzil and the phenyl pyridinyl-1,2-dione compounds were synthesized to validate the radiotracers through direct comparison using typical analytical equipment capable of detecting radiation.

Automated radiosynthetic technology was used to synthesize the radiotracers. The addition of microwave technology reduced the radiolabeling step from 45-minute reaction time to a 7-minute reaction time. The reduction in the radiosynthetic scheme is 
vital in PET radiotracer development. Every minute reduction of the synthesis scheme provides more time for the radiotracer to utilize the effective half-life.

The benefit of reduced reaction time did not overcome the inconsistencies encountered with the radiochemical yield. The variations may have been due to the solubility of the benzil compounds and is the reason why the phenyl pyridinyl-1,2-dione compounds were suggested as an alternative library. The greater solubility of the phenyl pyridinyl-1,2-dione ${ }^{103}$ compounds did not improve the radiochemical yield. The radiosynthetic scheme was adapted for the microfluidics flow chemistry system that reports to produce higher yields, higher purity, and faster reaction times using less precursor. The optimization did not improve the radiochemical yield beyond what was achieved on the PETChem automated radiosynthesis system. These combined data shifted the focus back to the design of the radiosynthetic standards. Colleagues in the CBT department continue to design selective CE inhibitors and a new library of compounds that has improved chemical properties could benefit from the radiochemistry development that this project has developed.

\section{Imaging Tropomyosin Receptor Kinase B Project}

The project discussed in Chapter $\mathbf{3}$ described the synthesis of the novel TrkB inhibitor radiotracers and the design of benzyl protected radiosynthetic precursors that allow for the selection for ${ }^{11} \mathrm{C}$ methylation. The exact mechanism of action of cell survival through the presence of TrkB is still under investigation. Current literature suggests that the presence of TrkB in NB tissue could be associated with an unfavorable prognosis and promotes resistance to chemotherapeutic agents through the intracellular signaling cascade. ${ }^{28,40,62,66,93,137-144}$ Since the Trks are selectively activated by a specific NT, it could be interpreted that selective radiotracers would be able to identify the presence of a specific Trk. The focus was to identify a selective TrkB inhibitor that could be used as a lead molecule for the development of the radiochemistry and evaluate its capacity as an imaging agent.

A new imaging radiotracer could also influence total health care costs. One key aspect of a successful radiotracer is that it could provide clinical information that is not available by alternative, cheaper methods. ${ }^{145}$ According to the NCI at the NIH website, a pathology report can take up to 10 days to get the preliminary report and much longer if additional information is desired as to the gene expression of the tissues in question. The cost of a needle, core, or large tissue biopsy carries a large burden on medical costs for both insurance companies and self-pay individuals. Each additional person that handles the sample escalates the cost of the procedure and each test performed on the tissue sample keeps adding to the total of the medical bills yielding a total cost of anywhere from \$5-10 thousand or greater. Compared to a single PET scan that would yield a total cost of approximately half ${ }^{146}$ and could have a turn-around time of less than 24 hours for the report. 
There is increasing interest in Trks and the role they play in cancer as seen with the development of pan-Trk selective inhibitors that are in Phase 1 clinical trials, and the development of PET radiolabeled pan-Trk inhibitors. ${ }^{120}$ The Trks have considerable structural similarity with a peptide sequence identity of approximately $50 \%$, but are only activated by distinct NTs. The current direction of Trk inhibition is through non-selective compounds. The design of selective inhibitors is challenging, but the potential benefit to patients could be worth the struggles.

The ideal goal of this project was to develop a TrkB selective radiotracer that could identify the presence and sites of upregulation of $\operatorname{TrkB}$, allowing for the modification of therapy to benefit patients. If a pan-Trk selective radiotracer is used, then there is no way to differentiate TrkA, a beneficial prognostic factor, from TrkB, a negative prognostic factor, thus neglecting to provide any guidance to the therapy of patients.

The 7,8-dihydroxyflavone and its derivatives or ANA-12 may be the path to pursue for selective TrkB radiotracers by targeting the extracellular domain. Although the 7,8-dihydroxyflavone is an agonist of the TrkB receptor, the sub-pharmacological dose should not cause a therapeutic effect. There is still a concern that even a subpharmacological dose could cause a cascade of the TrkB system and negatively affect the patient. Continued medicinal chemistry development is needed to identify a compound that could utilized the radiosynthesis optimizations of this body of work. The data reported here did not produce a radiotracer that could be used for patient care today, but the data is valuable and provides a glimpse as to the possibility of what could happen tomorrow.

This research allowed for the development of novel radiotracers that could be applied to the future design of Trk compounds, Figure 4-1. One area of improvement regarding the aminoquinazolines could be found in the active isomer of these racemic compounds. The individual isomers were tested for the $\mathrm{IC}_{50}$ against the Trks, see previous Table 3-4. Based on this information the cell uptake, biodistribution, and dynamic PET image were repeated with the $R$ isomer, yielding no significant difference from the racemic data.

\section{Final Thoughts}

NB is a challenging disease that has room for improvement in the overall survival of patients. Researchers from numerous scientific disciplines are collaborating to find new ways to diagnose and treat these patients. The projects discussed here cover two possible routes to achieve this goal in hopes to provide a benefit to a patient population in need. 


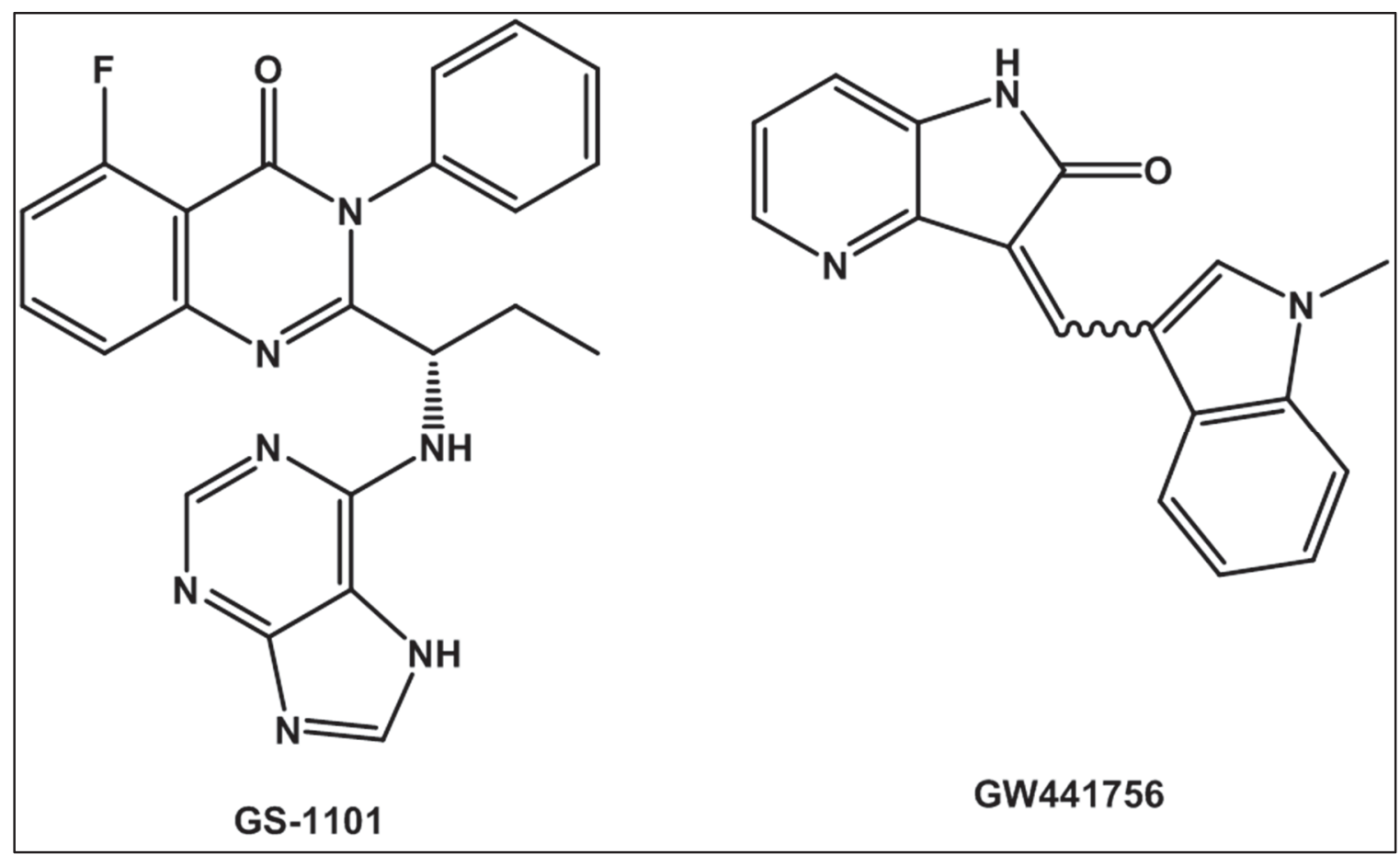

Figure 4-1. New Trk inhibitors under investigation that have radiotracer potential.

Sources: Yang, Q.; Modi, P.; Newcomb, T.; Queva, C.; Gandhi, V., Idelalisib: First-inClass PI3K Delta Inhibitor for the Treatment of Chronic Lymphocytic Leukemia, Small Lymphocytic Leukemia, and Follicular Lymphoma. Clin Cancer Res 2015, 21 (7), 153742. Bernard-Gauthier, V.; Aliaga, A.; Aliaga, A.; Boudjemeline, M.; Hopewell, R.; Kostikov, A.; Rosa-Neto, P.; Thiel, A.; Schirrmacher, R., Syntheses and evaluation of carbon-11- and fluorine-18-radiolabeled pan-tropomyosin receptor kinase (Trk) inhibitors: exploration of the 4-aza-2-oxindole scaffold as Trk PET imaging agents. ACS Chem Neurosci 2015, 6 (2), 260-76. 


\section{LIST OF REFERENCES}

1. Brodeur, G. M., Neuroblastoma: biological insights into a clinical enigma. Nat Rev Cancer 2003, 3 (3), 203-16.

2. Children's Neuroblastoma Cancer Foundation. Frequently asked questions for neuroblastoma. http://www.cncfhope.org/CNCF_FAQs. Accessed <11-6-2016>.

3. Maris, J. M., Recent advances in neuroblastoma. $N$ Engl J Med 2010, 362 (23), 2202-11.

4. $\quad P_{D Q}{ }^{\circledR}$ Pediatric Treatment Editorial Board. PDQ Neuroblastoma Treatment. http://www.cancer.gov/types/neuroblastoma/hp/neuroblastoma-treatment-pdq. Accessed <11/06/2016>. [PMID: 26389190].

5. Wagner, L. M.; Danks, M. K., New therapeutic targets for the treatment of highrisk neuroblastoma. $J$ Cell Biochem 2009, 107 (1), 46-57.

6. Di Paolo, D.; Yang, D.; Pastorino, F.; Emionite, L.; Cilli, M.; Daga, A.; Destafanis, E.; Di Fiore, A.; Piaggio, F.; Brignole, C.; Xu, X.; Liang, C.; Gibbons, J.; Ponzoni, M.; Perri, P., New therapeutic strategies in neuroblastoma: combined targeting of a novel tyrosine kinase inhibitor and liposomal siRNAs against ALK. Oncotarget 2015, 6 (30), 28774-89.

7. Matthay, K. K.; George, R. E.; Yu, A. L., Promising therapeutic targets in neuroblastoma. Clin Cancer Res 2012, 18 (10), 2740-53.

8. Yu, A. L.; Gilman, A. L.; Ozkaynak, M. F.; London, W. B.; Kreissman, S. G.; Chen, H. X.; Smith, M.; Anderson, B.; Villablanca, J. G.; Matthay, K. K.; Shimada, H.; Grupp, S. A.; Seeger, R.; Reynolds, C. P.; Buxton, A.; Reisfeld, R. A.; Gillies, S. D.; Cohn, S. L.; Maris, J. M.; Sondel, P. M.; Children's Oncology, G., Anti-GD2 antibody with GM-CSF, interleukin-2, and isotretinoin for neuroblastoma. $N$ Engl J Med 2010, 363 (14), 1324-34.

9. Kushner, B. H., Neuroblastoma: a disease requiring a multitude of imaging studies. J Nucl Med 2004, 45 (7), 1172-88.

10. Teitz, T.; Stanke, J. J.; Federico, S.; Bradley, C. L.; Brennan, R.; Zhang, J.; Johnson, M. D.; Sedlacik, J.; Inoue, M.; Zhang, Z. M.; Frase, S.; Rehg, J. E.; Hillenbrand, C. M.; Finkelstein, D.; Calabrese, C.; Dyer, M. A.; Lahti, J. M., Preclinical models for neuroblastoma: establishing a baseline for treatment. PLoS One 2011, 6 (4), e19133.

11. Pappo, A. Developmental Biology \& Solid Tumor Program. https://www.stjude.org/research/comprehensive-cancer- 
center/programs/developmental-biology-and-solid-tumor.html. Accessed $<12 / 12 / 2016>$.

12. Hooker, J. M., Modular strategies for PET imaging agents. Curr Opin Chem Biol 2010, 14 (1), 105-11.

13. Kowalsky, R. J.; Falen, S. W., Radiopharmaceutical Chemistry. In Radiopharmaceuticals in Nuclear Pharmacy and Nuclear Medicine, Second ed.; Landis, N. T., Ed. American Pharmacists Association: Washington, DC, 2004; p 825.

14. Cherry, S. R.; Sorenson, J. A.; Phelps, M. E., Physics in Nuclear Medicine. Third ed.; The Curtis Center: Philadelphia, Pennsylvania, 2003; p 523.

15. Alauddin, M. M., Positron emission tomography (PET) imaging with $\left({ }^{18}\right) \mathrm{F}$-based radiotracers. Am J Nucl Med Mol Imaging 2012, 2 (1), 55-76.

16. Moerlein, S. M., Radiopharmaceuticals for Positron Emission Tomography. In Radiopharmaceuticals in Nuclear Pharmacy and Nuclear Medicine, Landis, N. T., Ed. American Pharmacists Association: Washington, D.C., 2004; pp 337-379.

17. Pandey, M. K.; Byrne, J. F.; Jiang, H.; Packard, A. B.; DeGrado, T. R., Cyclotron production of $\left({ }^{68}\right) \mathrm{Ga}$ via the $\left({ }^{68}\right) \mathrm{Zn}(\mathrm{p}, \mathrm{n})\left({ }^{68}\right) \mathrm{Ga}$ reaction in aqueous solution. Am J Nucl Med Mol Imaging 2014, 4 (4), 303-10.

18. Cole, E. L.; Stewart, M. N.; Littich, R.; Hoareau, R.; Scott, P. J., Radiosyntheses using fluorine-18: the art and science of late stage fluorination. Curr Top Med Chem 2014, 14 (7), 875-900.

19. Danks, M. K.; Potter, P. M., Enzyme-prodrug systems: carboxylesterase/CPT-11. Methods Mol Med 2004, 90, 247-62.

20. Hatfield, M. J.; Umans, R. A.; Hyatt, J. L.; Edwards, C. C.; Wierdl, M.; Tsurkan, L.; Taylor, M. R.; Potter, P. M., Carboxylesterases: General detoxifying enzymes. Chem Biol Interact 2016, 259 (Pt B), 327-331.

21. Wierdl, M.; Tsurkan, L.; Hatfield, M. J.; Potter, P. M., Tumour-selective targeting of drug metabolizing enzymes to treat metastatic cancer. Br J Pharmacol 2016, 173 (19), 2811-8.

22. Pharmacia \& Upjohn Co, CAMPTOSAR- irinotecan hydrochloride injection, solution. Ed. Pfizer: New York, 1996.

23. Yoon, K. J.; Krull, E. J.; Morton, C. L.; Bornmann, W. G.; Lee, R. E.; Potter, P. M.; Danks, M. K., Activation of a camptothecin prodrug by specific 
carboxylesterases as predicted by quantitative structure-activity relationship and molecular docking studies. Mol Cancer Ther 2003, 2 (11), 1171-81.

24. Wadkins, R. M.; Hyatt, J. L.; Wei, X.; Yoon, K. J.; Wierdl, M.; Edwards, C. C.; Morton, C. L.; Obenauer, J. C.; Damodaran, K.; Beroza, P.; Danks, M. K.; Potter, P. M., Identification and characterization of novel benzil (diphenylethane-1,2dione) analogues as inhibitors of mammalian carboxylesterases. J Med Chem 2005, 48 (8), 2906-15.

25. Danks, M. K.; Yoon, K. J.; Bush, R. A.; Remack, J. S.; Wierdl, M.; Tsurkan, L.; Kim, S. U.; Garcia, E.; Metz, M. Z.; Najbauer, J.; Potter, P. M.; Aboody, K. S., Tumor-targeted enzyme/prodrug therapy mediates long-term disease-free survival of mice bearing disseminated neuroblastoma. Cancer Res 2007, 67 (1), 22-5.

26. Hicks, L. D.; Hyatt, J. L.; Moak, T.; Edwards, C. C.; Tsurkan, L.; Wierdl, M.; Ferreira, A. M.; Wadkins, R. M.; Potter, P. M., Analysis of the inhibition of mammalian carboxylesterases by novel fluorobenzoins and fluorobenzils. Bioorg Med Chem 2007, 15 (11), 3801-17.

27. Wang, T.; Yu, D.; Lamb, M. L., Trk kinase inhibitors as new treatments for cancer and pain. Expert Opin Ther Pat 2009, 19 (3), 305-19.

28. Brodeur, G. M.; Minturn, J. E.; Ho, R.; Simpson, A. M.; Iyer, R.; Varela, C. R.; Light, J. E.; Kolla, V.; Evans, A. E., Trk receptor expression and inhibition in neuroblastomas. Clin Cancer Res 2009, 15 (10), 3244-50.

29. Longo, F. M.; Massa, S. M., Small-molecule modulation of neurotrophin receptors: a strategy for the treatment of neurological disease. Nat Rev Drug Discov 2013, 12 (7), 507-25.

30. Vaishnavi, A.; Le, A. T.; Doebele, R. C., TRKing down an old oncogene in a new era of targeted therapy. Cancer Discov 2015, 5 (1), 25-34.

31. Eggert, A.; Grotzer, M. A.; Ikegaki, N.; Liu, X. G.; Evans, A. E.; Brodeur, G. M., Expression of neurotrophin receptor TrkA inhibits angiogenesis in neuroblastoma. Med Pediatr Oncol 2000, 35 (6), 569-72.

32. Eggert, A.; Grotzer, M. A.; Ikegaki, N.; Liu, X. G.; Evans, A. E.; Brodeur, G. M., Expression of the neurotrophin receptor TrkA down-regulates expression and function of angiogenic stimulators in SH-SY5Y neuroblastoma cells. Cancer Res 2002, 62 (6), 1802-8.

33. Iyer, R.; Evans, A. E.; Qi, X.; Ho, R.; Minturn, J. E.; Zhao, H.; Balamuth, N.; Maris, J. M.; Brodeur, G. M., Lestaurtinib enhances the antitumor efficacy of chemotherapy in murine xenograft models of neuroblastoma. Clin Cancer Res 2010, $16(5), 1478-85$. 
34. Smyth, L. A.; Collins, I., Measuring and interpreting the selectivity of protein kinase inhibitors. J Chem Biol 2009, 2 (3), 131-51.

35. Zhang, J.; Zheng, Y.; Wang, Y.; Tong, H., The studies on the correlation for gene expression of tyrosine-kinase receptors and vascular endothelial growth factor in human neuroblastomas. J Pediatr Hematol Oncol 2010, 32 (3), 180-4.

36. Yang, Q.; Modi, P.; Newcomb, T.; Queva, C.; Gandhi, V., Idelalisib: First-inClass PI3K Delta Inhibitor for the Treatment of Chronic Lymphocytic Leukemia, Small Lymphocytic Leukemia, and Follicular Lymphoma. Clin Cancer Res 2015, 21 (7), 1537-42.

37. Jansen, V. M.; Mayer, I. A.; Arteaga, C. L., Is There a Future for AKT Inhibitors in the Treatment of Cancer? Clin Cancer Res 2016, 22 (11), 2599-601.

38. Nitulescu, G. M.; Margina, D.; Juzenas, P.; Peng, Q.; Olaru, O. T.; Saloustros, E.; Fenga, C.; Spandidos, D.; Libra, M.; Tsatsakis, A. M., Akt inhibitors in cancer treatment: The long journey from drug discovery to clinical use (Review). Int $J$ Oncol 2016, 48 (3), 869-85.

39. Li, Z.; Oh, D. Y.; Nakamura, K.; Thiele, C. J., Perifosine-induced inhibition of Akt attenuates brain-derived neurotrophic factor/TrkB-induced chemoresistance in neuroblastoma in vivo. Cancer 2011, 117 (23), 5412-22.

40. Li, Z.; Thiele, C. J., Targeting Akt to increase the sensitivity of neuroblastoma to chemotherapy: lessons learned from the brain-derived neurotrophic factor/TrkB signal transduction pathway. Expert Opin Ther Targets 2007, 11 (12), 1611-21.

41. Sartelet, H.; Ohta, S.; Barrette, S.; Rougemont, A. L.; Brevet, M.; Regairaz, M.; Harvey, I.; Bernard, C.; Fabre, M.; Gaboury, L.; Oligny, L. L.; Bosq, J.; ValteauCouanet, D.; Vassal, G., High level of apoptosis and low AKT activation in mass screening as opposed to standard neuroblastoma. Histopathology 2010, 56 (5), 607-16.

42. Thiele, C. J.; Li, Z.; McKee, A. E., On Trk--the TrkB signal transduction pathway is an increasingly important target in cancer biology. Clin Cancer Res 2009, 15 (19), 5962-7.

43. Brodeur, G. M.; Nakagawara, A.; Yamashiro, D. J.; Ikegaki, N.; Liu, X. G.; Azar, C. G.; Lee, C. P.; Evans, A. E., Expression of TrkA, TrkB and TrkC in human neuroblastomas. $J$ Neurooncol 1997, 31 (1-2), 49-55.

44. Eggert, A.; Ikegaki, N.; Liu, X. G.; Brodeur, G. M., Prognostic and biological role of neurotrophin-receptor TrkA and TrkB in neuroblastoma. Klin Padiatr 2000, 212 (4), 200-5. 
45. Evangelopoulos, M. E.; Weis, J.; Kruttgen, A., Neurotrophin effects on neuroblastoma cells: correlation with trk and p75NTR expression and influence of Trk receptor bodies. J Neurooncol 2004, 66 (1-2), 101-10.

46. Hecht, M.; Schulte, J. H.; Eggert, A.; Wilting, J.; Schweigerer, L., The neurotrophin receptor TrkB cooperates with c-Met in enhancing neuroblastoma invasiveness. Carcinogenesis 2005, 26 (12), 2105-15.

47. Martens, L. K.; Kirschner, K. M.; Warnecke, C.; Scholz, H., Hypoxia-inducible factor-1 (HIF-1) is a transcriptional activator of the TrkB neurotrophin receptor gene. J Biol Chem 2007, 282 (19), 14379-88.

48. Nakagawara, A.; Brodeur, G. M., Role of neurotrophins and their receptors in human neuroblastomas: a primary culture study. Eur J Cancer 1997, 33 (12), 2050-3.

49. Schramm, A.; Schulte, J. H.; Astrahantseff, K.; Apostolov, O.; Limpt, V.; Sieverts, H.; Kuhfittig-Kulle, S.; Pfeiffer, P.; Versteeg, R.; Eggert, A., Biological effects of TrkA and TrkB receptor signaling in neuroblastoma. Cancer Lett 2005, 228 (1-2), 143-53.

50. Schulte, J. H.; Kuhfittig-Kulle, S.; Klein-Hitpass, L.; Schramm, A.; Biard, D. S.; Pfeiffer, P.; Eggert, A., Expression of the TrkA or TrkB receptor tyrosine kinase alters the double-strand break (DSB) repair capacity of SY5Y neuroblastoma cells. DNA Repair (Amst) 2008, 7 (10), 1757-64.

51. Siu, M. K.; Wong, O. G.; Cheung, A. N., TrkB as a therapeutic target for ovarian cancer. Expert Opin Ther Targets 2009, 13 (10), 1169-78.

52. Svensson, T.; Ryden, M.; Schilling, F. H.; Dominici, C.; Sehgal, R.; Ibanez, C. F.; Kogner, P., Coexpression of mRNA for the full-length neurotrophin receptor trk$\mathrm{C}$ and trk-A in favourable neuroblastoma. Eur J Cancer 1997, 33 (12), 2058-63.

53. Yamashiro, D. J.; Nakagawara, A.; Ikegaki, N.; Liu, X. G.; Brodeur, G. M., Expression of TrkC in favorable human neuroblastomas. Oncogene 1996, 12 (1), $37-41$.

54. McCarthy, C.; Walker, E., Tropomyosin receptor kinase inhibitors: a patent update 2009 - 2013. Expert Opin Ther Pat 2014, 24 (7), 731-44.

55. Undevia, S. D.; Vogelzang, N. J.; Mauer, A. M.; Janisch, L.; Mani, S.; Ratain, M. J., Phase I clinical trial of CEP-2563 dihydrochloride, a receptor tyrosine kinase inhibitor, in patients with refractory solid tumors. Invest New Drugs 2004, 22 (4), 449-58. 
56. Kirstein, M.; Farinas, I., Sensing life: regulation of sensory neuron survival by neurotrophins. Cell Mol Life Sci 2002, 59 (11), 1787-802.

57. Cheung, W. M.; Chu, P. W.; Kwong, Y. L., Effects of arsenic trioxide on the cellular proliferation, apoptosis and differentiation of human neuroblastoma cells. Cancer Lett 2007, 246 (1-2), 122-8.

58. Fryer, R. H.; Kaplan, D. R.; Kromer, L. F., Truncated trkB receptors on nonneuronal cells inhibit BDNF-induced neurite outgrowth in vitro. Exp Neurol 1997, 148 (2), 616-27.

59. Liu, Y.; Encinas, M.; Comella, J. X.; Aldea, M.; Gallego, C., Basic helix-loophelix proteins bind to TrkB and $\mathrm{p} 21$ (Cip1) promoters linking differentiation and cell cycle arrest in neuroblastoma cells. Mol Cell Biol 2004, 24 (7), 2662-72.

60. Pedraza, N.; Rafel, M.; Navarro, I.; Encinas, M.; Aldea, M.; Gallego, C., Mixed lineage kinase phosphorylates transcription factor E47 and inhibits TrkB expression to link neuronal death and survival pathways. J Biol Chem 2009, 284 (47), 32980-8.

61. Sakane, C.; Shidoji, Y., Reversible upregulation of tropomyosin-related kinase receptor B by geranylgeranoic acid in human neuroblastoma SH-SY5Y cells. $J$ Neurooncol 2011, 104 (3), 705-13.

62. Baj, G.; Tongiorgi, E., BDNF splice variants from the second promoter cluster support cell survival of differentiated neuroblastoma upon cytotoxic stress. J Cell Sci 2009, 122 (Pt 1), 36-43.

63. Cerchia, L.; D'Alessio, A.; Amabile, G.; Duconge, F.; Pestourie, C.; Tavitian, B.; Libri, D.; de Franciscis, V., An autocrine loop involving ret and glial cell-derived neurotrophic factor mediates retinoic acid-induced neuroblastoma cell differentiation. Mol Cancer Res 2006, 4 (7), 481-8.

64. Feng, X.; Jiang, H.; Baik, J. C.; Edgar, C.; Eide, F. F., BDNF dependence in neuroblastoma. $J$ Neurosci Res 2001, 64 (4), 355-63.

65. Girgert, R.; Wittrock, J.; Pfister, S.; Schweizer, P., Farnesyltransferase inhibitor FTI-277 prevents autocrine growth stimulation of neuroblastoma by BDNF. $J$ Cancer Res Clin Oncol 2003, 129 (4), 227-33.

66. Middlemas, D. S.; Kihl, B. K.; Zhou, J.; Zhu, X., Brain-derived neurotrophic factor promotes survival and chemoprotection of human neuroblastoma cells. $J$ Biol Chem 1999, 274 (23), 16451-60. 
67. Nakagawara, A.; Azar, C. G.; Scavarda, N. J.; Brodeur, G. M., Expression and function of TRK-B and BDNF in human neuroblastomas. Mol Cell Biol 1994, 14 (1), 759-67.

68. Thress, K.; Macintyre, T.; Wang, H.; Whitston, D.; Liu, Z. Y.; Hoffmann, E.; Wang, T.; Brown, J. L.; Webster, K.; Omer, C.; Zage, P. E.; Zeng, L.; ZweidlerMcKay, P. A., Identification and preclinical characterization of AZ-23, a novel, selective, and orally bioavailable inhibitor of the Trk kinase pathway. Mol Cancer Ther 2009, 8 (7), 1818-27.

69. Ulrich, R.; Stan, A. C.; Koch, A.; Beineke, A., Expression of brain-derived neurotrophic factor and tropomyosin-related kinase-B in a bovine jejunal nodular ganglioneuroblastoma. Vet Pathol 2008, 45 (3), 355-60.

70. Zaheer, A.; Zhong, W.; Lim, R., Expression of mRNAs of multiple growth factors and receptors by neuronal cell lines: detection with RT-PCR. Neurochem Res 1995, 20 (12), 1457-63.

71. Ho, R.; Eggert, A.; Hishiki, T.; Minturn, J. E.; Ikegaki, N.; Foster, P.; Camoratto, A. M.; Evans, A. E.; Brodeur, G. M., Resistance to chemotherapy mediated by TrkB in neuroblastomas. Cancer Res 2002, 62 (22), 6462-6.

72. Aoyama, M.; Asai, K.; Shishikura, T.; Kawamoto, T.; Miyachi, T.; Yokoi, T.; Togari, H.; Wada, Y.; Kato, T.; Nakagawara, A., Human neuroblastomas with unfavorable biologies express high levels of brain-derived neurotrophic factor mRNA and a variety of its variants. Cancer Lett 2001, 164 (1), 51-60.

73. Fung, W.; Hasan, M. Y.; Loh, A. H.; Chua, J. H.; Yong, M. H.; Knight, L.; Hwang, W. S.; Chan, M. Y.; Seow, W. T.; Jacobsen, A. S.; Chui, C. H., Gene expression of TRK neurotrophin receptors in advanced neuroblastomas in Singapore--a pilot study. Pediatr Hematol Oncol 2011, 28 (7), 571-8.

74. Weinreb, I.; Goldstein, D.; Irish, J.; Perez-Ordonez, B., Expression patterns of Trk-A, Trk-B, GRP78, and p75NRT in olfactory neuroblastoma. Hum Pathol 2009, 40 (9), 1330-5.

75. Eggert, A.; Grotzer, M. A.; Zhao, H.; Brodeur, G. M.; Evans, A. E., [Expression of the neurotrophin-receptor TrkB predicts outcome in nephroblastomas: results of a pilot-study]. Klin Padiatr 2001, 213 (4), 191-6.

76. Han, L.; Zhang, Z.; Qin, W.; Sun, W., Neurotrophic receptor TrkB: Is it a predictor of poor prognosis for carcinoma patients? Med Hypotheses 2007, 68 (2), 407-9. 
77. Lucarelli, E.; Kaplan, D.; Thiele, C. J., Activation of trk-A but not trk-B signal transduction pathway inhibits growth of neuroblastoma cells. Eur J Cancer 1997, 33 (12), 2068-70.

78. Nakamura, K.; Martin, K. C.; Jackson, J. K.; Beppu, K.; Woo, C. W.; Thiele, C. $\mathrm{J}$., Brain-derived neurotrophic factor activation of TrkB induces vascular endothelial growth factor expression via hypoxia-inducible factor-1alpha in neuroblastoma cells. Cancer Res 2006, 66 (8), 4249-55.

79. Saulnier Sholler, G. L.; Brard, L.; Straub, J.; Dorf, L.; Illeyne, S.; Koto, K.; Kalkunte, S.; Bosenberg, M.; Nishi, R., Nifurtimox induces apoptosis of neuroblastoma cells in vitro and in vivo. J Pediatr Hematol Oncol 2009, 31 (3), $187-93$.

80. Schulte, J. H.; Pentek, F.; Hartmann, W.; Schramm, A.; Friedrichs, N.; Ora, I.; Koster, J.; Versteeg, R.; Kirfel, J.; Buettner, R.; Eggert, A., The low-affinity neurotrophin receptor, $\mathrm{p} 75$, is upregulated in ganglioneuroblastoma/ganglioneuroma and reduces tumorigenicity of neuroblastoma cells in vivo. Int $J$ Cancer 2009, 124 (10), 2488-94.

81. Jaboin, J.; Kim, C. J.; Kaplan, D. R.; Thiele, C. J., Brain-derived neurotrophic factor activation of TrkB protects neuroblastoma cells from chemotherapyinduced apoptosis via phosphatidylinositol 3'-kinase pathway. Cancer Res 2002, $62(22), 6756-63$.

82. Lavoie, J. F.; Lesauteur, L.; Kohn, J.; Wong, J.; Furtoss, O.; Thiele, C. J.; Miller, F. D.; Kaplan, D. R., TrkA induces apoptosis of neuroblastoma cells and does so via a p53-dependent mechanism. J Biol Chem 2005, 280 (32), 29199-207.

83. D'Angelo, B.; Benedetti, E.; Di Loreto, S.; Cristiano, L.; Laurenti, G.; Ceru, M. P.; Cimini, A., Signal transduction pathways involved in PPARbeta/delta-induced neuronal differentiation. $J$ Cell Physiol 2011, 226 (8), 2170-80.

84. Ho, R.; Minturn, J. E.; Simpson, A. M.; Iyer, R.; Light, J. E.; Evans, A. E.; Brodeur, G. M., The effect of P75 on Trk receptors in neuroblastomas. Cancer Lett 2011, 305 (1), 76-85.

85. Matsumoto, K.; Wada, R. K.; Yamashiro, J. M.; Kaplan, D. R.; Thiele, C. J., Expression of brain-derived neurotrophic factor and p145TrkB affects survival, differentiation, and invasiveness of human neuroblastoma cells. Cancer Res 1995, $55(8), 1798-806$.

86. Sitek, B.; Apostolov, O.; Stuhler, K.; Pfeiffer, K.; Meyer, H. E.; Eggert, A.; Schramm, A., Identification of dynamic proteome changes upon ligand activation of Trk-receptors using two-dimensional fluorescence difference gel electrophoresis and mass spectrometry. Mol Cell Proteomics 2005, 4 (3), 291-9. 
87. Cimmino, F.; Schulte, J. H.; Zollo, M.; Koster, J.; Versteeg, R.; Iolascon, A.; Eggert, A.; Schramm, A., Galectin-1 is a major effector of TrkB-mediated neuroblastoma aggressiveness. Oncogene 2009, 28 (19), 2015-23.

88. Camby, I.; Le Mercier, M.; Lefranc, F.; Kiss, R., Galectin-1: a small protein with major functions. Glycobiology 2006, 16 (11), 137R-157R.

89. Cazorla, M.; Premont, J.; Mann, A.; Girard, N.; Kellendonk, C.; Rognan, D., Identification of a low-molecular weight TrkB antagonist with anxiolytic and antidepressant activity in mice. J Clin Invest 2011, 121 (5), 1846-57.

90. Norris, R. E.; Minturn, J. E.; Brodeur, G. M.; Maris, J. M.; Adamson, P. C., Preclinical evaluation of lestaurtinib (CEP-701) in combination with retinoids for neuroblastoma. Cancer Chemother Pharmacol 2011, 68 (6), 1469-75.

91. Li, Z.; Zhang, J.; Liu, Z.; Woo, C. W.; Thiele, C. J., Downregulation of Bim by brain-derived neurotrophic factor activation of TrkB protects neuroblastoma cells from paclitaxel but not etoposide or cisplatin-induced cell death. Cell Death Differ 2007, 14 (2), 318-26.

92. Zage, P. E.; Graham, T. C.; Zeng, L.; Fang, W.; Pien, C.; Thress, K.; Omer, C.; Brown, J. L.; Zweidler-McKay, P. A., The selective Trk inhibitor AZ623 inhibits brain-derived neurotrophic factor-mediated neuroblastoma cell proliferation and signaling and is synergistic with topotecan. Cancer 2011, 117 (6), 1321-91.

93. Middlemas, D. S.; Kihl, B. K.; Moody, N. M., Brain derived neurotrophic factor protects human neuroblastoma cells from DNA damaging agents. J Neurooncol 1999, 45 (1), 27-36.

94. Jaboin, J.; Hong, A.; Kim, C. J.; Thiele, C. J., Cisplatin-induced cytotoxicity is blocked by brain-derived neurotrophic factor activation of TrkB signal transduction path in neuroblastoma. Cancer Lett 2003, 193 (1), 109-14.

95. Minturn, J. E.; Evans, A. E.; Villablanca, J. G.; Yanik, G. A.; Park, J. R.; Shusterman, S.; Groshen, S.; Hellriegel, E. T.; Bensen-Kennedy, D.; Matthay, K. K.; Brodeur, G. M.; Maris, J. M., Phase I trial of lestaurtinib for children with refractory neuroblastoma: a new approaches to neuroblastoma therapy consortium study. Cancer Chemother Pharmacol 2011, 68 (4), 1057-65.

96. American Cancer Society, Neuroblastoma. http://www.cancer.org/cancer/neuroblastoma/detailedguide/index. Ed. 2014; p 47. Accessed $<12 / 12 / 2016>$. 
97. Akbari Sari, A.; Ravaghi, H.; Mobinizadeh, M.; Sarvari, S., The Cost-Utility Analysis of PET-Scan in Diagnosis and Treatment of Non-Small Cell Lung Carcinoma in Iran. Iran J Radiol 2013, 10 (2), 61-7.

98. Gambhir, S. S., Molecular imaging of cancer with positron emission tomography. Nat Rev Cancer 2002, 2 (9), 683-93.

99. Lehouritis, P.; Stanton, M.; McCarthy, F. O.; Jeavons, M.; Tangney, M., Activation of multiple chemotherapeutic prodrugs by the natural enzymolome of tumour-localised probiotic bacteria. J Control Release 2016, 222, 9-17.

100. Connors, T. A.; Knox, R. J., Prodrugs in cancer chemotherapy. Stem Cells 1995, $13(5), 501-11$.

101. Hyatt, J. L.; Wadkins, R. M.; Tsurkan, L.; Hicks, L. D.; Hatfield, M. J.; Edwards, C. C.; Ross, C. R., 2nd; Cantalupo, S. A.; Crundwell, G.; Danks, M. K.; Guy, R. K.; Potter, P. M., Planarity and constraint of the carbonyl groups in 1,2-diones are determinants for selective inhibition of human carboxylesterase 1. J Med Chem 2007, 50 (23), 5727-34.

102. Ross, M. K.; Borazjani, A., Enzymatic activity of human carboxylesterases. Curr Protoc Toxicol 2007, Chapter 4, Unit 424.

103. Young, B. M.; Hyatt, J. L.; Bouck, D. C.; Chen, T.; Hanumesh, P.; Price, J.; Boyd, V. A.; Potter, P. M.; Webb, T. R., Structure-activity relationships of substituted 1-pyridyl-2-phenyl-1,2-ethanediones: potent, selective carboxylesterase inhibitors. J Med Chem 2010, 53 (24), 8709-15.

104. Stone-Elander, S.; Elander, N.; Thorell, J. O.; Fredriksson, A., Microwaving in F18 chemistry: quirks and tweaks. Ernst Schering Res Found Workshop 2007, (62), 243-69.

105. Lidstrom, P.; Tierney, J.; Wathey, B.; Westman, J., Microwave assisted organic synthesis--a review. Tetrahedron 2001, 57, 9225-9283.

106. Mandap, K. S.; Ido, T.; Kiyono, Y.; Kobayashi, M.; Lohith, T. G.; Mori, T.; Kasamatsu, S.; Kudo, T.; Okazawa, H.; Fujibayashi, Y., Development of microwave-based automated nucleophilic $\left[\left({ }^{18}\right) \mathrm{F}\right]$ fluorination system and its application to the production of $\left[\left({ }^{18}\right)\right.$ F]flumazenil. Nucl Med Biol 2009, 36 (4), 403-9.

107. Snyder, S. E.; Kume, A.; Jung, Y. W.; Connor, S. E.; Sherman, P. S.; Albin, R. L.; Wieland, D. M.; Kilbourn, M. R., Synthesis of carbon-11-, fluorine-18-, and iodine-125-labeled GABAA-gated chloride ion channel blockers: substituted 5tert-butyl-2-phenyl-1,3-dithianes and -dithiane oxides. J Med Chem 1995, 38 (14), 2663-71. 
108. Haka, M. S.; Kilbourn, M. R.; Watkins, L.; Toorongian, S. A., Aryltrimethylammonium trifluoromethanesulfonates as precursors to aryl $\left[{ }^{18} \mathrm{~F}\right]$ fluorides: improved synthesis of $\left[{ }^{18} \mathrm{~F}\right] \mathrm{gbr}-13119$. Journal of Labelled Compounds and Radiopharmaceuticals 1989, 27 (7), 823-833.

109. Khalil, M. A.; Hrabeta, J.; Cipro, S.; Stiborova, M.; Vicha, A.; Eckschlager, T., Neuroblastoma stem cells - mechanisms of chemoresistance and histone deacetylase inhibitors. Neoplasma 2012, 59 (6), 737-46.

110. Vangipuram, S. D.; Buck, S. A.; Lyman, W. D., Wnt pathway activity confers chemoresistance to cancer stem-like cells in a neuroblastoma cell line. Tumour Biol 2012, 33 (6), 2173-83.

111. Ayers, D.; Mestdagh, P.; Van Maerken, T.; Vandesompele, J., Identification of miRNAs contributing to neuroblastoma chemoresistance. Comput Struct Biotechnol J 2015, 13, 307-19.

112. Buhagiar, A.; Ayers, D., Chemoresistance, cancer stem cells, and miRNA influences: the case for neuroblastoma. Anal Cell Pathol (Amst) 2015, 2015, 150634

113. Carta, A.; Chetcuti, R.; Ayers, D., An Introspective Update on the Influence of miRNAs in Breast Carcinoma and Neuroblastoma Chemoresistance. Genet Res Int 2014, 2014, 743050.

114. Kuo, Y. T.; Liu, Y. L.; Adebayo, B. O.; Shih, P. H.; Lee, W. H.; Wang, L. S.; Liao, Y. F.; Hsu, W. M.; Yeh, C. T.; Lin, C. M., JARID1B Expression Plays a Critical Role in Chemoresistance and Stem Cell-Like Phenotype of Neuroblastoma Cells. PLoS One 2015, 10 (5), e0125343.

115. Uren, R. T.; Turnley, A. M., Regulation of neurotrophin receptor (Trk) signaling: suppressor of cytokine signaling 2 (SOCS2) is a new player. Front Mol Neurosci 2014, 7, 39 .

116. Jang, S. W.; Liu, X.; Yepes, M.; Shepherd, K. R.; Miller, G. W.; Liu, Y.; Wilson, W. D.; Xiao, G.; Blanchi, B.; Sun, Y. E.; Ye, K., A selective TrkB agonist with potent neurotrophic activities by 7,8-dihydroxyflavone. Proc Natl Acad Sci U S A 2010, 107 (6), 2687-92.

117. Russo, M.; Misale, S.; Wei, G.; Siravegna, G.; Crisafulli, G.; Lazzari, L.; Corti, G.; Rospo, G.; Novara, L.; Mussolin, B.; Bartolini, A.; Cam, N.; Patel, R.; Yan, S.; Shoemaker, R.; Wild, R.; Di Nicolantonio, F.; Bianchi, A. S.; Li, G.; Siena, S.; Bardelli, A., Acquired Resistance to the TRK Inhibitor Entrectinib in Colorectal Cancer. Cancer Discov 2016, 6 (1), 36-44. 
118. Ruggeri, B. A.; Miknyoczki, S. J.; Singh, J.; Hudkins, R. L., Role of neurotrophin-trk interactions in oncology: the anti-tumor efficacy of potent and selective trk tyrosine kinase inhibitors in pre-clinical tumor models. Curr Med Chem 1999, 6 (9), 845-57.

119. Baindur, N.; Gaul, M.; Kreutter, K.; Baumann, C.; Kim, A.; Xu, G.; Zhao, B. P., Aminoquinoline and aminoquinazoline kinase modulators. US patent: US20070004763 A1, 2007.

120. Bernard-Gauthier, V.; Aliaga, A.; Aliaga, A.; Boudjemeline, M.; Hopewell, R.; Kostikov, A.; Rosa-Neto, P.; Thiel, A.; Schirrmacher, R., Syntheses and evaluation of carbon-11- and fluorine-18-radiolabeled pan-tropomyosin receptor kinase (Trk) inhibitors: exploration of the 4-aza-2-oxindole scaffold as Trk PET imaging agents. ACS Chem Neurosci 2015, 6 (2), 260-76.

121. Chae, J., Practical demethylation of aryl methyl ethers using an odorless thiol reagent. Arch Pharm Res 2008, 31 (3), 305-9.

122. Johnstrom, P.; Fredriksson, A.; Thorell, J. O.; Stone-Elander, S., Synthesis of $\left[\right.$ methoxy- $\left.{ }^{11} \mathrm{C}\right] \mathrm{PD} 153035$, a selective EGF receptor tyrosine kinase inhibitor. Journal of Labelled Compounds and Radiopharmaceuticals 1998, 41 (7), 623629.

123. Fredriksson, A.; Stone-Elander, S., Rapid microwave-assisted cleavage of methyl phenyl ethers: new method for synthesizing desmethyl precursors and for removing protecting groups. Journal of Labelled Compounds and Radiopharmaceuticals 2002, 2002 (45), 529-538.

124. Pandey, A.; Scarborough, R. M.; Matsuno, K.; Ichimura, M.; Nomoto, Y.; Ide, S.; Tsukuda, E.; Irie, J.; Oda, S., Quinazoline derivatives as kinase inhibitors. European Patent: EP1964839 A2, 2008.

125. Fletcher, S.; Gunning, P. T., Mild, efficient and rapid O-debenzylation of orthosubstituted phenols with trifluoroacetic acid. Tetrahedron Letters 2008, 2008 (49), 4817-4819.

126. Jewett, D. M., A simple synthesis of $\left[{ }^{11} \mathrm{C}\right]$ methyl triflate. Int J Rad Appl Instrum A 1992, 43 (11), 1383-5.

127. Mason, N. S.; Mathis, C. A., Positron emission tomography radiochemistry. Neuroimaging Clin N Am 2003, 13 (4), 671-87.

128. Miller, P. W.; Long, N. J.; Vilar, R.; Gee, A. D., Synthesis of ${ }^{11} \mathrm{C},{ }^{18} \mathrm{~F},{ }^{15} \mathrm{O}$, and ${ }^{13} \mathrm{~N}$ radiolabels for positron emission tomography. Angew Chem Int Ed Engl 2008, 47 (47), 8998-9033. 
129. Nagren, K.; Muller, L.; Halldin, C.; Swahn, C. G.; Lehikoinen, P., Improved synthesis of some commonly used PET radioligands by the use of $\left[{ }^{11} \mathrm{C}\right]$ methyl triflate. Nucl Med Biol 1995, 22 (2), 235-9.

130. Wuest, F.; Berndt, M.; Kniess, T., Carbon-11 labeling chemistry based upon $\left[{ }^{11} \mathrm{C}\right]$ methyl iodide. Ernst Schering Res Found Workshop 2007, (62), 183-213.

131. Corbett, J. F., Pseudo first-order kinetics. J Chem Educ 1972, 49 (10).

132. Iyer, R.; Wehrmann, L.; Golden, R. L.; Naraparaju, K.; Croucher, J. L.; MacFarland, S. P.; Guan, P.; Kolla, V.; Wei, G.; Cam, N.; Li, G.; Hornby, Z.; Brodeur, G. M., Entrectinib is a potent inhibitor of Trk-driven neuroblastomas in a xenograft mouse model. Cancer Lett 2016, 372 (2), 179-86.

133. Kim, C. J.; Matsuo, T.; Lee, K. H.; Thiele, C. J., Up-regulation of insulin-like growth factor-II expression is a feature of TrkA but not TrkB activation in SHSY5Y neuroblastoma cells. Am J Pathol 1999, 155 (5), 1661-70.

134. Savjani, K. T.; Gajjar, A. K.; Savjani, J. K., Drug solubility: importance and enhancement techniques. ISRN Pharm 2012, 2012, 195727.

135. van Breemen, R. B.; Li, Y., Caco-2 cell permeability assays to measure drug absorption. Expert Opin Drug Metab Toxicol 2005, 1 (2), 175-85.

136. Chhabra, N.; Aseri, M. L.; Padmanabhan, D., A review of drug isomerism and its significance. Int J Appl Basic Med Res 2013, 3 (1), 16-8.

137. Li, A. M.; Zhang, J. H.; Zhang, J. H.; Zhang, K. R.; Rong, D. J., [Effects of tyrosine kinase receptor $\mathrm{B}$ and brain-derived neurotrophic factor on chemoresistance in neuroblastoma]. Zhonghua Er Ke Za Zhi 2006, 44 (7), 535-9.

138. Li, Z.; Jaboin, J.; Dennis, P. A.; Thiele, C. J., Genetic and pharmacologic identification of Akt as a mediator of brain-derived neurotrophic factor/TrkB rescue of neuroblastoma cells from chemotherapy-induced cell death. Cancer Res 2005, 65 (6), 2070-5.

139. Li, Z.; Tan, F.; Thiele, C. J., Inactivation of glycogen synthase kinase-3beta contributes to brain-derived neutrophic factor/TrkB-induced resistance to chemotherapy in neuroblastoma cells. Mol Cancer Ther 2007, 6 (12 Pt 1), 311321.

140. Scala, S.; Wosikowski, K.; Giannakakou, P.; Valle, P.; Biedler, J. L.; Spengler, B. A.; Lucarelli, E.; Bates, S. E.; Thiele, C. J., Brain-derived neurotrophic factor protects neuroblastoma cells from vinblastine toxicity. Cancer Res 1996, 56 (16), 3737-42. 
141. Schulte, J. H.; Schramm, A.; Klein-Hitpass, L.; Klenk, M.; Wessels, H.; Hauffa, B. P.; Eils, J.; Eils, R.; Brodeur, G. M.; Schweigerer, L.; Havers, W.; Eggert, A., Microarray analysis reveals differential gene expression patterns and regulation of single target genes contributing to the opposing phenotype of TrkA- and TrkBexpressing neuroblastomas. Oncogene 2005, 24 (1), 165-77.

142. Zhang, J. H.; Li, A. M.; Chen, S.; Tong, H. X.; Zhang, K. R.; Zhang, J. H., [Blocking TrkB-BDNF signal pathway decreases the livability of neuroblastoma cells]. Zhongguo Dang Dai Er Ke Za Zhi 2008, 10 (1), 47-50.

143. Vasudevan, S. A.; Nuchtern, J. G.; Shohet, J. M., Gene profiling of high risk neuroblastoma. World J Surg 2005, 29 (3), 317-24.

144. Tanaka, K.; Mohri, Y.; Nishioka, J.; Kobayashi, M.; Ohi, M.; Miki, C.; Tonouchi, H.; Nobori, T.; Kusunoki, M., Neurotrophic receptor, tropomyosin-related kinase $\mathrm{B}$ as an independent prognostic marker in gastric cancer patients. $J$ Surg Oncol 2009, 99 (5), 307-10.

145. Kowalsky, R. J.; Falen, S. W., Radiopharmaceuticals for Positron Emission Tomography. In Radiopharmaceuticals in Nuclear Pharmacy and Nuclear Medicine, Second ed.; Landis, N. T., Ed. American Pharmacists Association: Washington, DC, 2004; p 825.

146. Rohren, E. M., PET scanning: worth the cost in cancer? Not only worth the cost, but sometimes a cost-cutter! Oncology (Williston Park) 2014, 28 (5), 390, 392. 


\section{VITA}

Christopher P. Surdock was born in Downey, California in 1977, and graduated from Downey High School in 1996 with honors. He then attended California State Polytechnic University in Pomona, California, where he received his Bachelors of Science in Pre-Veterinary Medicine in 2001. After graduation, he spent a year doing research on leptin and its effects on maturation in large farm animals. In 2002, he was accepted into the Pharm.D./Ph.D. program at the University of Tennessee Health Science Center (UTHSC). While at UTHSC, Christopher completed the didactic coursework for the authorized nuclear pharmacy education, and was intrigued by the possibility of working with radioactivity. In 2006, Christopher graduated with his Doctor of Pharmacy, and continued his research, working with Dr. Vivian Loveless. Christopher began doing research at St. Jude Children's Research Hospital in June 2008 as a student, and was hired on as a nuclear pharmacist and researcher in March 2009. Christopher has plans to graduate from UTHSC in May 2017. 